\title{
EROSION-CORROSION RESISTANCE OF TUNGSTEN CARBIDE HARD METALS WITH DIFFERENT BINDER COMPOSITIONS
}

\section{by}

\section{Eduard J. Wentzel}

Thesis prepared in fulfilment of the requirements for the degree of M.Sc. Materials Engineering.

Department of Materials Engineering

University of Cape Town

September 1995 
The copyright of this thesis vests in the author. No quotation from it or information derived from it is to be published without full acknowledgement of the source. The thesis is to be used for private study or noncommercial research purposes only.

Published by the University of Cape Town (UCT) in terms of the non-exclusive license granted to UCT by the author. 


\section{ACKNOWLEDGEMENTS}

I wish to thank all the people who assisted me with this project.

Professor $C$ Allen, my supervisor, for his support and guidance.

Messrs G. Newins and N. Dreze, for their technical assistance.

Messrs B. Greeves and J. Petersen, for their photographic work.

Mr lan Northrop and his staff at Boart Longyear Research Centre for their assistance and support. 


\section{ABSTRACT}

A study has been made of the slurry erosion resistance of a series of cemented tungsten carbides with different binder compositions consisting of combinations of cobalt, nickel and chromium. Testing was carried out on a specially designed laboratory rig in both tap and salt water using silica sand as an erodent.

The synergistic action of erosion and corrosion on WC hard metals results in greatly enhanced wear rates compared to either erosion or corrosion processes alone. Cemented carbides with a $10 \mathrm{wt} \%$ binder were found to have a better slurry erosion resistance than the corresponding 6 wt\% binder grades or the pure metal binder alloys alone. The performance of all the materials was found to be much worse in a salt water medium compared to tap water.

The alloying of either pure Nickel or Cobalt binders was found to influence the fracture properties and corrosion resistance and lead to an improvement in the slurry erosion resistance of the cemented carbides. However any improvement in the corrosion resistance of the binder did not directly enhance the slurry erosion resistance of the cermet. Explanations are advanced to explain these differences in behaviour linked to chemical composition, mechanical properties of the binder phase and the dynamic nature of the slurry erosion system.

Comparisons are also made between the performance of the Ni-Cr-Co based cermets and the pure alloyed metal binder grades. The acceptability of modelling the slurry erosion and corrosion resistance of cermets based on the behaviour of the binder phase materials is discussed. 


\section{CONTENTS}

ACKNOWLEDGEMENTS

ABSTRACT

CONTENTS

LIST OF ABBREVIATIONS

Chapter One

INTRODUCTION

\section{Chapter Two}

\section{LITERATURE REVIEW}

2.1 CEMENTED CARBIDES

2.1.1 Chemical Composition and Crystallographic Structure 2

Tungsten Carbide 3

Binder Metals 3

2.1.2 Manufacturing and the Sintered Structure 4

2.1.3 Properties of Tungsten Carbide Hardmetals 6

Properties of Hardmetals with Alloyed Binders $\quad 7$

In Situ versus Bulk Properties of Binder Phase $\quad \cdot 7$

2.2 EROSION BY SOLID PARTICLE IMPACT 8

2.2.1 Erosion Mechanisms 9

Impact Damage in Ductile Materials 10

Impact Damage in Brittle Materials $\quad 12$

Impact Damage in Dual Phase Materials 14

2.2.2 Variables Affecting Erosion $\quad 16$

Particle Variables $\quad 16$

Target Material Properties $\quad 17$

System Variables $\quad 19$

2.2.3 Erosion of Tungsten Carbide Hardmetals 20 


\subsection{CORROSION}

2.3.1 Electrochemical Corrosion $\quad 22$

Passivation $\quad 22$

2.3.2 Galvanic Corrosion 23

2.3.3 Corrosion of Tungsten Carbide Hardmetals 25

2.4 SLURRY EROSION-CORROSION 27

\section{Chapter Three}

\section{MATERIALS}

3.1 TARGET MATERIALS $\quad 30$

3.1.1 Chemical Compositions 31

3.1.2 Crystal Structures 33

3.1.3 Microstructures $\quad 34$

WC-Based Cermet Grades $\quad 34$

Binder Metal Grades $\quad 35$

3.1.4 Physical Properties $\quad 36$

$\begin{array}{ll}3.2 \text { ERODENT } & 38\end{array}$

Erodent Degradation $\quad 39$

\section{Chapter Four}

\section{EXPERIMENTAL METHODS}

4.1 SPECIMEN PREPARATION 40

4.2 THE SLURRY EROSION RIG 41

4.2.1 Slurry Erosion Test Procedure $\quad 44$

4.3 THE CORROSION POTENTIOSTAT $\quad 45$

4.3.1 Potentiodynamic Scan Procedure $\quad 46$

4.3.2 Corrosion Test Solutions ' 47

4.4 REPRODUCIBILITY OF STANDARD TESTS 47

4.5 COMPRESSION TESTING $\quad 49$ 


\section{Chapter Five}

\section{RESULTS}

5.1 SLURRY EROSION $\quad 50$

5.1.1 Slurry Erosion Surface Microscopy 53

5.1.2 Influences on Slurry Erosion $\quad 56$

Effect of Hardness on Slurry Erosion Rate 56

Effect of Carrier Fluid on Slurry Erosion Rate $\quad 58$

The Importance of Binder Strain Behaviour 59

Binder Phase Transformation 61

$\begin{array}{ll}5.2 \text { CORROSION } & 62\end{array}$

\section{Chapter Six}

DISCUSSION

6.1 INTRODUCTION 68

6.2 MODE OF MATERIAL REMOVAL $\quad 69$

6.3 SLURRY EROSION $\quad 70$

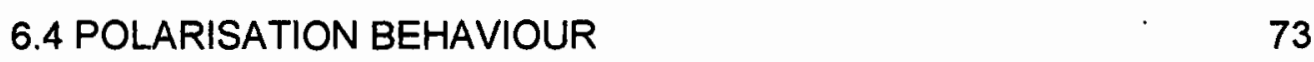

Post Polarisation Surface Microscopy $\quad 74$

$\begin{array}{ll}6.5 \text { SUMMARY } & 75\end{array}$

\section{Chapter Seven}

CONCLUSIONS $\quad 76$

$\begin{array}{ll}\text { REFERENCES } & 77\end{array}$

APPENDICES

Appendix 1: Ternary diagrams of binder phase compositions. 83

Appendix 2: Turbo $\mathrm{C}++$ program for thinning polarisation data. $\quad 84$

Appendix 3: List of Publications and Presentations 93 


\section{LIST OF ABBREVIATIONS}

\begin{tabular}{|c|c|}
\hline WC & Tungsten Carbide \\
\hline C & Carbon \\
\hline Co & Cobalt \\
\hline $\mathrm{Ni}$ & Nickel \\
\hline $\mathrm{Cr}$ & Chromium \\
\hline Mo & Molybdenum \\
\hline $\mathrm{TaC}$ & Tantalum Carbide \\
\hline TiC & Titanium Carbide \\
\hline $\mathrm{NbC}$ & Niobium Carbide \\
\hline h.c.p. & hexagonal close packed \\
\hline f.c.c & face centered cubic \\
\hline PM & powder metallurgical \\
\hline wt \% & weight percentage \\
\hline$\AA$ & Angström $\left(10^{-10} \mathrm{~m}\right)$ \\
\hline XRD & $X$-ray diffraction \\
\hline SEM & Scanning Electron Microscope \\
\hline HV 30 & Vickers Hardness (30 kgf) \\
\hline SCE & Standard Calomel Electrode \\
\hline SWS & Salt Water Solution \\
\hline TWS & Tap Water Solution \\
\hline $\mathrm{T}: \mathrm{S}$ & tap water to salt water slurry erosion rate ratio \\
\hline$i_{c c}$ & critical current density \\
\hline$E_{p p}$ & primary passivation potential \\
\hline$I_{T}$ & total current \\
\hline$E_{g}$ & galvanic potential \\
\hline $\lg$ & galvanic current \\
\hline$i_{0}$ & exchange current density \\
\hline$i_{p}$ & passive current density \\
\hline$E_{\text {corr }}$ & corrosion potential \\
\hline$I_{\text {corr }}$ & corrosion current \\
\hline
\end{tabular}




\section{CHAPTER ONE}

\section{INTRODUCTION}

The exceptional wear resistance of cemented carbides, due to the combination of a tough metal binder with a hard carbide, has resulted in their application in many engineering fields. Cemented carbides are known for their high performance in mining and cutting tool applications and are increasingly used in a variety of other industrial applications, such as seal rings, linings, valves, jet nozzles, saw blades, fluid mixers and conveyer belt scrapers. These applications differ from the traditional uses in that significantly longer lifetimes are demanded and components may be expected to remain in service for several years. In most industrial applications, components are not only subjected to wear processes but can also be in contact with chemically aggressive environments. It is now known that for long-life cemented carbide components, corrosion can play a major role in the degradation of the wear surface and can significantly expediate degradation. The ability of the material to resist the synergistic action of slurry erosion and corrosion is thus of the utmost importance.

In most cases cobalt has been used as the tough metal binder phase, due to its excellent wetting, adhesion and adequate mechanical properties. It is also possible to substitute cobalt with other metals or metallic alloys to improve the wear resistance in corrosive environments. However there appears to be no systematic quantitative work carried out on the effect of different alloy binder compositions on the slurry erosion resistance of hardmetals. This study is an attempt to redress this balance by examining the slurry erosion resistance of a series of hardmetals containing variable binder compositions based on cobalt, nickel and chromium. A further aim of this work is to determine if pure binder metal behaviour can be used to model cermet behaviour in slurry erosion or pure corrosive environments. 


\section{CHAPTER TWO}

\section{LITERATURE REVIEW}

\subsection{CEMENTED CARBIDES}

Cemented carbides are sintered two phase alloys that derive their properties from a high percentage of carbide particles bonded together by a ductile metal. Tungsten carbide (WC) the hard constituent ( +2000 HV 30 ), together with cobalt (Co), the ductile metal binder, form the basic type of cemented carbide from which other types have been developed.

In addition to tungsten carbides, cemented carbides may contain some percentage of other carbides such as titanium carbide ( $\mathrm{TiC})$, tantalum carbide ( $\mathrm{TaC}$ ) and niobium carbide $(\mathrm{NbC})$. The carbides of these three metals are completely soluble in one another and can dissolve a high percentage of tungsten carbide. It is also possible to use nickel and/or iron as a full or partial replacement of cobalt as alloying elements in the binder metal, for special applications. Moreover vanadium, chromium and molybdenum can occur as special additions in cemented carbides ${ }^{1,2}$.

This combination of tungsten carbide in a metal binder is thus used very successfully in applications where the demands call for strength and for resistance against abrasion and attrition wear ${ }^{3}$.

\subsubsection{CHEMICAL COMPOSITION AND CRYSTALLOGRAPHIC STRUCTURE}

The phase based on the tungsten carbide constituent, with the basic tungsten carbide crystal structure is described as the $\alpha$-phase (alpha). The phase based on the TiC with variable amounts of $\mathrm{WC}, \mathrm{TaC}$ and $\mathrm{NbC}$ is described as the $\gamma$-phase (gamma). The metallic binder is described as the $\beta$-phase (beta). 


\section{Tungsten Carbide}

Tungsten combines with carbon to form two hexagonal carbides, the monocarbide WC and the subcarbide $W_{2} C$.
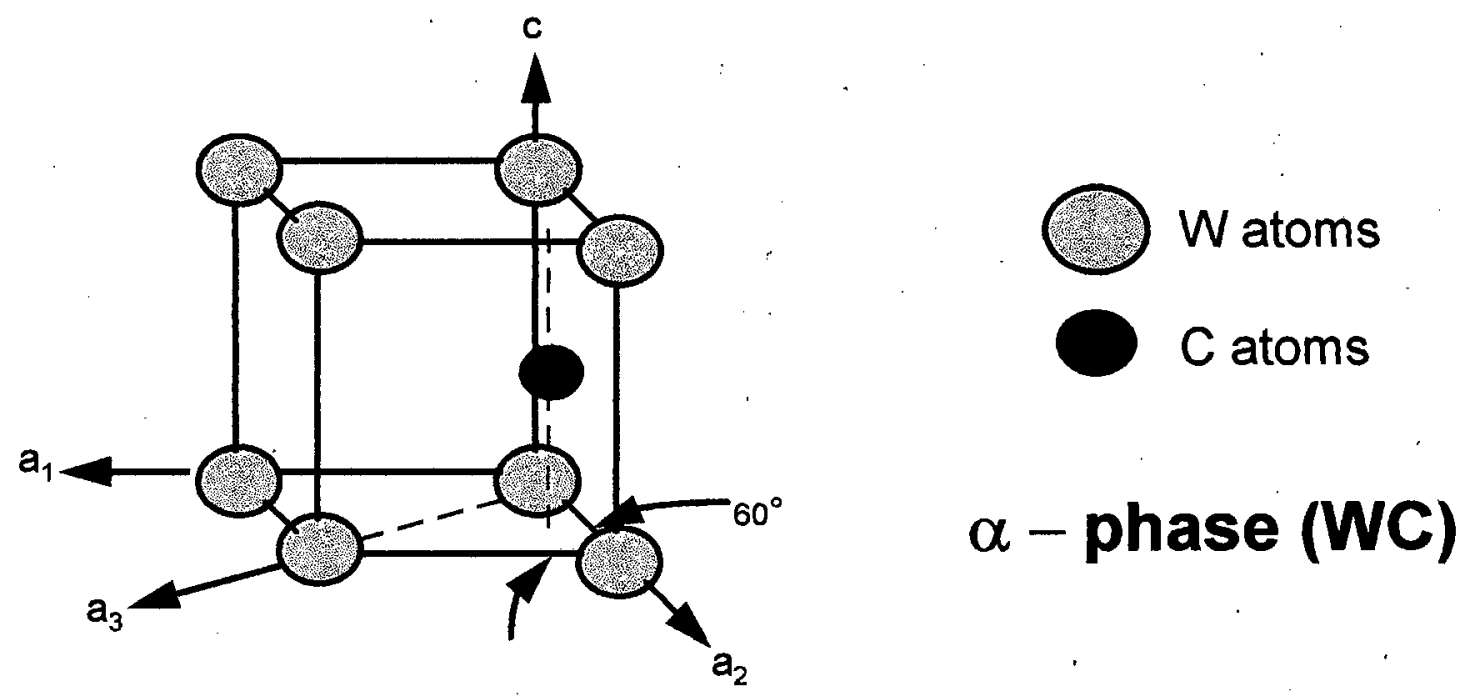

Figure 2.1: Crystal structure of tungsten carbide

The crystal structure of tungsten carbide is a simple hexagonal as shown in figure 2.1, with the lattice constants $a=2.91 \AA$ and $c=2.84 \AA .{ }^{4,5,6}$ French et $a l^{7}$ found the Knoop hardness of the WC crystal to vary along different directions in the basal and prism planes. This anisotropic nature of the crystal however, does not affect the alloy where there is random orientation of WC grains.

In the past WC crystals were believed to deform in a brittle fashion. Plastic deformation was noted by Luyckx ${ }^{4}$ in the form of slip lines when the WC crystal was subjected to bending and microindentation. Dislocations in the hard carbide phase have also been observed by Greenwood et $a^{8}{ }^{8}$ while analysing deformed WC-Co alloys using transmission electron microscopy.

\section{Binder Metals}

Due to cobalt's excellent wetting and adhesion to metallic carbides and adequate mechanical properties, it is the most common binder metal for cemented carbide applications. At room temperature, the equilibrium crystal structure for cobalt is close 
packed hexagonal (h.c.p.), but above a temperature of $700 \mathrm{~K}$ this structure modifies to face centered cubic (f.c.c.). Roebuck et $\left.a\right|^{9}$ found by examining diffraction patterns obtained from electron microscopy, that the binder was predominantly f.c.c. in sintered WC-Co alloys. Roebuck established that the amount of f.c.c present was determined by:

- plastic strain introduced after cooling,

- the mean free path,

- the cooling rate and

- the amount of WC dissolved in the binder.

Rüdiger et $a^{10}$ analysed the binder phase of sintered cemented carbides by $X$-ray fluorescence after electrolytically removing the carbide phase. They found the amount of dissolved tungsten in the binder is dependent on the overall carbon content, the cobalt content, the WC grain size and on sintering and cooling conditions. The amount of f.C.C phase in the binder is also found to vary with binder content and WC grain size. The cubic content increases with decreasing binder content and with increasing WC grain size. Thus Rüdiger reached the conclusion that cubic phase content is possibly related to binder composition, since it varies with the amount of $W$ in the binder.

\subsubsection{MANUFACTURING AND THE SINTERED STRUCTURE}

Cemented carbides are manufactured from powders using standard powder metallurgical (PM) techniques. The basic manufacturing process has not changed significantly since WC-Co was first commercially marketed in 1926, although many refinements have been introduced and automated processes developed through the years. The basic manufacturing techniques have been well described by Brookes ${ }^{11}$ and Aronsson ${ }^{12}$ and are briefly outlined below.

Powders of the individual components are mixed and a wax added to help compaction. After compaction, the components are dewaxed at relatively low temperatures after which further shaping operations can be executed before final sintering. Sintering takes place at temperatures at which the binder phase is in the liquid state. This 
results in a shrinkage of the pressed component and an associated decrease in porosity. Control of the sintering time, temperature and atmosphere during liquid phase sintering is crucial to the final properties of the component.

The phase relationships between the metal binder and the carbide influence the manufacturing process and hence the final properties of the sintered components. Consequently the phase diagram of WC-Co cemented carbides has been extensively researched. While tungsten and carbon are soluble in cobalt, there is negligible solubility of cobalt in WC. The $W$-C-Co system includes the two phase region, $W C+\beta$ (where $\beta$ is a solid solution of cobalt, tungsten and carbon), which is stable down to room temperature and results in the microstructure of a hard, brittle skeleton of WC bound by a tough alloy. This microstructure accounts for the high wear resistance, combined with substantial toughness, exhibited by cemented carbides. An excess or deficiency of carbon results in the formation of a third phase. Free graphite arises from an excess of carbon whilst a deficiency of carbon causes the formation of the $\eta$-phase (a metal stabilised substoichiometric carbide $\mathrm{M}_{6} \mathrm{C}$ ). The $\eta$-phase (e.g. $\mathrm{W}_{3} \mathrm{Co}_{3} \mathrm{C}$ ) occurs as hard brittle particles within the matrix. As the $\eta$-phase reacts with the cobalt in the binder, the region around the $\eta$-phase is denuded of binder, creating areas of weakness. The presence of low strength free graphite in the microstructure is also deleterious to the mechanical properties of the sintered component. The formation of either of these phases is usually avoided in the commercial production of cemented carbides by careful control of the carbon level and sintering parameters. 


\subsubsection{PROPERTIES OF TUNGSTEN CARBIDE HARDMETALS}

The physical properties of cemented carbides are influenced by many factors. Microstructural features such as mean free path, contiguity and average WC grain size are dictated by the nature and volume fractions of the initial powders and the sintering process parameters ${ }^{9}$. Many researchers ${ }^{4,5,6}$ believe a continuous carbide 'skeleton' exists in WC-based hardmetal alloys containing up to 15 vol\% binder phase. Lee et $\mathrm{al}^{13}$ found the volume fraction of the continuous carbide volume to be equal to the volume fraction of the carbide phase multiplied by the contiguity.

The properties of cemented carbides and other sintered materials vary with density. High porosity due to insufficient milling results in poor transverse rupture strength; the hardness, in contrast is not affected by the vanation in porosity within limits ${ }^{14}$. Large pores often coexist with other coarse flaws such as graphite inclusions and uneven cobalt distribution and thus make their influence difficult to quantify.

Hardness and compressive strength of cemented carbides decrease with increasing tungsten carbide (WC) particle size. The transverse rupture strength is found to reach a maximum at a particle size of $3 \mu \mathrm{m}$ for a $12 \mathrm{wt} \%$ Co alloy ${ }^{14}$. This maximum is attributed to crack propagation resistance ie. toughness. In small carbide size alloys, fracture occurs mainly in the cobalt phase, but proceeds preferentially through the carbide phase in coarse carbide alloys.

The mean free path is a measure of the thickness of the binder phase layer and depends on both the binder content and the particle size. The hardness of commercial alloys is considered to be a simple function of mean free path although an additional independent parameter, such as particle size or binder composition, is necessary to describe the relation precisely ${ }^{14}$. The compressive strength also decreases with increasing binder layer thickness.

The thermal expansion coefficient of cobalt is about three times greater than that of tungsten carbide. This variation in expansion causes considerable stresses during cooling from the sintering temperature. These stresses are compressive in the WC and tensile in the binder phase ${ }^{15}$. 


\section{Properties of Hardmetals with Alloyed Binders}

Hardmetals with improved corrosion resistance can be produced using standard production techniques by substituting cobalt with $\mathrm{Ni}-\mathrm{Cr}$ and $\mathrm{Ni}-\mathrm{Cr}-\mathrm{Mo}$ binders ${ }^{16}$. These additions of chromium and molybdenum to nickel as a binder result in high levels of porosity. High sintering temperatures $\left(1450^{\circ} \mathrm{C}-1480^{\circ} \mathrm{C}\right)$ combined with hot isostatic pressing are required to reduce porosity to acceptable levels. The resulting mechanical properties are comparable to those of conventional cobalt binders, although WC grain growth inhibition during sintering leads to higher hardness and lower toughness.

The microstructure becomes more refined with increased leveis of chromium and molybdenum, resulting in different properties in comparison with cobalt binder hardmetals with the same binder content and WC starting powder. Cooper et $a l^{17}$ found that increasing the chromium content in an $\mathrm{Ni}-\mathrm{Cr}$ bonded hard metal results in an increased sintering activation energy, resulting in an increased temperature requirement to induce densification at normal heating rates. They also found that with no chromium additions to a nickel binder most of the densification appears to occur in the solid state, whereas increasing chromium additions results in a decreasing solid state contribution to total shrinkage.

\section{In Situ versus Bulk Properties of Binder Phase}

Several factors have been noted to cause the in situ deformation behaviour of a ductile metal phase in a composite to deviate from its deformation properties in the bulk form ${ }^{18}$. The main contributions to the in situ strengthening of the binder phase of WCCo are solid solutions of tungsten and carbon, the limitation of the slip length of dislocations by the WC, which can be correlated to the mean free path of the binder in terms of a Hall-Petch relationship, and plastic constraint. The largest contribution to the deformation behaviour of the phases is their mutual plastic constraint during deformation; the resultant hydrostatic stress components causing a 'harder' response of the soft phase, and a 'softer' response of the hard phase. 


\subsection{EROSION BY SOLID PARTICLE IMPACT}

Erosive wear is caused by the impacting action of solids, liquids, gases or a combination of these on a parent material. Tribological systems suffering erosive wear in practice can be characterised as open systems or systems where the counterbody is continuously replaced. Erosive wear can be divided into different wear modes as is illustrated in figure $2.2^{19}$.

When considering slurry erosion, a combination of blast erosion and erosion-corrosion phenomena are important. Although the following review of erosive wear is limited to blast erosion or erosion by solid particle impact, corrosion and erosion-corrosion will be reviewed later in this chapter.

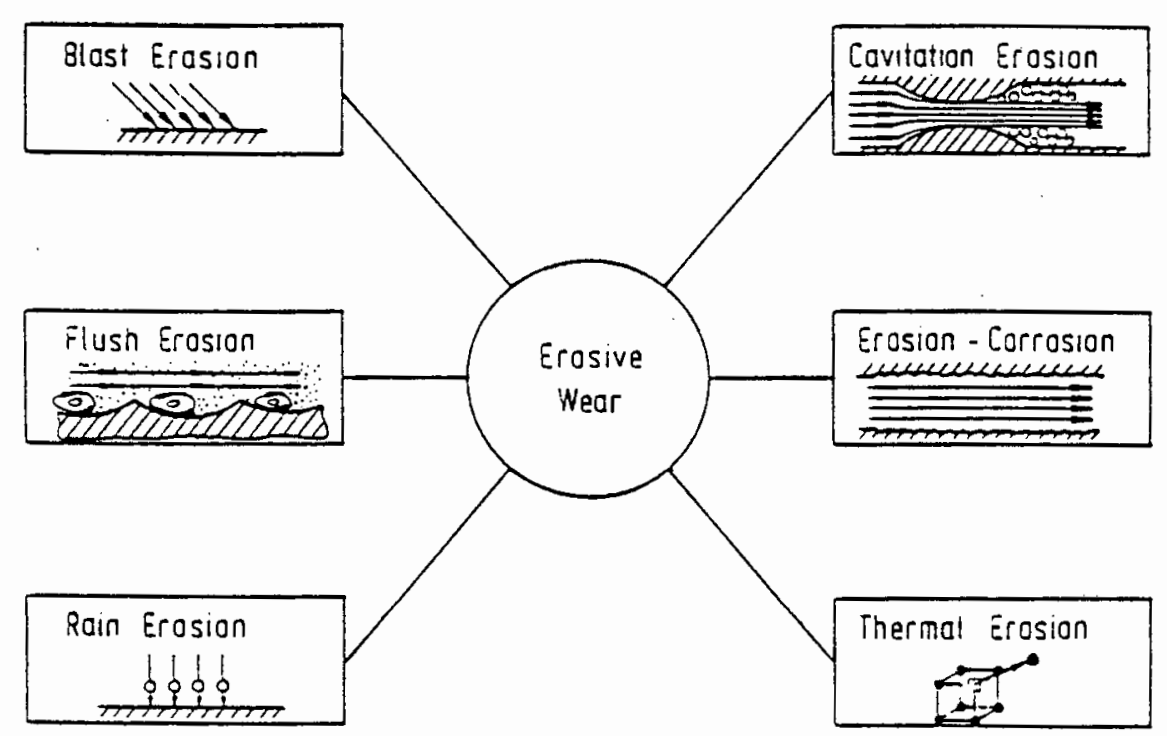

Figure 2.2: Classification of erosive wear modes. ${ }^{19}$ 


\subsubsection{EROSION MECHANISMS}

The effect of impingement angle on the erosion rate of different materials highlights two different types of response. One is characteristic of brittle and the other is characteristic of ductile materials. Brittle materials generally exhibit a maximum erosion rate at normal impact angles as opposed to ductile materials where a maximum erosion rate is observed at angles closer to $30^{\circ}$. These two different responses are illustrated in figure 2.3. Various theories have been developed to explain this erosion phenomena in terms of the mechanisms of material removal. Tilly ${ }^{20}$ noted that although the theoretical models differ, there is agreement that ductile and brittle erosion occur by different mechanisms.

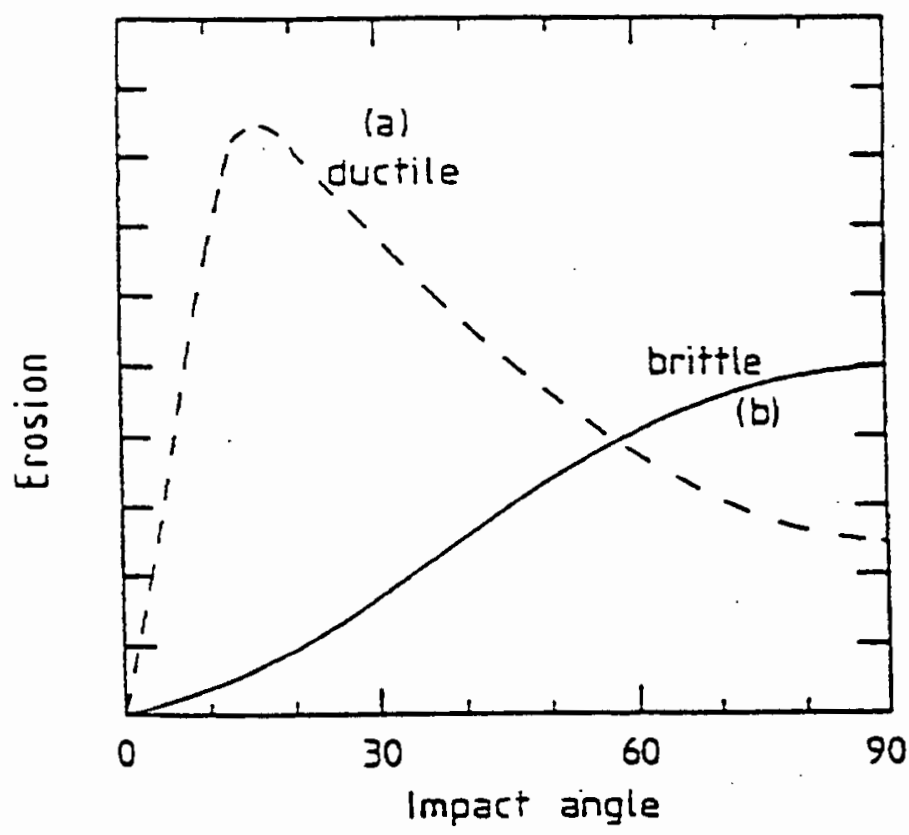

Figure 2.3: Effect of angle on material loss. ${ }^{21}$ 


\section{Impact Damage In Ductile Materials}

Finnie ${ }^{22}$ proposed a model for ductile material erosion where the cutting action of the eroding particles is the only mode of material removal. The model is expressed by the following equation:

$$
Q=\frac{M V^{2}}{p} f(\alpha)
$$

where $\mathbf{Q}$ is the volume of material removed; $\boldsymbol{M}$ is the mass of the impacting particles; $\mathbf{V}$ is the particle velocity, $\mathbf{p}$ is a constant flow stress of the target material assumed to be reached immediately upon impact and $f(\alpha)$ is a function of the angle of impact. The function related to the impact angle varies for two postulated types of cutting wear.

- For glancing angles of impact, the particle leaves the surface when its perpendicular velocity is zero.

- For higher angles of impact, the cutting action stops when the kinetic energy of the particle is zero.

It has been shown that Finnie's equations correlate with ductile erosion for glancing angles but predict zero loss for $90^{\circ}$ impacts where there is invariably substantial erosion.

Further theories based on models of brittle cracking and ductile cutting ${ }^{23,24}$ resulted in equations which related to erosion in terms of impact angle but require empirical calibration. Tilly ${ }^{20}$ stated that these equations incorrectly predicted that erosion depends on the square of velocity. Tilly found that although ductile cutting and brittle cracking occur in ductile materials, other modes of material removal are also involved. This led to Tilly's ${ }^{25}$ hypothesis of a two stage mechanism of ductile erosion based on extrusion of lips of material followed by damage caused by fragments of the particies scouring across the surface. Bellman and Levy ${ }^{26}$ consider the formation of an extruded lip, or platelet, and its subsequent fracture as the dominant mode of material removal. Figure 2.4 illustrates the platelet formation sequence. 
INITIAL CONOITION

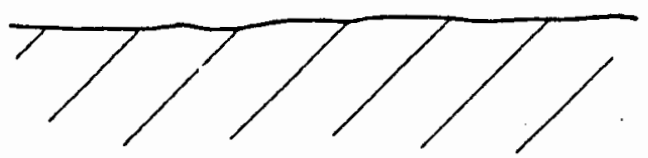

FIRST IMPACT

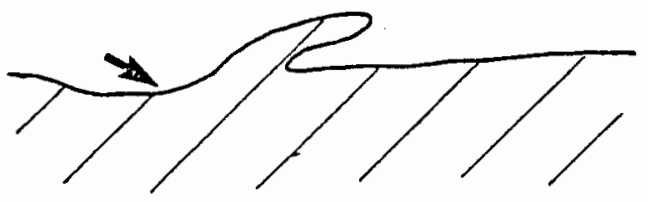

SECONO IMPACT

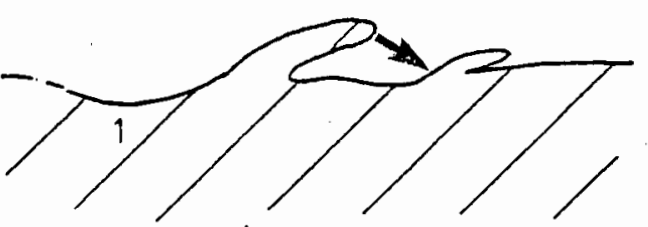

THIRO IMPACT

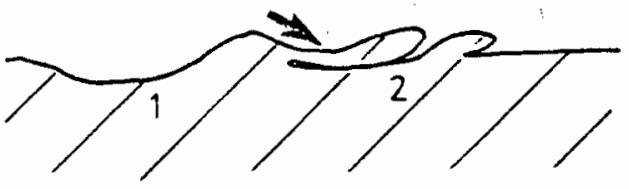

FOURTH IMPACT

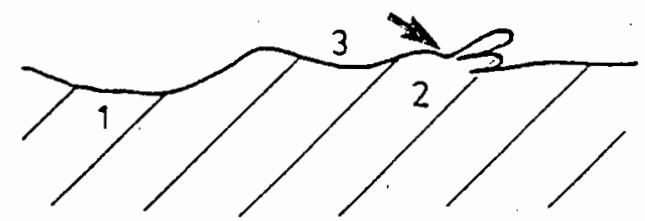

$10 \mu \mathrm{m}$

Figure 2.4: A schematic representation of the platelet formation sequence. ${ }^{26}$

Shewdon et $a^{27}$ note that during further impact a lip, or platelet, can fracture by either necking or by material separation along an adiabatic shear band formed at the base of the extruded lip. Other models have been developed where material loss is considered to occur only once a critical strain is reached. Ball ${ }^{28}$ notes that in general, erosion can be regarded as a two-stage process, that is the accumulation of strain preceding the loss of material by microfracture. Thus materiais that have the ability to absorb strain and work harden without the initiation of fracture and the ability to resist the propagation of the fracture process, will provide good erosion resistance. The importance of work hardening highlighted by $\mathrm{Ball}^{29}$ is discussed later in the section dealing with target material properties. Levy ${ }^{30}$ later found that of the mechanical properties he tested, the ductility of ductile metal alloys, as measured by their tensile elongation, correlate most closely to their erosion resistance. He found that strength and hardness, except for those of solid solution strengthened alloys, do not relate directly to the erosion resistance of the alloys. Levy also postulated that a subsurface work hardened zone acts as an anvil to increase the erosion efficiency of the impacting particles and that the strain hardening coefficient relates to how soon the alloy reaches steady state erosion, but not to the magnitude of the steady state erosion. 


\section{Impact Damage in Brittle Materials}

Material loss in brittle materials occurs during solid particle erosion through the formation and interaction of subsurface microcracks and microcrack networks. The material surface must reach a critical stress before these microcracks develop ${ }^{22}$. To resist the initiation and propagation of these cracks and thus be more erosion resistant, the material must have high fracture toughness and high resistance to crack initiation and propagation.
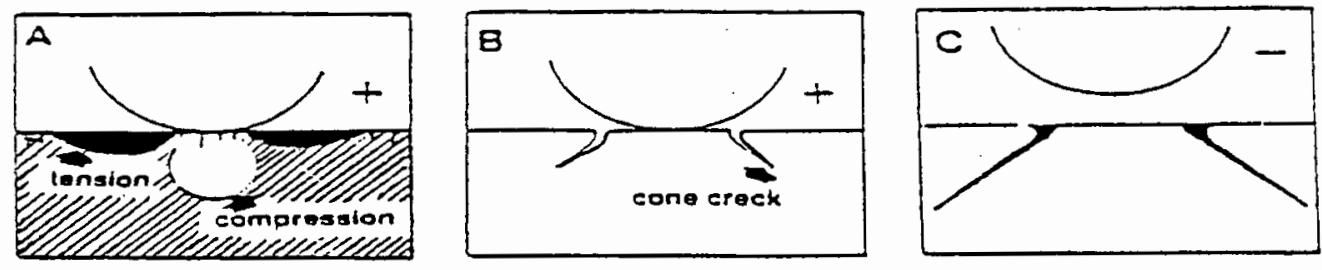

Figure 2.5: The development of cone cracks.

The modes of fracture and deformation depend on the particle velocity, shape and mechanical properties relative to those of the target material ${ }^{31}$. Low velocity, blunt particles set up elastic Hertzian stress fields in the target which initiate cone cracking. Material removal will depend on the propagation of the fracture into the material and its interaction with other fractures. Figure 2.5 shows the development of cone cracks.

On initial loading the compressive field is set up directly below the impact, with a tensile stress outside the expanding contact circle (A). Upon attaining a critical Griffith configuration, a surface flaw runs around the area of contact to form a ring crack, which will extend downwards out of the surface skin region (B). As loading increases, tensile stresses accumulate until the ring crack spontaneously develops into a full cone crack. On unloading, the cone crack tries to close and heal in order to recover some of the stored elastic energy but is prevented from doing so by the mechanical obstruction of debris $(C)$. If the unloading is rapid enough the base of the cone may turn up in a hat brim fashion ${ }^{32}$.

Sharp particles impacting at high velocities produce inelastic deformation zones and initiate median and lateral cracking ${ }^{31}$. When eroding with relatively hard or incompressible particles, the target is plastically deformed and two types of cracking 
occur. These are median cracks which propagate downward from the contact zone and lateral cracks which develop below the contact zone and propagate parallel to the surface eventually curving up towards to the surface ${ }^{32}$.

Lawn and Swain ${ }^{33}$ have described the loading sequence for a sharp indenter, as illustrated in figure 2.6 .

A zone of irreversible deformations induced around the sharp indenter occurs which increases with increasing load (a). At some critical load a crack (median crack) suddenly initiates under the contact point (b). Increasing the applied load will cause further extension of the median vent (c). On unloading, the median vent begins to close but does not heal $(d)$. Relaxation of deformed material within the contact zone just prior to the removal of the indenter superimposes intense residual tensile stresses upon the applied field. This causes the initiation of sideways-extending or lateral cracks $(e)$. On complete unloading (f) the lateral crack continues to grow and can intersect with the surface causing chipping ${ }^{33}$.

(a)

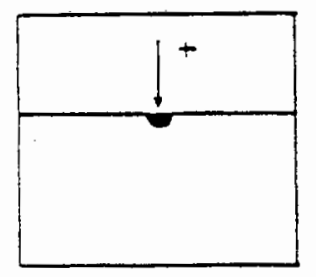

(b)

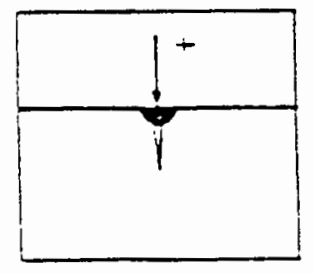

(c)

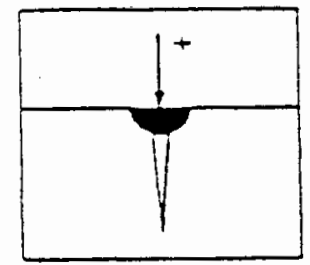

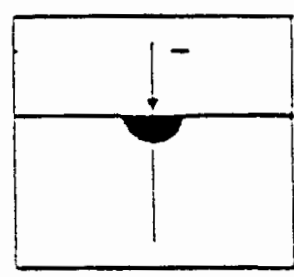

(d)
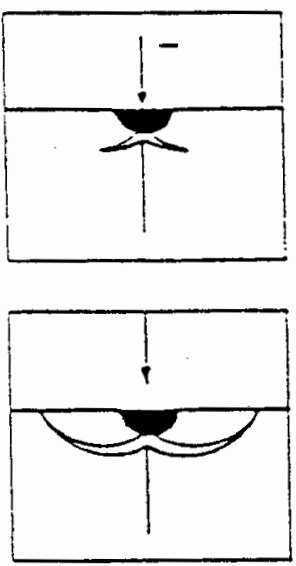

(e)

(f)

Figure 2.6: The development of radial/lateral cracks. ${ }^{33}$ 


\section{Impact Damage in Dual Phase Materials.}

The erosion of dual-phase materials containing ductile and brittle phases is often different from what is expected, based on the erosion response of the individual constituents. The erosion of dual-phase materials can be fully understood only if the size of the impact damage zone relative to the microstructure is known $n^{34}$. In this regard two situations exist as shown below in figure $2.7(a)$ and (b).

\section{Case (a)}

The impact damage zone is appreciably larger than the microstructural feature size. The erosion behaviour in this case is generally more like that of the ductile materials, with maximum erosion rate occurring at an oblique impact angle $\left(20^{\circ}-60^{\circ}\right)$. The angle however tends to increase with increasing volume fraction of the brittle phase. Although the maximum erosion rate decreases with volume fraction of the brittle phase, no simple correlation exists between the erosion rate of the mixture and that of the individual phases. i.e. erosion rate cannot be expressed in terms of the rule of mixtures.

\section{Case (b)}

The size of the impact damage zone is smaller than that of the microstructural feature size. In such a situation, the ductile and brittle constituents are sampled separately by the erodent particles and the erosion rate of the alloy can be expressed in terms of the erosion rates of the individual phases through a rule of mixtures. It is worth noting however, that enhanced erosion rates due to edge spalling of brittle particles in dual phase materials containing large brittle particles in a ductile matrix have been observed, leading to a departure from predictions based on a rule of mixtures ${ }^{34}$. 
(a)
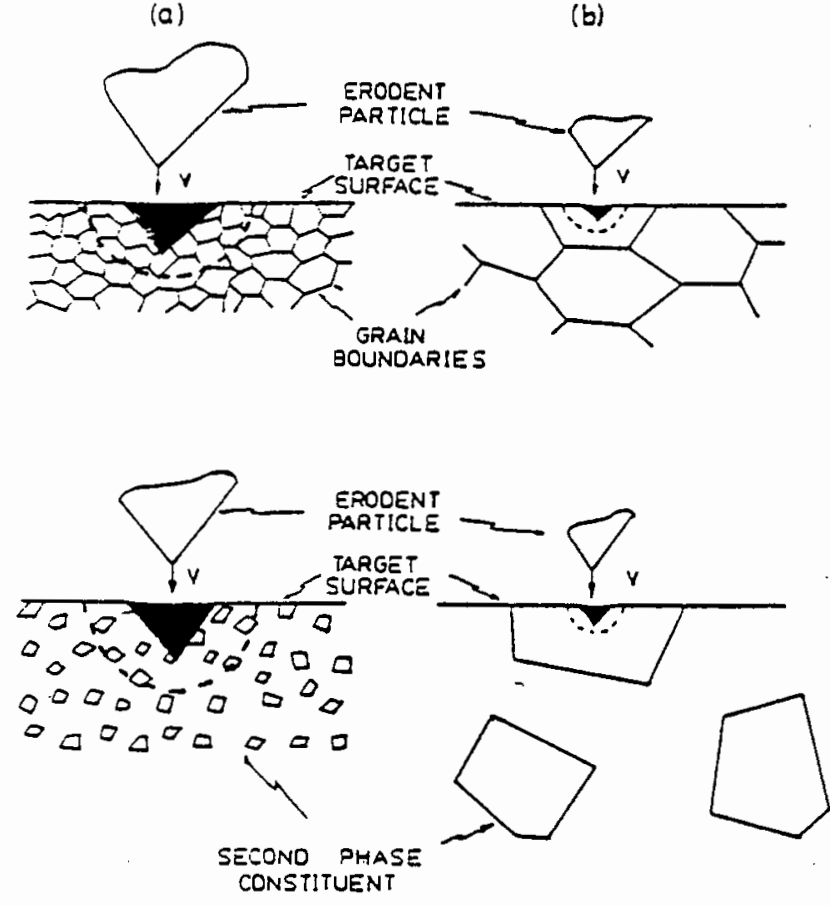

Figure 2.7: Schematic of scaling effects showing the influence of microstructure on erosion: (a) impact damage zone is appreciably larger than the microstructure size and (b) impact damage is smaller than microstructure size. ${ }^{34}$

Hovis et $\mathrm{al}^{35}$ also found the erosion rate behaviour of multiphase systems can be analysed in terms of the mechanism independent averaging laws, if the size of the erosion impact events are small relative to the microstructural scale. In this case an inverse rule of mixtures law can be derived. They also found systematic deviations from the predictions as the erodent particle size increased and a number of complications to the predictions including the effects of interface debonding failures. 


\subsubsection{VARIABLES AFFECTING EROSION}

Wear of materials is systems related and thus changes to the system variables involved in erosive wear are critical in determining material loss. The particle variables such as size, density, shape, hardness and fracture toughness and the target material properties such as hardness, fracture toughness, microstructure, work hardening capacity and elongation as well as system variables such as angle of impact, velocity of impact, particle concentration and carrier fluid, all influence the erosion rates.

\section{Particle Variables}

The erosion rate of brittle materials was found to increase monotonically as particle size increases ${ }^{36}$. Shewmon ${ }^{37}$ found that in ductile materials, the erosion rate is significantly reduced when impacting particles are below a certain threshold size of $20 \mu \mathrm{m}$. Beyond this threshold size it has been noted ${ }^{38,39}$ that a general trend of increasing erosion rate with increasing particle size is observed. In the erosion of both ductile and brittle materials the particle size distribution is very important. A mixture of different size particles will produce an erosion rate greater than the erosion rate of sum of the individual components ${ }^{39}$.

It has been shown that the shape and hardness of the particle determines the depth of the impact crater in the target material and hence affects the erosion rate ${ }^{40}$. In both ductile and brittle materials a greater erosion rate is generally associated with more angular particles ${ }^{38}$. Vaughn ${ }^{41}$ found that when the hardness of the erodent is slightly more than that of the target material, the erosion rates are relatively high. Furthermore there is a sudden decrease in the erosion rate when the particle/target hardness ratio is unity, after which a slight decrease in erosion rates with increasing target hardness occurs in tests performed using 120 grit silica, alumina and silicon carbide particles against alumina and ultra hard materials at impact velocities of $40 \mathrm{~m} . \mathrm{s}^{-1}$. In addition to hardness, the fracture toughness of the particle will determine whether the particle will fragment upon impact, absorbing energy and thus reduce the transferred energy and hence the erosion rate ${ }^{42}$. 


\section{Target Material Properties}

For the erosion of ductile materials where plastic deformation predominates, hardness is considered an important parameter. Finnie et $a^{43}$ showed the erosion rate of different ductile materials to decrease with increasing hardness. However little change was observed when the hardness of an individual alloy was varied by heat treatment or work hardening.

Pennefather ${ }^{44}$ found a general trend of increased erosion rate with decreased hardness for tests performed on WC-Co grades. For glancing angles the dependence of erosion rate on hardness was more marked as the microstructural features were masked.

Most brittle erosion models involve the initiation and propagation of cracks in the target as discussed in 'impact damage in brittle materials'. Hence the fracture toughness of the material (ability of the material to resist crack growth) will influence the erosion rate. Pennefather ${ }^{44}$, however found no relationship between macro fracture toughness and erosion rate in tests conducted on WC-Co cermets.

During erosive wear, localised regions on the metal surface experience high stresses, strains and strain rates. The ability of a material to withstand strain and to resist microfractures is influenced by strain hardening capacity. Ball ${ }^{28,29}$ discusses the interaction of abrasive wear and strain hardening for different classes of materials. Figure 2.8 shows the stress strain curves and a basic model of the wear behaviour of materials I, II and III. 


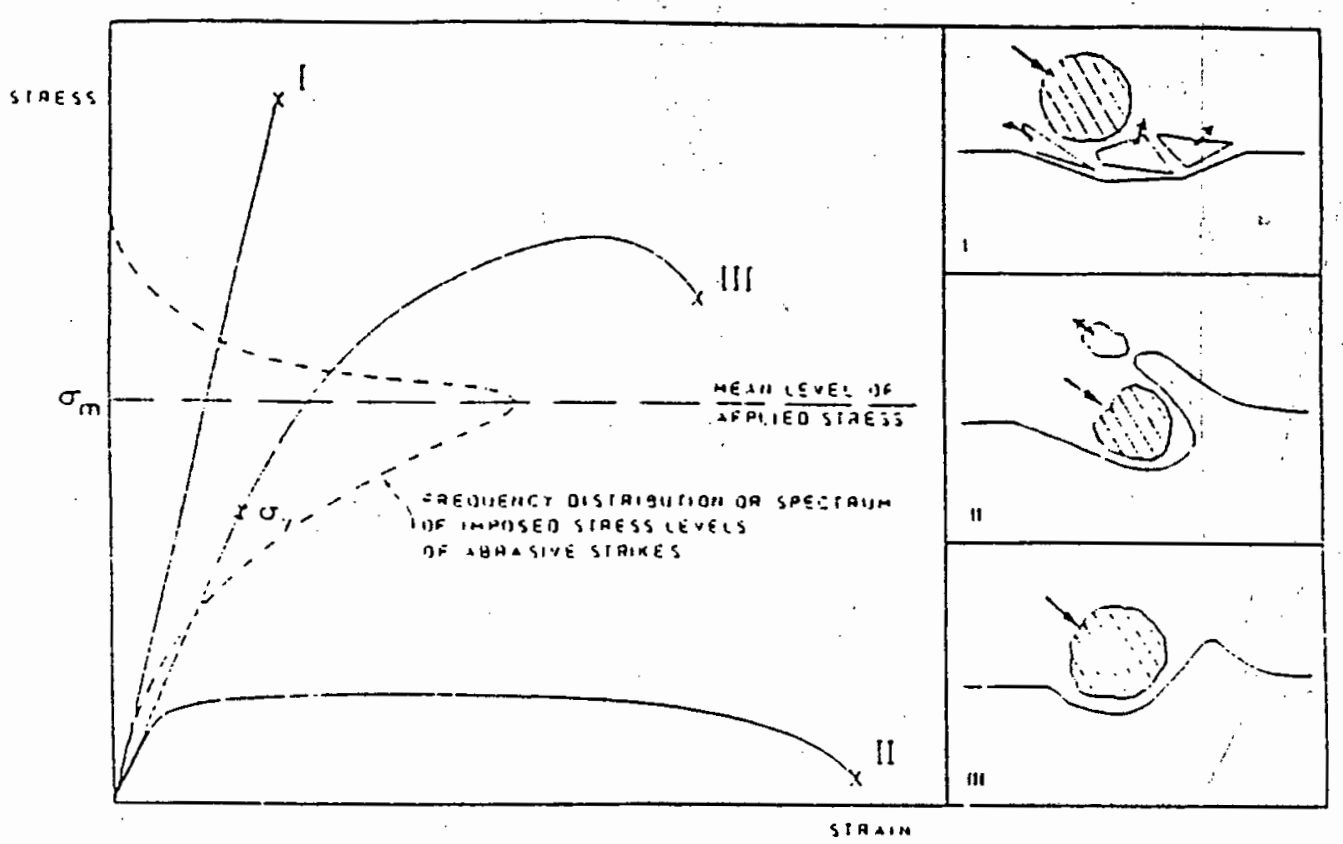

Figure 2.8: Hypothetical stress-strain wear curves for a hard, brittle material(I), a soft, ductile material(II) and a material that has a capacity to strain harden and resist brittle fracture(III). ${ }^{20}$

Stress strain curve $I$ is representative of hard brittle solids. During abrasive wear microfracture is initiated by small defects in the material and the low resistance to crack propagation of the microstructure results in high wear losses. Material II represents soft, ductile metals. The mean level of stress $\left(\sigma_{m}\right)$ associated with abrasive wear is such that critical stresses and strains required for microfracture are easily achieved and wear loss occurs by ductile cutting. These materials have poor wear resistance. The rapidly rising stress-strain curve of material III indicates a good combination of strength and strain hardening capacity. In this case, abrasive stress levels are such that localised regions on the metal surface accumulate strain and become work hardened. Strength and hardness increases through work hardening also afford a degree of toughness and in effect a higher resistance to wear is achieved. 


\section{System Variables}

The velocity, impact angle and concentration of the impacting particles as well as the temperature of the gas stream will all have different effects on the rate of material removal. The individual effects of these parameters will not be discussed as they are constant for all tests performed in this project. A study by $\mathrm{Zu}$ et $\mathrm{al}^{45}$ compared the differences between aqueous slurry erosion and airborne particle erosion of soft aluminium alloys, under similar impact conditions. $\mathrm{Zu}$ found that a heterogeneous surface layer, due to embedment of fine silica erodent particle fragments in an aluminium surface, only forms during airborne solid particle erosion. The slurry erosion surface was free of erodent particle fragments. This led $\mathrm{Zu}$ to conclude that a fluid cleaning effect must be operative during slurry erosion. The fluid washes debris of detached target material away before it can be reattached onto the target surface by subsequent impacting particles.

Another reason why embedment under slurry erosion conditions is less likely, is because the higher viscosity fluid reduces the velocity of the impacting particle close to the surface and the resultant kinetic energy of the particle is thus lowered. The prevention of embedment due to the fluid protection effect in slurry erosion conditions is possibly the reason why there is only an incubation period phenomenon noted under airborne solid particle erosion conditions ${ }^{46}$.

The fluid dynamic forces acting on the erodent particles due to flow patterns over the target also. affect the impact angle. When a fluid jet impacts on a flat surface the fluid will spread out along the surface. In an air jet, the direction of the particles will be affected to a lesser extent by the direction of the air stream as the viscosity of the air stream is lower. In slurry erosion however, the direction of the erodent will be in the direction of the flow of the high viscosity fluid. Thus with a slurry jet, the majority of the particles impact the surface at oblique angles ${ }^{46}$. 


\subsubsection{EROSION OF TUNGSTEN CARBIDE HARDMETALS}

Thus far ductile and brittle erosion mechanisms have been discussed as independent, alternative mechanisms. In many cases materials exhibit a combination of ductile and brittle characteristics, dependent on the test conditions ${ }^{47}$. Due to the two-phase nature of WC based hardmetals the mode of erosion in these alloys is considered to be mixed. Ball et $\left.a\right|^{3}$, Wright et $\left.a\right|^{48}$ and Pennefather ${ }^{44}$ all observed brittle fracture of the WC grains while the softer binder phase was deformed by ductile mode. Microstructural properties, impact conditions and system variables all influenced the erosion behaviour of these WC-based hardmetals.

Various modes of materials removal have been reported in the literature ${ }^{3,44,48}$. The common factor among these models is that the initial and rate controlling step is the preferential removal of binder followed by the fracture and removal of the brittle WC grains. Conrad et al ${ }^{49}$ considered separate mechanisms for the erosion of the WC phase and the cobalt phase. Ball et al in tests performed at $40 \mathrm{~ms}^{-1}$ and impact angles of $45^{\circ}$ found that the erosion rate values do not increase with increasing cobalt content. Instead the relationship as shown in figure 2.9 was found. The local maximum found at approximately $10 \mathrm{wt} \%$ was explained in terms of a change in structure. Below $10 \mathrm{wt} \%$ the erosion is controlled by the WC skeleton. As the amount of contiguity is increased, the skeleton becomes more rigid, resulting in a decrease in erosion rate. At $10 \mathrm{wt} \%$ the cobalt has low toughness and the WC skeleton is fragile and discontinuous. Above this maximum, the erosion is controlled by the strength and microtoughness of the binder. The minimum at $20 \mathrm{wt} \%$ cobalt is explained as being as a result of a optimum combination of hardness and toughness of the cobalt binder. 


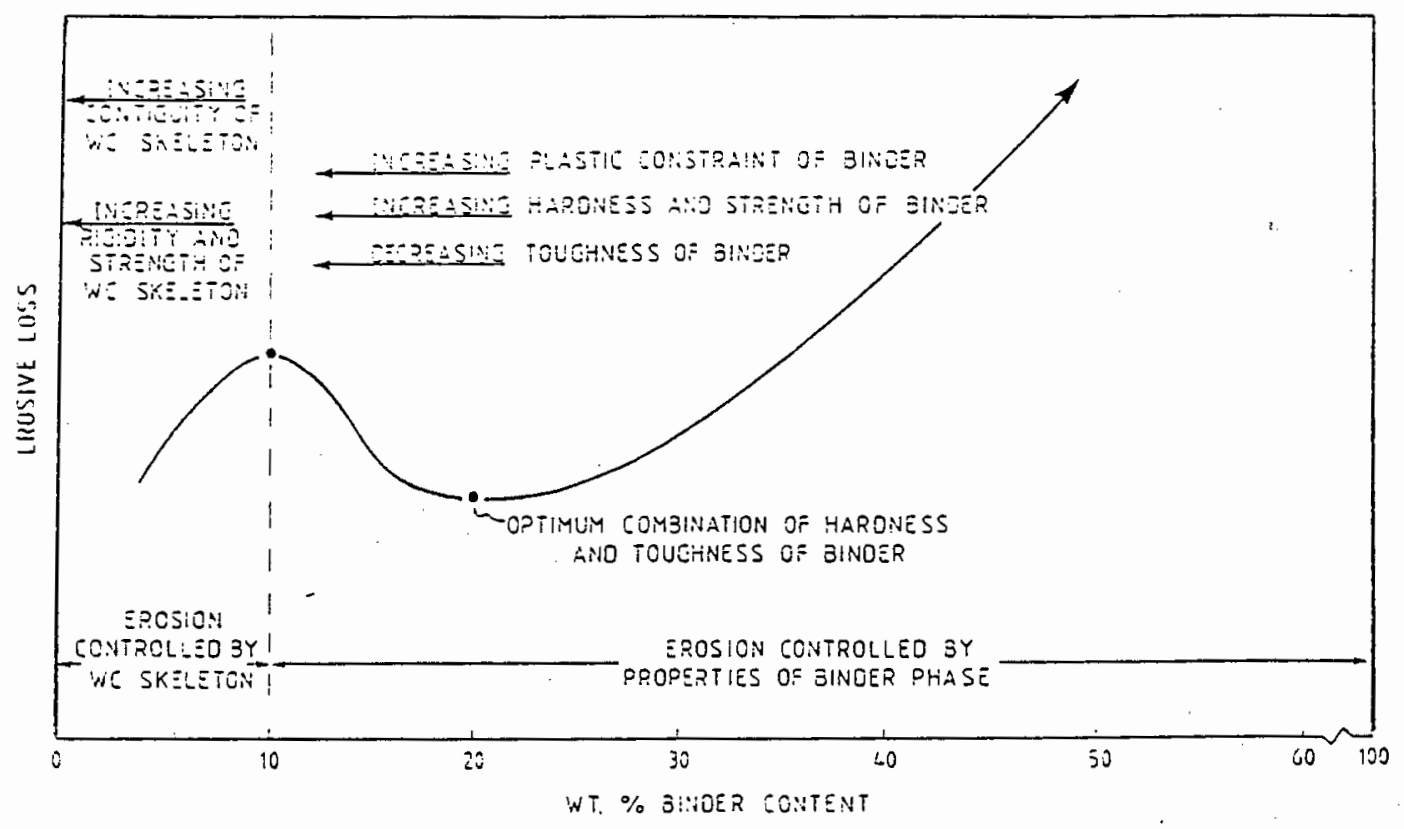

Figure 2.9: A schematic representation of the erosion of WC-Co alloys as a function of binder content. The factors considered to control erosion are indicated ${ }^{3}$.

Shetty et $a^{50}$ found a similar change in mechanism at $9 w 1 \%$ cobalt in slurry erosion studies. At low binder contents the erosion is controlled by the transgranular wear of the contiguous network of WC grains. At high binder levels the erosion occurs by removal of the binder, undercutting of the WC grains and the release of whole particles. This change in loss mechanism did not however interfere with the linear dependence of erosion rate on binder content. 


\subsection{CORROSION}

\subsubsection{ELECTROCHEMICAL CORROSION}

When a metal is placed in an aqueous solution some metal dissolves. Some of these metal ions in solution are reprecipitated on the metal surface:

$$
M=M^{n+}+n e^{-}
$$

Dissolved ions accumulate in the solution while the electrons remain in the metal which results in a potential difference at the metal-solution interface, the magnitude of which is dependent on the tendency of the metal to dissolve, the concentration of the ions in the solution and the tendency of the ions to be reduced onto the metal. When the system is in equilibrium the nett charge transfer is zero and the magnitude of the flux of charge is termed the exchange current density, $i$.

A number of electrochemical reactions can take place in an aqueous solution.

In acids:

$$
\begin{aligned}
& 2 \mathrm{H}^{+}+2 \mathrm{e}^{-}=\mathrm{H}_{2} \\
& \mathrm{O}_{2}+4 \mathrm{H}^{+}+4 \mathrm{e}^{-}=2 \mathrm{H}_{2} \mathrm{O} \\
& \mathrm{O}_{2}+2 \mathrm{H}_{2} \mathrm{O}+4 \mathrm{e}^{-}=2 \mathrm{OH}^{-} \\
& 2 \mathrm{H}_{2} \mathrm{O}+2 \mathrm{e}^{-}=\mathrm{H}_{2}+2 \mathrm{OH}^{-}
\end{aligned}
$$$$
\text { In aerated acids: }
$$$$
\text { In neutral aerated electrolytes: }
$$$$
\text { At low potentials: }
$$

As in the case of the metal reaction above, each of the reactions has a reversible potential.

\section{Passivation}

In many systems, anodic dissolution increases exponentially with increasing polarisation until a critical current density, $i_{c c}$, is reached at a primary passivation potential, $E_{p p}$. At this point a stable film forms on the surface and the oxidation and/or reduction reactions are hindered, resulting in a significant decrease in the exchange current density, io. Passivating films are made up of a solid corrosion product and form uniformly on the metal surface. The film acts as a barrier and for corrosion to continue 
metals ions must diffuse through the film to the film/solution interface or the oxidiser (eg. hydrogen ions or oxygen) must diffuse through the film to the metal surface. The ease with which the ions are transported across the film directly influences the rate of corrosion. The resulting passive current density, $i_{p}$, remains constant over a certain potential range, the passive range, which is dependent on the stability of the passive film, until a potential is reached at which the film becomes unstable and breaks down. The region above the breakdown potential is called the transpassive region.

The ability of a corrosion product to act as a passive film on a metal surface is dependent on a number of factors, such as chemical composition, thickness, crystallographic structure, electronic properties and mechanical properties.

\subsubsection{GALVANIC CORROSION}

As WC-based hardmetals are two phase composites, it is important to understand the fundamentals of galvanic corrosion which are briefly outlined.

Galvanic corrosion describes the behaviour of two or more metals, electrically coupled in an electrolyte. This type of couple results in an increase in the dissolution rate of the less noble metal and a decrease in the corrosion rate of the more noble metal.

Consider two metals, $P$ and $Q$, corroding independently as depicted in figure 2.10 above, with corrosion potentials $E_{c o r r}^{P}$ and $E_{c o r r}^{Q}$ and corresponding corrosion currents $P_{\text {corr }}$ and $P_{\text {corr. }}$. If the two metals are electrically coupled then the potential of both metals becomes equal, the system moves to a potential, the galvanic potential $E_{g}$, where the total oxidation rate equals the total reduction rate, having a nett total current IT of zero:

$$
I_{T}=I_{g}^{P}+I_{g}^{Q}=0
$$

This is due to the condition that the charge must be conserved in the system. The only significant reaction on $P$ is metal oxidation (anode) and the only significant reaction on metal $Q$ is reduction (cathode). Thus after galvanic coupling, the corrosion rate of $P$ 


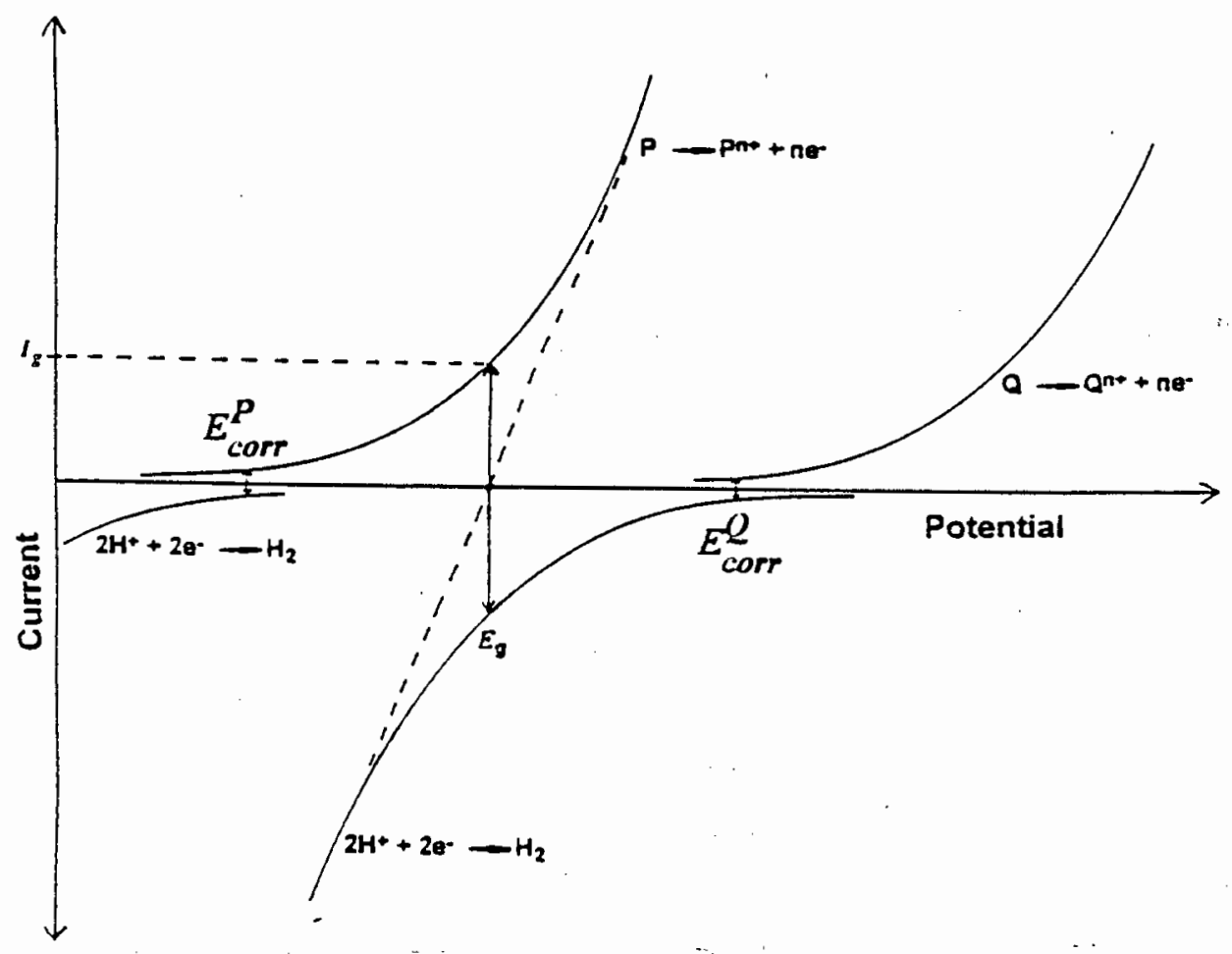

Figure 2.10: Schematic current vs potential relationship showing galvanic effects ${ }^{51}$.

increases from $P_{\text {corr }}$ to $I_{g}$ while the corrosion of the more noble metal $Q$ ceases completely and only hydrogen reduction takes place on its surface, with a current equal in magnitude but opposite in direction to the metal oxidation corrosion current $\left(I_{g}\right)$ :

$$
P_{\text {ox }}=-P_{\text {red }}=I_{g}
$$

At potentials other than $E_{g}$ the currents $\rho^{P}$ and $\rho^{\rho}$ are not equal and the total current is not zero:

$$
I_{T}=I_{\text {ox }}^{P}+I_{\text {red }}^{P}+I_{\text {ox }}^{Q}+I_{\text {red }}^{Q} \neq 0
$$

The degree of polarisation after coupling is dependent on the relative potentials of the two metals and the magnitudes of the currents. It is, for example, possible that after coupling anodic and cathodic reactions occur on the surface of one metal whilst only cathodic reactions occur on the surface of the other metal. There are a number of possibilities, but the common factor is that in every case the system is at rest at a potential where the sum of all oxidation currents equals that of all reduction currents. 
Irrespective of the areas of the two metals exposed to the electrolyte, the sum of all the currents (anodic and cathodic) must be at zero for the system to be at rest. Thus equation (2.2) is valid for any area ratio. The relationship is also valid for current densities in the specific case where the exposed areas of the metals $A^{P}$ and $A^{Q}$ are the same. For any other ratio of areas the total current density and the individual current densities of the metals are related by:

$$
\begin{aligned}
i_{T} & =I_{T} / A_{T}=\left(A^{P} / A_{T} \times I^{P} / A^{P}\right)+\left(A^{Q} / A_{T} \times I^{Q} / A^{Q}\right) \\
& =A_{A}^{P} \times P^{P}+A_{A}^{Q} \times P^{Q}
\end{aligned}
$$

Where $A^{P}$ and $A^{Q}{ }_{A}$ are respective area fractions of metals $P$ and $Q, A^{P}$ and $A^{Q}$ are the exposed areas of $P$ and $Q$ respectively and $A_{T}$ the total exposed area. Equation (2.4) is referred to as Stern's Rule. Human ${ }^{51}$ concluded that Stern's rule can only be applied to heterogeneous alloys if the area fractions and current densities refer to the true areas and not the cross-sectional areas after polishing and only if the alloys used have similar compositions to those expected in the corresponding binder phase and only if cathodic currents are not neglected.

The relative area of the two metals galvanically coupled plays an important role in the corrosion behaviour of the couple. In Figure 2.10 current is plotted versus potential. While the current density, $i$, is independent of the specimen area, the current $l$, increases proportionally with specimen size. Thus changing the area of $P$ or $Q$ will shift the corrosion curves vertically up or down. In this particular case (dotted line in Figure 2.10), an increase in the area of $Q$ will result in a more noble galvanic potential and an increased galvanic current. Thus increasing the cathode to anode ratio increases the corrosion rate and vice versa.

\subsubsection{CORROSION OF TUNGSTEN CARBIDE HARDMETALS}

Human et al. ${ }^{16}$ found that the corrosion resistance of cemented carbides is generally improved by substituting cobalt by a more corrosion resistant binder, although this was dependent on the acid medium and the substitute alloy composition. Chromium additions increase the passivation of nickel binders in sulphuric acid and both chromium and molybdenum are beneficial in nitric acid. There was no significant 
difference observed between the cobalt and the nickel based binders in boiling hydrochioric acid. Human also found that the corrosion resistance of the WC(Ni-CrMo) cermets decreased with increasing Ni-Cr-Mo alloy binder content. However the corrosion resistance of the $10 w t \%$ alloy binder was still significantly higher than the 6 $w t \%$ cobalt binder.

Anodic polarisation tests done by Tomlinson et $\mathrm{al}^{1}$ in a solution with $\mathrm{pH}$ of 2.55 showed that passivation of the pure metals nickel, tungsten and cobalt is excellent, good and zero respectively. Tungsten exhibits good passivation over a wide potential range. In the WC-Co based hardmetals the cobalt binder was selectively dissolved. Tomlinson also found that the polarisation behaviour of the WC-Co based cermets reflected mainly on the behaviour of the binder phase. A nickel binder was more corrosion resistant than a cobalt binder, but the effect was not as large as the differences between the pure metals.

Human ${ }^{51}$ found that the polarisation behaviour of the individual phases could be used to model the behaviour of WC-based composites and that the rule of mixtures proposed by Stern could be applied to WC based materials. Human noted that the corrosion of the cobalt binder is strongly influenced by the dissolution of tungsten and carbon in the binder during liquid phase sintering. He also noted that alloying with tungsten and carbon leads to an increase in f.c.c. content and that this change in crystal structure influenced corrosion. The behaviour of WC-Co composites could thus not be predicted from WC and pure cobalt, which has a h.c.p structure. at room temperature. When substituting Co with a more corrosion resistant binder, Human found a large influence on the overall corrosion of the composite. He found that a $\mathrm{Ni}(\mathrm{Cr}, \mathrm{Mo})$ binder passivates to the extent that the WC corrosion current density in the passive regime is of the same order. 


\subsection{SLURRY EROSION-CORROSION}

The effect of corrosion on mechanical wear rates has been studied by a number of researchers ${ }^{52,53}$ and it is generally agreed that this synergism is very important in regard to slurry wear rates of metal alloys. The processes governing material wastage are, however, still poorly understood.

Erosion-corrosion synergism effects can be analysed by following an experimental programme which includes three types of tests ${ }^{54}$ :

(1) pure erosion tests to determine the erosive wear rate;

(2) pure corrosion tests to determine the corrosive wear rate;

(3) combined tests to determine the total wear rate when conditions in both test ( 1 ) and test (2) are acting.

These experiments allow evaluation of the synergistic effect by using the equation:

$$
S=T-(E+C)
$$

where $S$ is the synergistic wear rate, $\boldsymbol{T}$ the total wear rate, $E$ the erosive wear rate and $C$ the corrosive wear rate.

Wood et $a{ }^{54}$ used their equation to analyse results taken from the literature. 'The synergistic mechanism was then explained as one of erosion-enhanced corrosion. The effect of solid particle impacts, during slurry erosion, is to remove the corrosion product mechanically and thus generate fresh, highly reactive new surfaces. It was also proposed that the fatigue strength of the target metal is lowered by corrosion. Further possible corrosion enhanced mechanisms postulated are the removal of workhardened surfaces by corrosion exposing the softer base material to erosion mechanisms, the preferential attack at grain boundaries resulting in grain loosening and the increase in the number of stress concentrating defects resulting from corrosion micropitting. 
Madsen ${ }^{55}$ developed a slurry test rig for the measurement of wear rates and electrochemical corrosion rates during slurry wear in order to establish relationships between erosion and corrosion of metal specimens. The results showed that the combined effects of erosion and corrosion resulted in wear rates far in excess of the additive effects of each process alone, thus showing the effect of the synergism between erosion and corrosion.

Under erosive-corrosive conditions, the mechanical damage may be restricted to surface layers or to both the surface layer and the base metal, depending on the energy and/or frequency of the particles hitting the surface. Heitz et al ${ }^{56}$ has distinguished three cases of increasing energy or frequency of the particles hitting the surface: these are illustrated in figure 2.11.

\section{Energy and/ or \\ Frequency}

1

(3)

(2)
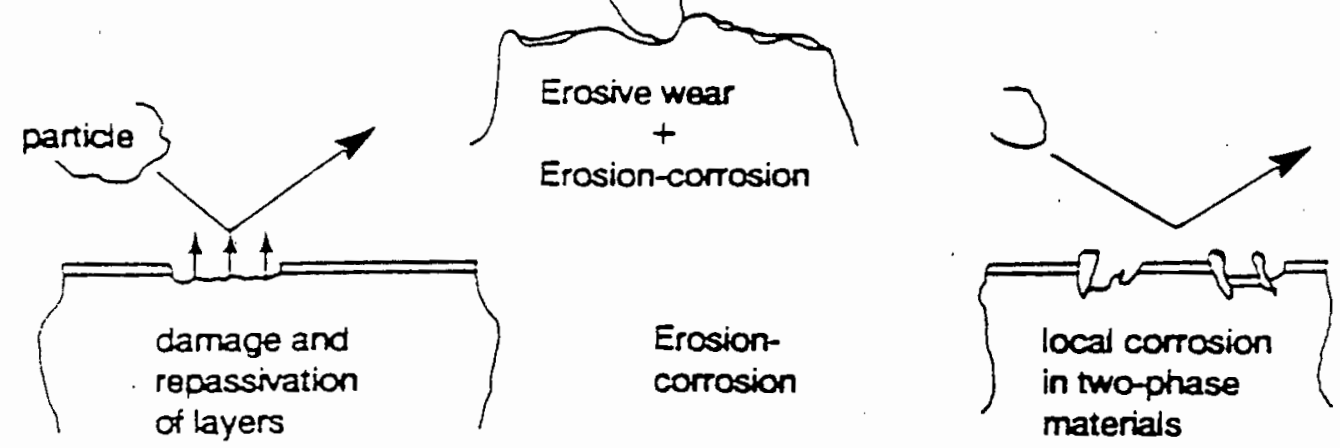

(1)

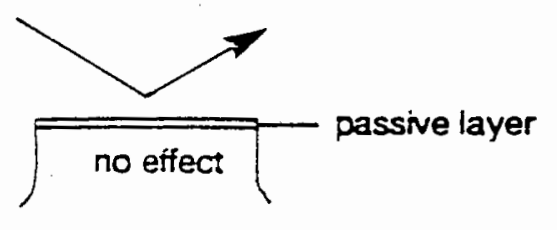

Figure 2.11: Chemo-mechanical effect of a particle impact on a metal surface. 
The three cases are:

1. The particle energy is too small to damage even the passive layer of the passivated metal or the impact events are too rare to have a measurable effect on the slurry erosion rate.

2. The particle energy is sufficient to account for damage to the passive or other surface layers and to deform the outer regions of the base metal mechanically. The activated surface of the metal corrodes in the presence of aggressive agents. Erosive wear and corrosion rates are of the same magnitude. Damage and healing kinetics of passive or other layers are involved. In materials with two-phase structures, local corrosion on a micro scale is observed.

3. The particle energy is so great that the base metal is preferentially eroded and the attack is mainly erosive wear. 


\section{CHAPTER THREE}

\section{MATERIALS}

\subsection{TARGET MATERIALS}

The materials used in this project were chosen to examine the effects of compositional changes within the binder on the slurry erosion-corrosion behaviour of WC-based hardmetals. The materials were all manufactured by the Boart Longyear Research Centre.

The target materials can be separated into two distinct groups, tungsten carbide based cermets and binder metal alloys containing no tungsten carbide particles. The tungsten carbide based cermets can again be separated into two categories, those with $10 w t \%$ binder and those with $6 w t \%$ binder. The binder metal alloys have compositions similar to those of the binder phase of the $10 \mathrm{wt} \%$ cermets. These binder metal alloys have been manufactured by powder metallurgical techniques and were used to examine the behaviour of the binders.

Alloyed binder phase metals in WC-based hardmetals have been used to improve the corrosion resistance of the cermets as the common binder, cobalt, has poor corrosion resistance ${ }^{16}$. Nickel and nickel with additions of chromium and/or molybdenum have been used successfully in corrosive environments to increase the lifespan of the cermet ${ }^{17}$. Slurry erosion conditions, however require the cermet to have good mechanical properties in addition to improved corrosion resistance.

The different grades of materials that were employed in this study can be identified as follows:
$10 w t \%$ binder cermets
e.g. 833,439
6 wt\% binder cermets
e.g. P6, V6
$100 \mathrm{wt} \%$ binder alloys
e.g. Uct 1 , Uct 2

A comprehensive description of these materials follows in section 3.1.1. 


\subsubsection{CHEMICAL COMPOSITIONS}

The chemical compositions of the different materials used in this work are tabulated in table 3.1 below:

\begin{tabular}{|c|c|c|c|c|c|}
\hline \multirow[t]{2}{*}{ Grade } & \multicolumn{5}{|c|}{$\begin{array}{c}\text { Composition } \\
\text { (wt } \%)\end{array}$} \\
\hline & WC & $\mathrm{Ni}$ & $\mathrm{Cr}$ & Co & Total C \\
\hline \multicolumn{6}{|c|}{$10 \mathrm{wt} \%$ Binder Cermets } \\
\hline 439 & \pm 90 & 0 & 0 & 10.24 & 5.60 \\
\hline 833 & \pm 90 & 0 & 0 & 9.86 & 5.64 \\
\hline 842 & \pm 90 & 0.13 & 0.460 & 9.09 & 5.55 \\
\hline 839 & \pm 90 & 2.13 & 0.470 & 7.04 & 5.58 \\
\hline 840 & \pm 90 & 4.57 & 0.507 & 5.71 & 5.50 \\
\hline 841 & \pm 90 & 5.49 & 0.450 & 3.89 & 5.65 \\
\hline 864 & \pm 90 & 7.42 & 0.501 & 2.28 & 5.50 \\
\hline 834 & \pm 90 & 9.15 & $<0.005$ & 0 & 5.54 \\
\hline \multicolumn{6}{|c|}{6 wt $\%$ Binder Cermets } \\
\hline $\mathrm{C6}$ & \pm 94 & 0 & 0 & \pm 6.0 & - \\
\hline P6 & \pm 94 & \pm 3.0 & \pm 0.6 & \pm 2.4 & - \\
\hline V7 & \pm 94 & 5.67 & 0.350 & 0.35 & 5.79 \\
\hline V6 & \pm 94 & \pm 6.0 & 0 & 0 & - \\
\hline \multicolumn{6}{|c|}{100 wt $\%$ Binder Alloys } \\
\hline Uct 1 & 0 & 0.01 & 0.01 & 99.96 & - \\
\hline Uct 2 & 0 & 0.01 & 5.80 & 94.2 & - \\
\hline Uct 3 & 0 & 33.0 & 4.10 & 72.9 & - \\
\hline Uct 4 & 0 & 60.0 & 5.50 & 34.3 & - \\
\hline Uct 5 & 0 & 70.0 & 3.50 & 26.8 & - \\
\hline Uct 6 & 0 & 95.2 & 4.10 & 0.01 & - \\
\hline Uct 7 & 0 & 99.91 & 0.01 & 0.01 & - \\
\hline
\end{tabular}

Table 3.1: Chemical compositions of the materials.

The chemical compositions of the binder phases are represented schematically in relevant sections of the $\mathrm{Ni}-\mathrm{Cr}$-Co ternary diagrams in figure $3.1(\mathrm{a}-\mathrm{c})$. 


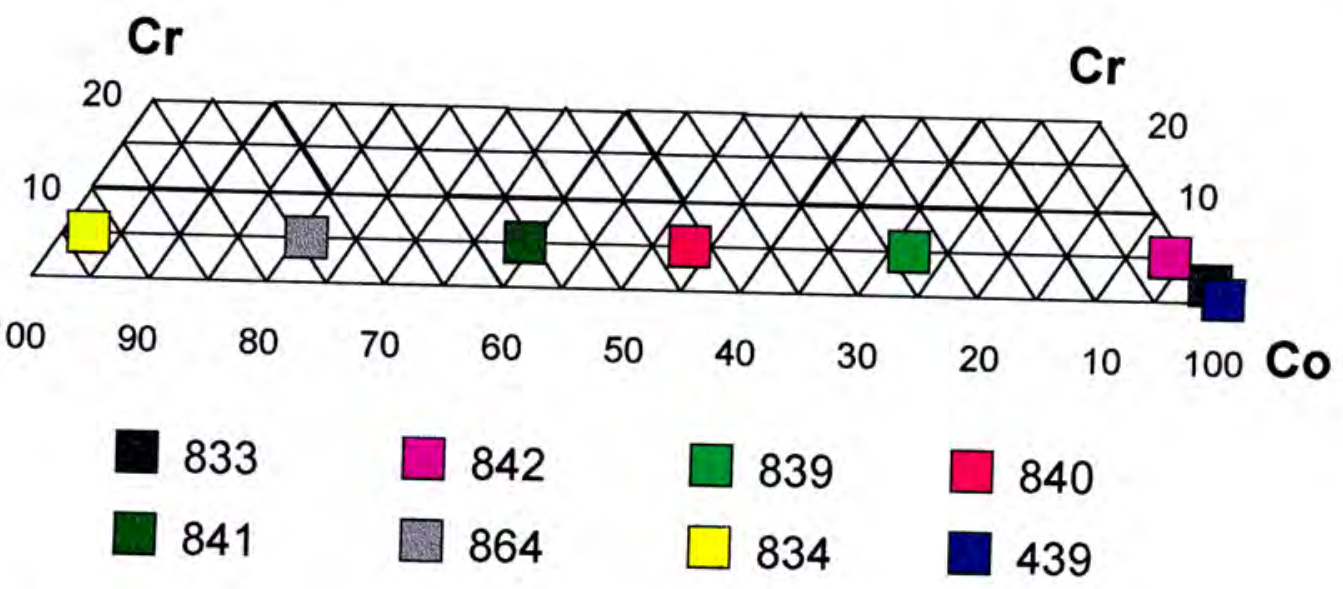

Figure 3.1 (a): 10 wt\% Cermet Binder Compositions.

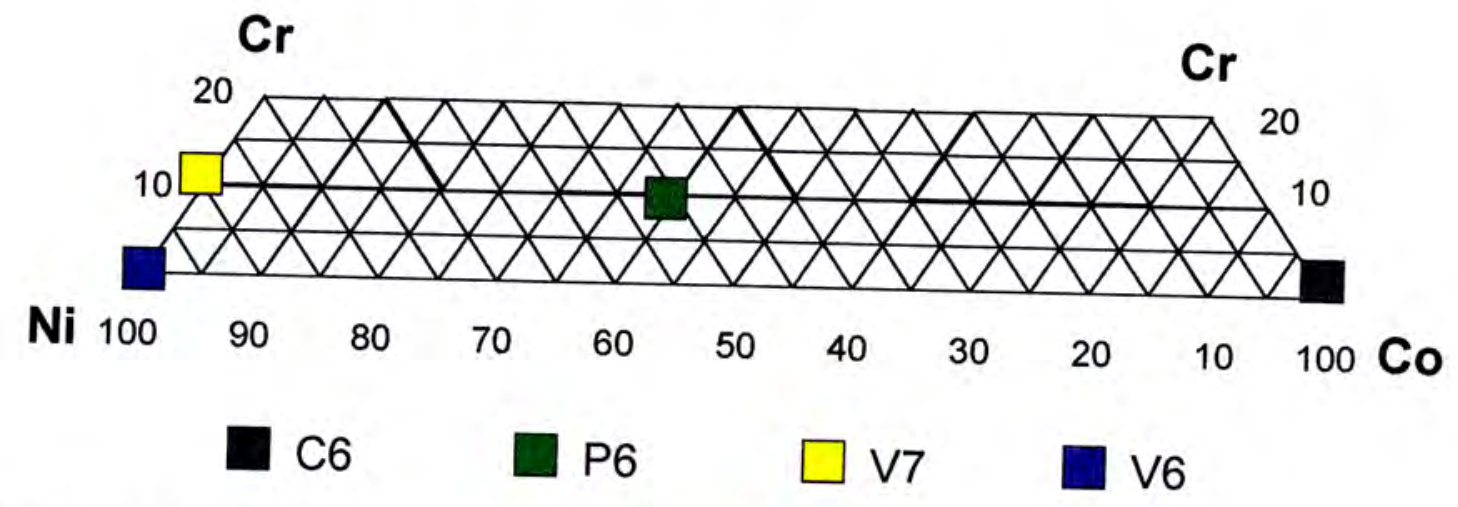

Figure 3.1 (b): 6 wt\% Cermet Binder Compositions.

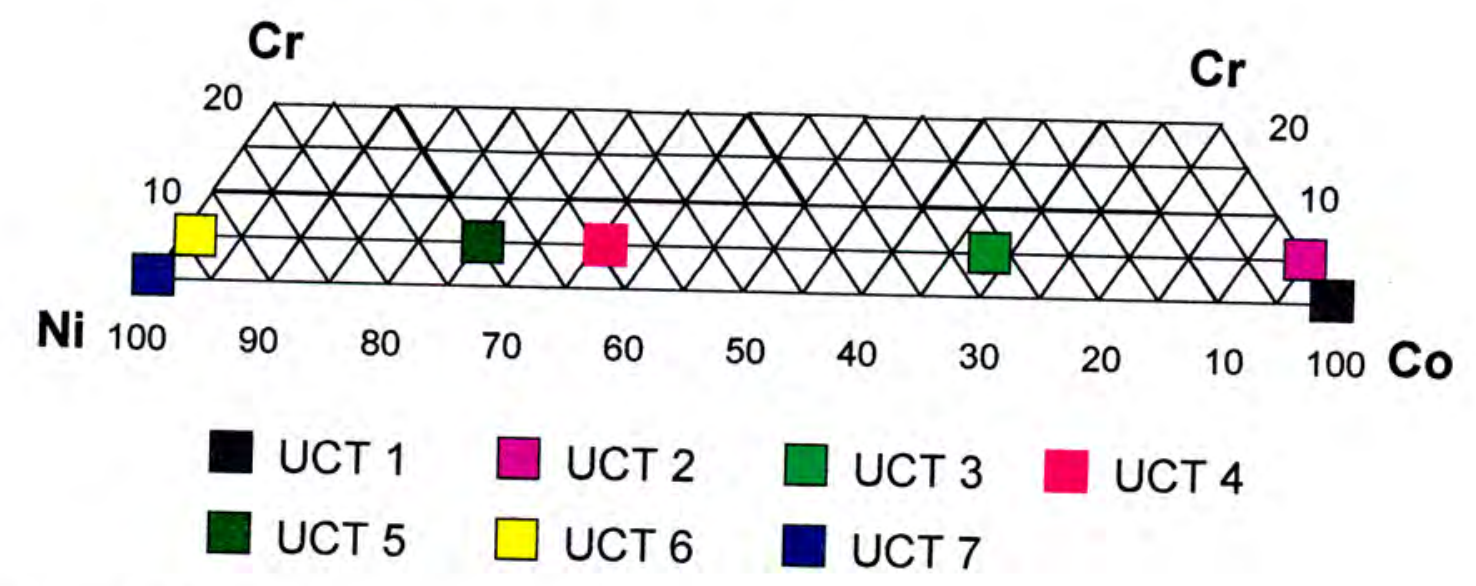

Figure 3.1 (c): Binder Metal Alloy Compositions.

The colours designated to each grade in these figures will be kept throughout this document and thus figure 3.1 is attached at the end of the document as Appendix 1. 


\subsubsection{CRYSTAL STRUCTURES}

$X$-ray diffraction analysis of the target materials was conducted to evaluate the crystal structure of the binder phase and the influence of composition on this crystal structure. The $10 \mathrm{wt} \%$ cermet XRD traces are shown in figure 3.2. The WC (hcp) (101) peak and the Co (hcp) (101) peak overlay each other. Thus determining whether the Co (hcp) crystal structure is present in the high cobalt grades is not possible by this means. The $\mathrm{Ni}$ and $\mathrm{Co}$ cubic peaks also overlay each other, but as the lattice parameters of the two element crystal structures are similar and the solubility of $\mathrm{Co}$ in $\mathrm{Ni}$ and $\mathrm{Ni}$ in $\mathrm{Co}$ is good, no crystal structure change is expected.

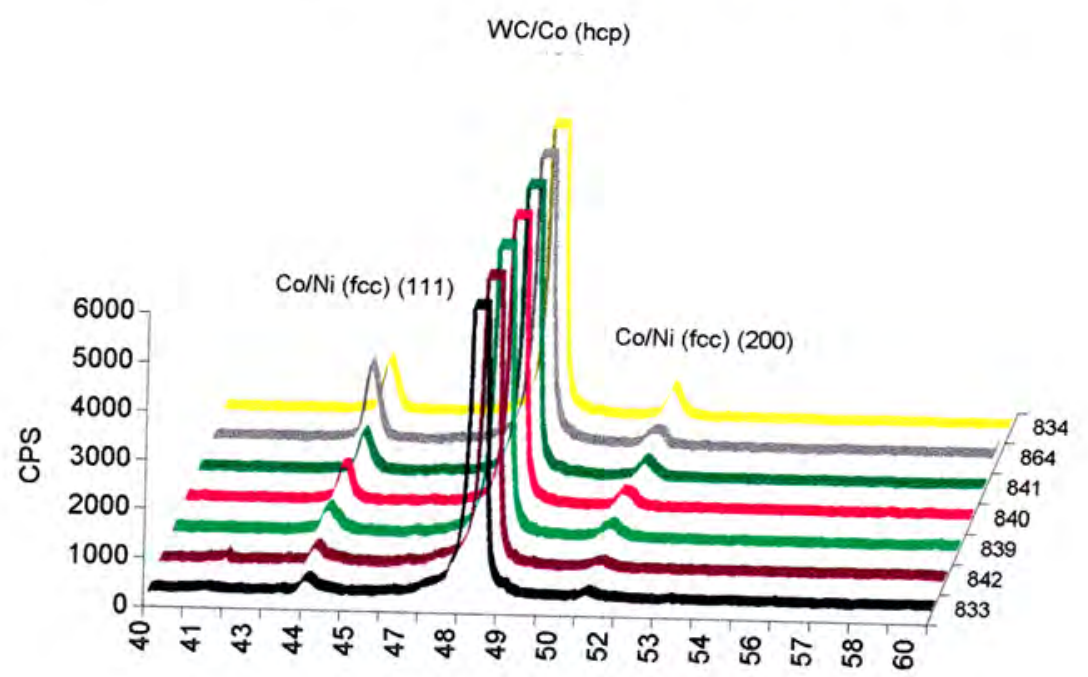

Figure 3.2: X-Ray Diffraction of 10 wt\% cermet grades.

$X$-Ray diffraction traces of the pure binder grades showed the cobalt hexagonal phase to be present in the high cobalt grades, but not in grades with over $30 \mathrm{wt} \% \mathrm{Ni}$ in the binder phase. The $\mathrm{Co}$ and $\mathrm{Ni}$ cubic phases are also present in these pure binder grades. Good correlation exists between the crystal structures of the pure binder grades and the crystal structure of the binder phase in the 10 wt\% cermet grades. The XRD traces of the pure binder grades are shown in figure 3.3. 


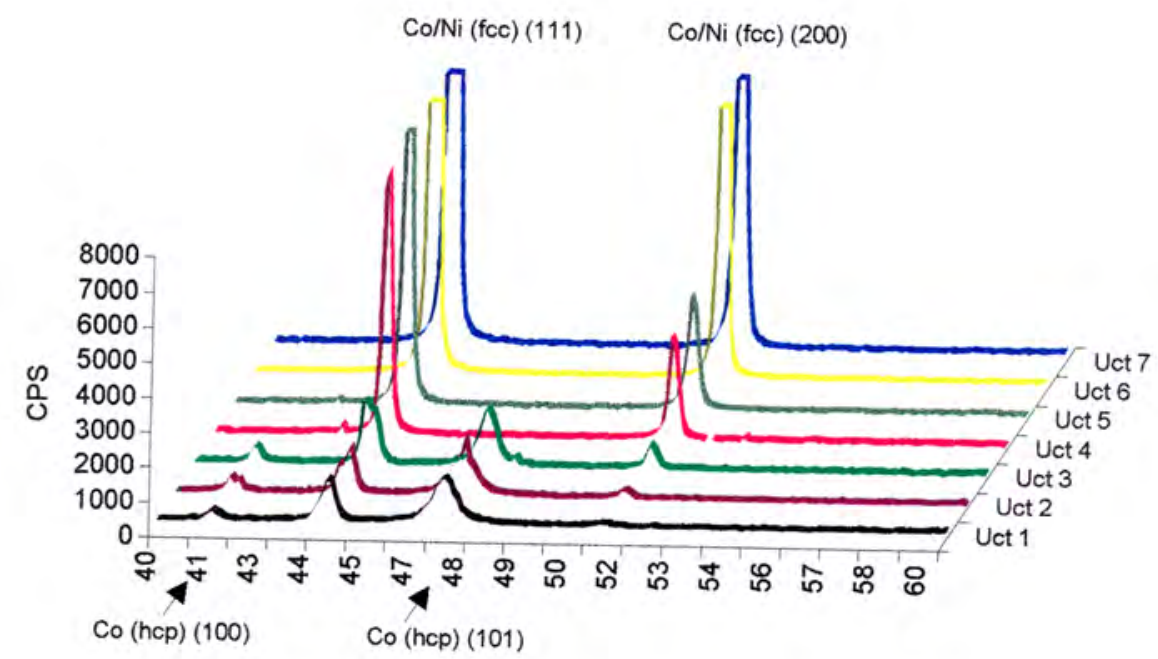

Figure 3.3: X-Ray diffraction traces of the pure binder metal grades.

\subsubsection{MICROSTRUCTURES}

\section{WC-Based Cermet Grades}

The $10 \mathrm{wt} \%$ and $6 \mathrm{wt} \%$ cermets are made using the same $1.0-1.5 \mu \mathrm{m}$ specification WC powder. The microstructures of the various grades of a certain binder volume fraction are thus very similar. Chromium additions to the binder inhibit WC grain growth during sintering ${ }^{13,14}$ and subsequently the grades containing no chromium exhibit a small size increase in some WC grains. This is a consequence of changes in composition of the binder and is thus unavoidable. The characteristic microstructure of the cermets is shown in figure 3.4. The angular particles are the WC grains. The binder phase is not clearly visible, but forms a matrix surrounding the WC grains. 


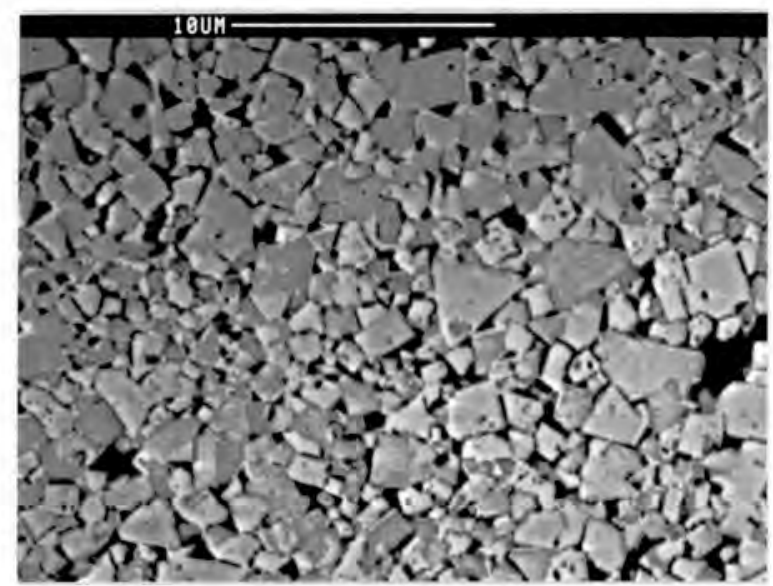

Figure 3.4: SEM micrograph of the microstructure of the $\mathrm{C} 6$ grade (Co), which is characteristic of the microstructures of the cermet grades tested. Note the variation of grain size and the angular nature of the WC grains. Etchant: Murikami's Reagent.

\section{Binder Metal Grades}

The microstructures of the binder metal alloys vary as their composition changes. SEM micrographs of the Uct 1,4 and 7 grades in the unetched and etched condition are shown in figures $3.5(\mathrm{a}-\mathrm{c})$. The unetched condition provides an estimate of the degree of porosity present in each pure binder metal grade.

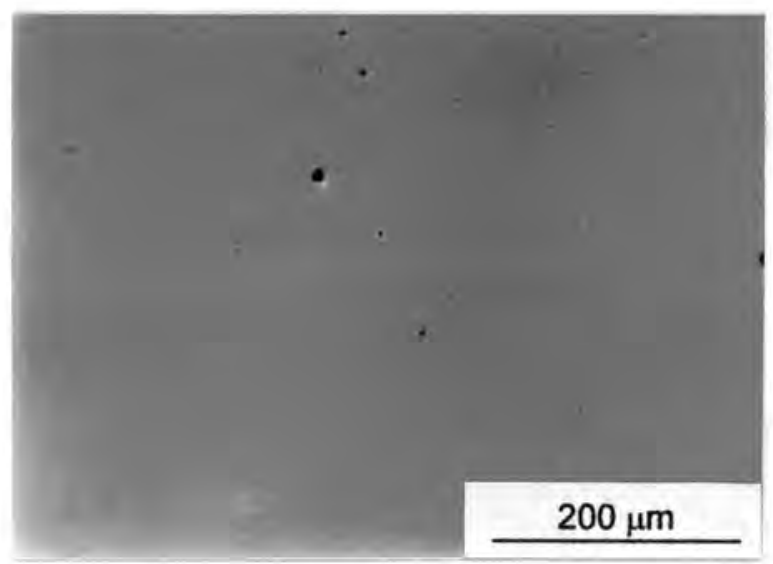

(a)

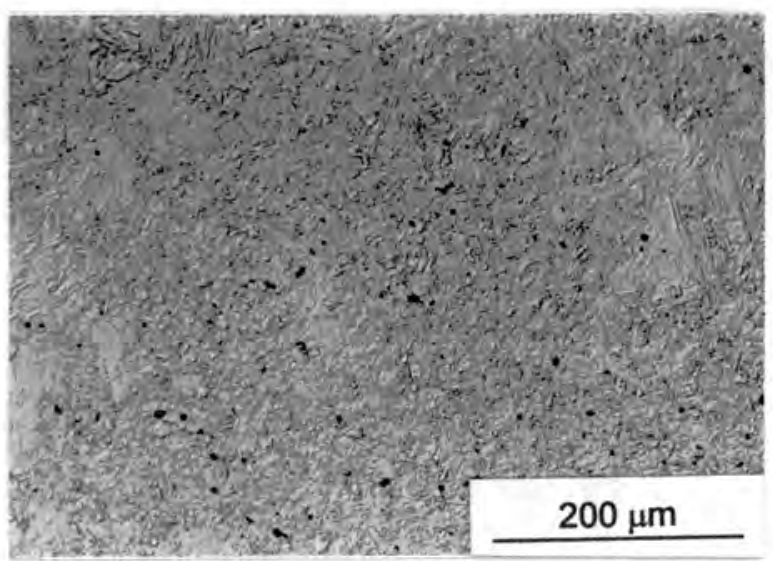

(b)

Figure 3.5 (a): UCT 1: (a) Unetched condition showing low porosity. (b) Nital etch reveals fine grain structure. 


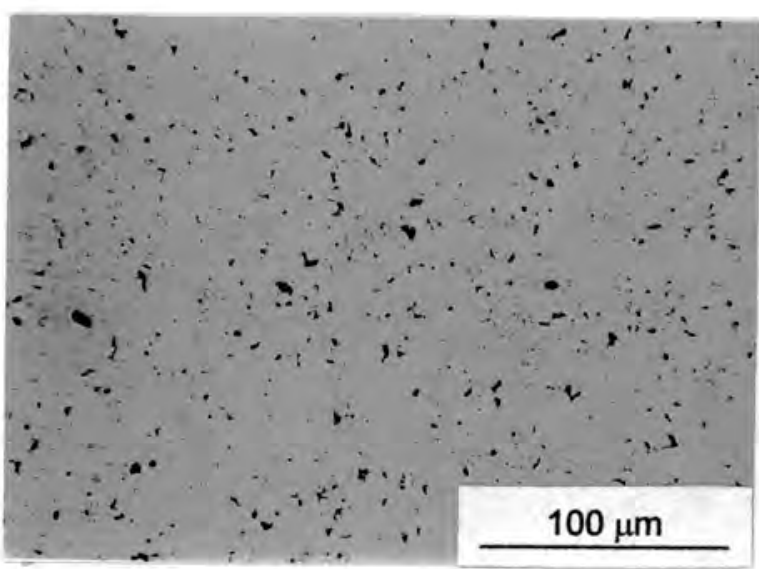

(a)

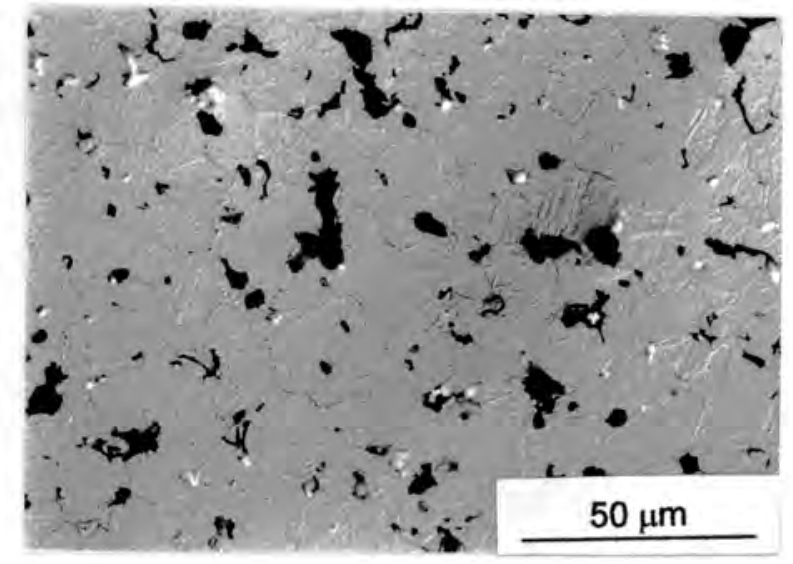

(b)

Figure 3.5 (b): UCT 4: (a) Unetched condition showing porosity. (b) Nital etch reveals fine grain structure with twinning lines present.

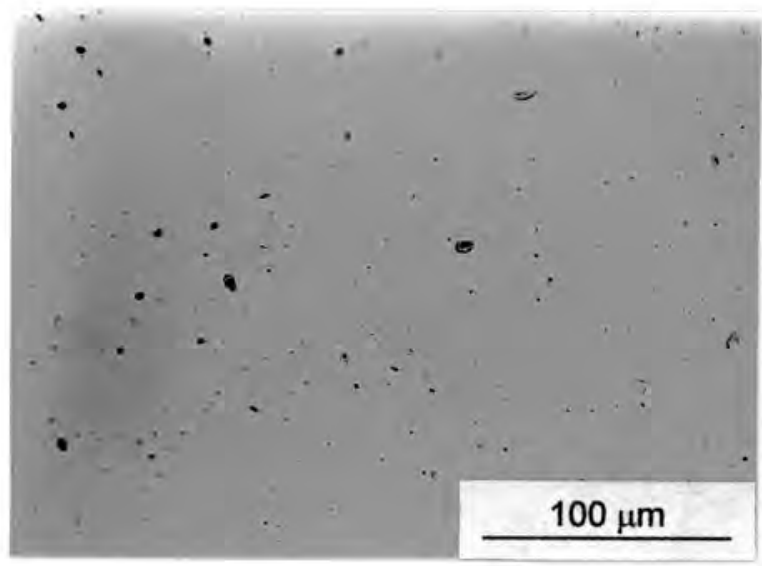

(a)

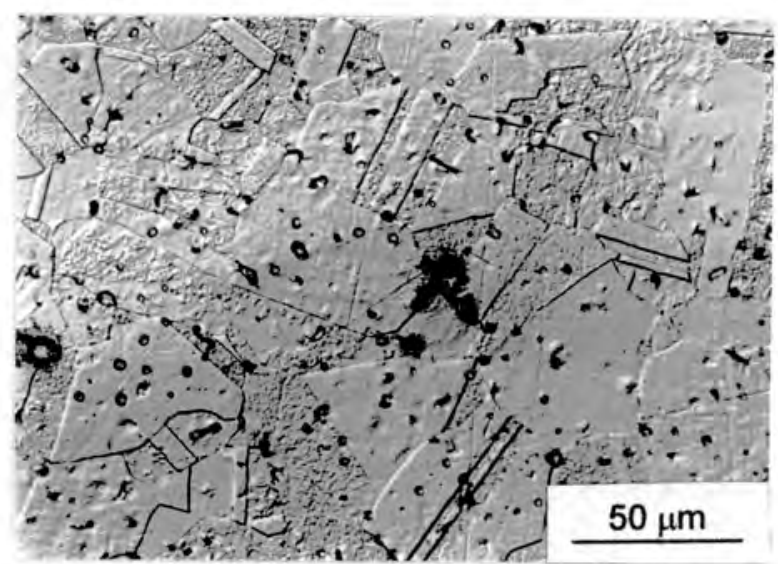

(b)

Figure 3.5 (c): UCT 7: (a) Unetched condition showing porosity. (b) Conc. nitric acid etch reveals equiaxed grains with twinning.

\subsubsection{PHYSICAL PROPERTIES}

Vickers hardness values were obtained, using a $30 \mathrm{~kg}$ load for both the WC-based cermets and the pure binder alloys, in order to facilitate comparisons between hardness and slurry erosion resistance. 
Density measurements were obtained using the submersion Archimedes test method for all specimens. Pyncometer density values using hydrogen impregnation techniques were also obtained for the pure binder grades, as these values represent the true density of the material and are thus higher than the Archimedes values. Pyncometer density values do not take factors such as internal porosity into account. The values of hardness and density for all grades of materials tested are shown in table 3.2 .

\begin{tabular}{|c|c|c|c|}
\hline Grade & $\begin{array}{c}\text { Hardness } \\
\text { HV30 }\end{array}$ & $\begin{array}{l}\text { Archimedes Density } \\
\qquad\left(\mathrm{g} / \mathrm{cm}^{3}\right)\end{array}$ & $\begin{array}{l}\text { Pyncometer Density } \\
\qquad\left(\mathrm{g} / \mathrm{cm}^{\mathbf{3}}\right)\end{array}$ \\
\hline \multicolumn{4}{|c|}{10 wt $\%$ Binder Cermets } \\
\hline 439 & 1400 & 14.48 & - \\
\hline 833 & 1473 & 14.53 & - \\
\hline 842 & 1546 & 14.53 & - \\
\hline 839 & 1498 & 14.51 & - \\
\hline 840 & 1499 & 14.58 & - \\
\hline 841 & 1424 & 14.48 & - \\
\hline 864 & 1400 & 14.58 & - \\
\hline 834 & 1409 & 14.55 & - \\
\hline \multicolumn{4}{|c|}{6 wt $\%$ Binder Cermets } \\
\hline C6 & 1550 & 14.97 & - \\
\hline P6 & 1687 & 14.95 & - \\
\hline v7 & 1674 & 14.95 & - \\
\hline V6 & 1448 & 14.93 & - \\
\hline \multicolumn{4}{|c|}{100 wt $\%$ Binder Alloys- } \\
\hline Uct 1 & 258 & 8.52 & 8.73 \\
\hline Uct 2 & 227 & 8.25 & 8.02 \\
\hline Uct 3 & 146 & 8.00 & 8.01 \\
\hline Uct 4 & 91 & 7.71 & 8.46 \\
\hline Uct 5 & 87 & 7.64 & 7.83 \\
\hline Uct 6 & 80 & 7.65 & 8.31 \\
\hline Uct 7 & 95 & 8.54 & 8.48 \\
\hline
\end{tabular}

Table 3.2: Hardness and density values for the materials tested. 
The grading analysis for the silica sand erodent, type 20/40 density sand from Consul Industrial Minerals is given in table 3.4 .

\begin{tabular}{|c|c|c|}
\hline Aperture Size $(\mu \mathrm{m})$ & U.S. Mesh & \% Retained \\
\hline 1000 & 18 & 0.1 \\
850 & 20 & 0.2 \\
710 & 25 & 0.7 \\
600 & 30 & 23.5 \\
500 & 35 & 67.4 \\
425 & 40 & 6.6 \\
355 & 45 & 1.2 \\
300 & 50 & 0.3 \\
250 & 60 & 0 \\
\hline
\end{tabular}

Table 3.4: Grading analysis of silica sand erodent.

\section{Erodent Degradation}

The slurry erosion test rig used recycles the erodent for the duration of the test, thus introducing the possibility of erodent degradation. Erodent fragmentation has been seen to influence erosion rate. ${ }^{57}$ The SEM micrograph shown below of erodent that has been used for 4 hours of slurry erosion indicates that little erodent degradation has occurred. The silica sand particles become smoother, but fragmentation does not occur.

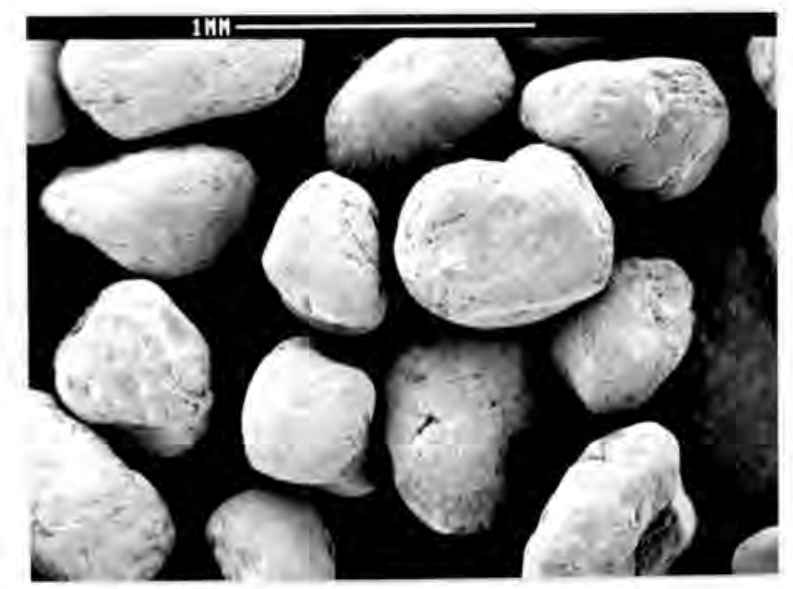

Figure 3.7: Silica sand erodent after 4 hours of use. Note the smoothing of the erodent surfaces. 


\section{CHAPTER FOUR}

\section{EXPERIMENTAL METHODS}

\subsection{SPECIMEN PREPARATION}

All the specimens were supplied as sintered, round discs. The cermet grades were surface ground using a 600 grit diamond wheel to reduce polishing time. These specimens were then mounted for automated polishing in cold cure resin. The polishing procedure followed was:

- Approximately 10 Hours polishing with $15 \mu \mathrm{m}$ diamond paste

- 2 hours polishing with $6 \mu \mathrm{m}$ diamond paste

- 15 minutes polishing with $1 \mu \mathrm{m}$ diamond paste

After the polishing process the specimens were removed from the resin to ensure accurate mass measurements during slurry erosion testing.

The binder metal alloys were polished using conventional polishing techniques with the final polish on a $0.25 \mu \mathrm{m}$ diamond paste nap.

Binder alloy cylinders for compression testing were machined from the sintered discs. The compression cylinders were taken from the discs with the height of the cylinder parallel to the diameter of the original disc. The cylinders were $15 \mathrm{~mm}$ in height and $7,5 \mathrm{~mm}$ in diameter and thus had a h/d ratio of $2: 1$. The orientation of the compression cylinders relative to the original sintered discs is shown in figure 4.1.

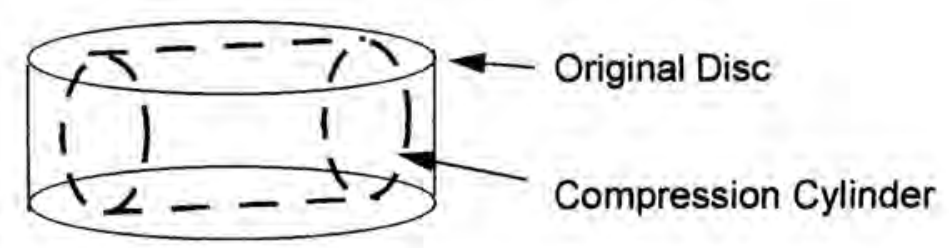

Figure 4.1: Orientation of compression cylinder relative to original sintered disc. 


\subsection{THE SLURRY EROSION RIG}

A slurry jet erosion rig based on that of $\mathrm{Zu}^{58}$ and Bester ${ }^{59}$ was constructed from noncorrosive plastic components. A photograph of the slurry rig is shown in figure 4.2.

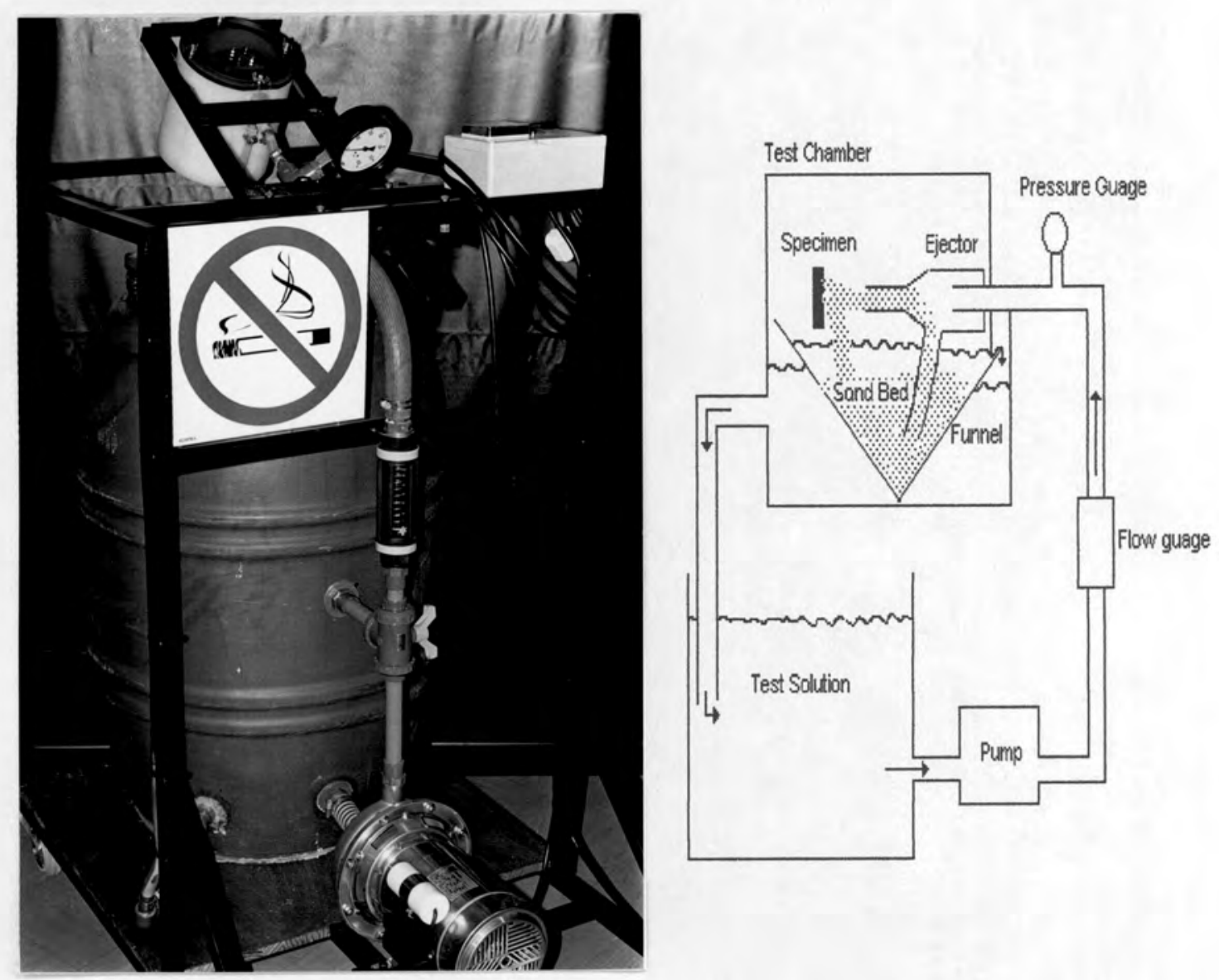

Figure 4.2: The slurry jet erosion rig and a schematic diagram of the rig.

The carrier fluid is circulated by a stainless steel centrifugal pump from the holding tank, via a bypass valve, a rotameter, a pressure gauge, and the ejector to the specimen surface. Erodent is mixed with the carrier fluid in the ejector to form a slurry jet which is accelerated through the ejector and impinges on the specimen surface.

The design of the ejector ensures a pressure drop between the input and exit nozzles. This vacuum draws a mixture of erodent particles and carrier fluid up through a vertical suction tube. The pressure drop and thus the concentration of the erodent in the carrier fluid can be controlled by changing the diameter ratios of the 
three nozzles. The suction tube extends downwards to the bottom of a closed funnel-shaped container holding a fluidised erodent and carrier fluid mixture. Figure 4.3(a) shows the funnel shape container, the ejector and the impact chamber with the specimen holder in place. The erodent returns to the funnel-shaped container through the open, submersed base of the impact chamber. Carrier fluid fills the funnel-shaped container, which overflows into a second container before returning to the holding tank. This gravity filter system ensures that no erodent enters the holding tank and is fed through the centrifugal pump and pipeline, which consequently does not meet with erosive wear damage.

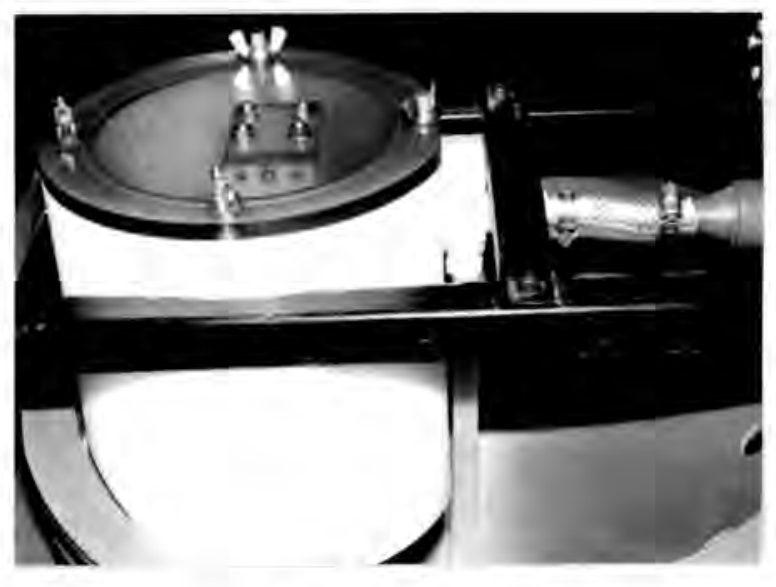

(a)

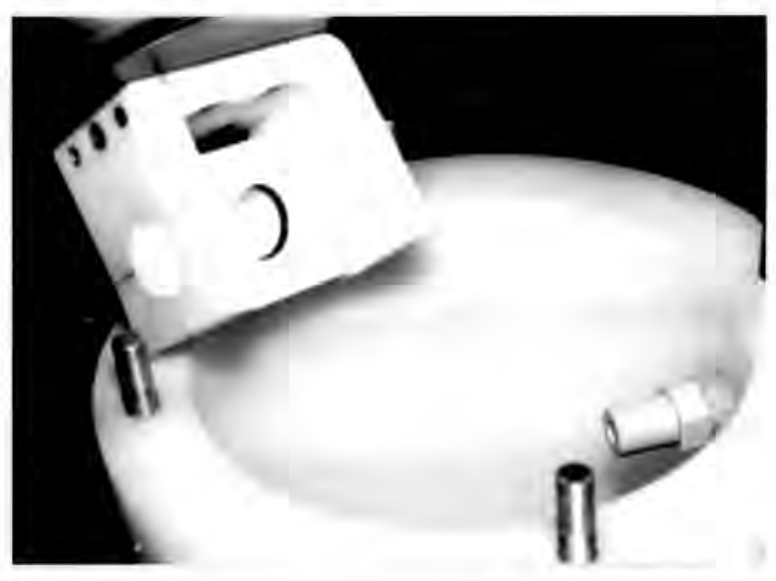

(b)

Figure 4.3: (a) Photograph showing impact chamber with specimen holder in place, ejector and suction tube into funnel-shaped container. (b) Photograph shows specimen holder, impact chamber and exit nozzle.

The specimen is held in a Teflon specimen holder connected to the lid of the impact chamber. The exit nozzle of the ejector enters the impact chamber through the wall of the chamber with the tip of the exit nozzle $30 \mathrm{~mm}$ from the centre of the specimen. The specimen holder with the open impact chamber and the exit nozzle are shown in figure 4.3(b). The specimen is held in the holder with the impact surface flush with the surrounding specimen holder. This flush surface ensures that the fluid flow interference is minimised

The slurry jet erosion rig permits the impact angle, erodent size, erodent concentration, impact velocity, and carrier fluid to be changed. It also allows the erodent concentration to be kept constant while the impact velocity is altered. The 
different impact angles are obtained by rotating the specimen holder about its horizontal axis. This makes it possible for the slurry, which is ejected horizontally from the exit nozzle, to impact the specimen at any preset angle between $0^{\circ}$ and $90^{\circ}$. The angular dependence of slurry erosion rate was determined by Wentzel et $a^{60}$ on the 6 wt\% grades used in this work. A maximum erosion rate was found at an impact angle of approximately $75^{\circ}$ and thus this angle is used in this work to maximise the effects of compositional changes on slurry erosion rates.

A testing temperature of $50^{\circ} \mathrm{C}$ was used as this is the equilibrium temperature of the slurry erosion rig under continuous operating conditions. The system is allowed to reach this equilibrium temperature before erosion testing commences.

The following test parameters were selected:

- Impact Angle:

$75^{\circ}$

- Impact Velocity:

$7 \mathrm{~m} / \mathrm{s}$

- Erodent:

Silica Sand $(500 \mu \mathrm{m})$

- Erodent Concentration:

$6.3 w$ t\% of water

- Erodent/hour:

$37.8 \mathrm{~kg} /$ hour

- Fluid Flow Rate:

$10 \mathrm{l} / \mathrm{min}$

- Test Time:

Cermets: $\quad 4$ hours

Binder Alloys 1 hour

- Carrier Fluid:

Tap Water

Substitute Ocean Water

Tap water is used as a carrier fluid to provide a base against which to compare the erosion rate of a substitute ocean water based slurry and thus determine the degree that the corrosive environment influences slurry erosion rate.

Slurry erosion tests were planned using paraffin as the carrier fluid. Paraffin was chosen as a carrier fluid as it is non-corrosive and has a viscosity similar to that of water. These tests would have allowed the determination of the effect of the erodent in the slurry erosion process and thus separate the effects of erosion and corrosion. The similar viscosity would not alter the flow characteristic of the slurry jet or interfere with the working of the venturi ejector. Unfortunately, silica sand agglomerates in paraffin and thus loses the ability to flow freely. The silica sand did not fall to the 
centre of the funnel shaped container and was thus not fed into the suction tube, even when agitated. The non-polar nature of paraffin has been postulated as a cause for this problem. Consequently no testing was carried out in this medium.

\subsubsection{SLURRY EROSION TEST PROCEDURE}

Carrier fluid was prepared in 100 litre batches and placed in the holding tank of the slurry rig. The slurry rig was then turned on and allowed to operate with a dummy specimen in place until the temperature reached $50^{\circ} \mathrm{C}$. Two kilograms of unused silica sand erodent was placed in the funnel-shaped container, and the dummy specimen removed. Polished specimens were cleaned ultrasonically in alcohol, weighed and positioned in the specimen holder. The specimen holder was then secured to the top of the impact chamber thus positioning the specimen directly in the path of the slurry jet. The specimen was then tested in a slurry jet for one quarter of the total test time, removed from the rig, cleaned ultrasonically in alcohol, dried, reweighed and replaced in the specimen holder and tested further. The test period of one hour for the cermet grades and fifteen minutes for the pure binder metal grades allowed enough mass loss to occur so the error on weighing was less than $1.0 \%$.

Each test was conducted with fresh erodent, for which $2 \mathrm{~kg}$ was found to be sufficient, to ensure that the effects of the erodent degradation were minimised. Examination of the erodent after a four hour test showed that there was no fragmentation of the erodent particles as shown in figure 3.11

Mass loss was normalised to volume loss and a regression analysis conducted on the cumulative volume loss as a function of mass of erodent impacting the surface. All regressions were done through the origin and the slope of the curve was then the slurry erosion rate. This slurry erosion rate is given in units of $\mathrm{mm}^{3} / \mathrm{kg}$ of erodent. 


\subsection{THE CORROSION POTENTIOSTAT}

A fully automated, computer interfaced Amel 5000 Potentiostat was used for all potentiodynamic scans. In order to minimise electrical noise, the corrosion cell was enclosed in a Faraday cage and all leads were shielded. The Amel 5000 Potentiostat and the copper lined, wooden Faraday cage are shown in figure 4.4.

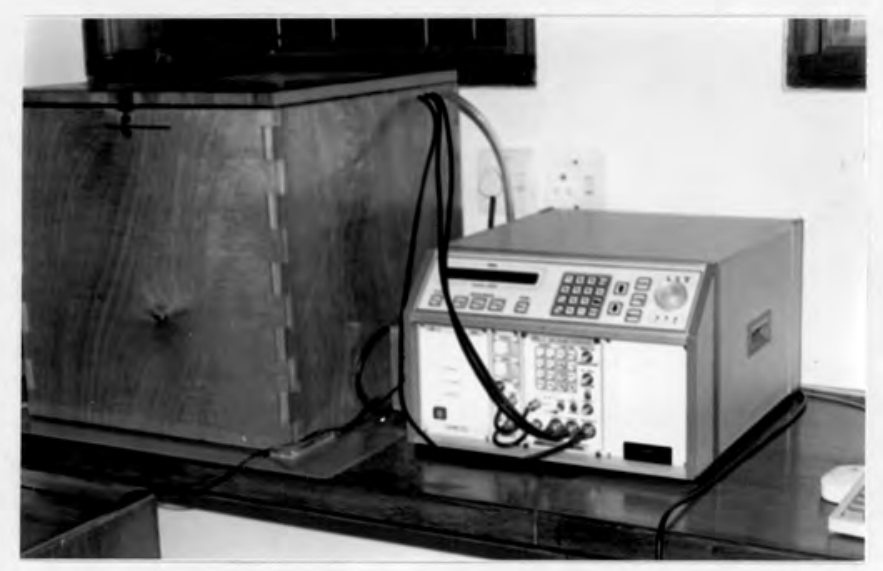

Figure 4.4: The Amel 500 Potentiostat and Faraday cage.

The Amel 5000 controlled the potentiodynamic scan from $-500 \mathrm{mV}$ to $1500 \mathrm{mV}$ at a scan rate of $167 \mu \mathrm{V} / \mathrm{sec}$ and simultaneously collected data at a rate of 300 $\mu \mathrm{V} /$ reading. As large amounts of data points are generated on the full $2 \mathrm{~V}$ scan, a computer program was written to thin the data for ease of representation. This Turbo $\mathrm{C}++$ program is shown in Appendix 4.

A photograph of the corrosion cell is shown in figure 4.4(a). The specimen surface is regarded as the working electrode. The specimen is held in a specimen holder shown in figure $4.5(\mathrm{~b})$. A Teflon gasket placed against the specimen surface ensures that the exposed surface area is $1 \mathrm{~cm}^{2}$ and no crevice corrosion occurs around the edges of the exposed surface. A brass backing disc provides continuous electrical conductivity from the specimen to the stainless steel shaft where the working electrode lead is attached. A Teflon screw secures the specimen in position and prevents the corrosion solution from entering through the rear of the specimen holder. The counter electrodes are two carbon rods and can be seen in figure 4.5(a). The reference electrode is a Standard Calomel Electrode (SCE). All potentiodynamic scans were conducted at $22^{\circ} \mathrm{C}$ and followed the same standard procedure. 


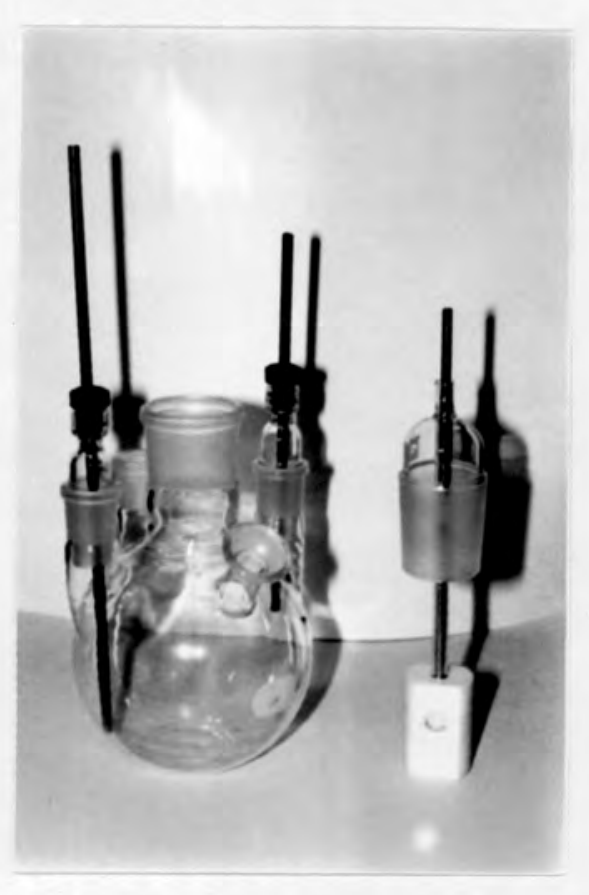

Figure 4.5: (a) Corrosion Cell

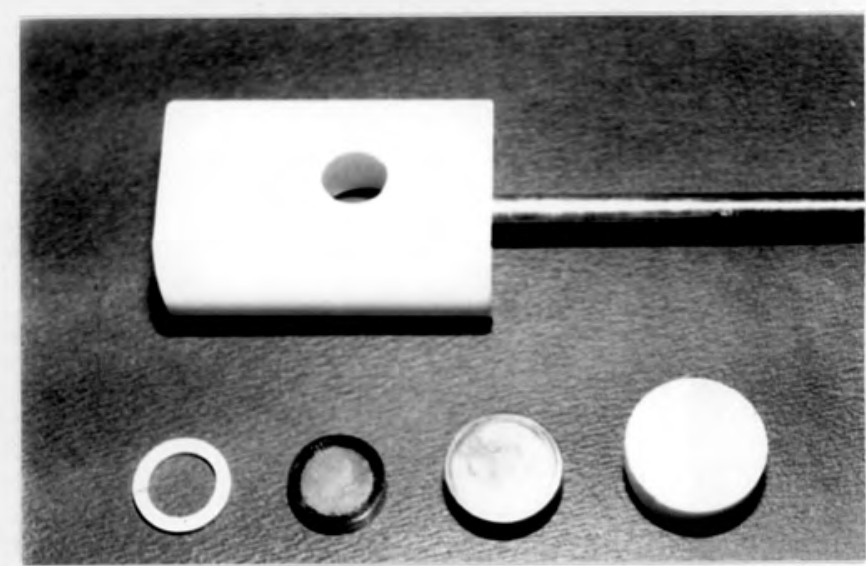

(i)

(iii)

(iv)

Figure 4.5: (b) Specimen holder with: (i) Teflon gasket (ii) Specimen (iii) Brass Backing Disc (iv) Teflon securing screw

\subsubsection{POTENTIODYNAMIC SCAN PROCEDURE}

Clean, polished specimens were placed in a dry specimen holder behind the Teflon gasket, the brass backing disc was placed behind the specimen and the specimen holder closed with the backing screw. Before inserting the Teflon gasket it was smoothed on both sides with $\mathbf{8 0 0}$ grit water paper to remove any burrs and ensure no crevice corrosion occurs. The stainless steel rod was screwed securely into the brass disc and an o-ring seals the specimen holder and the corrosion cell lid. Thus continuity was ensured between the specimen surface and the stainless rod.

The test solution was aerated with argon to remove the oxygen for half an hour. The working electrode was then placed in the test solution and all electrical leads were connected. The specimen was then left in the solution to stabilise for half an hour before the potentiodynamic scan began. During the scan, the argon was 
continuously bubbled through the test solution. After testing the specimen was rinsed with alcohol, dried and placed in a desiccator awaiting electron microscopy.

\subsubsection{CORROSION TEST SOLUTIONS}

Two corrosion test solutions were used. A $1.0 \mathrm{~N} \mathrm{H}_{2} \mathrm{SO}_{4}$ solution with a $\mathrm{pH}$ of 1.24 and a substitute ocean water solution with a $\mathrm{pH}$ of 6.35 were used to investigate the corrosion resistance and polarisation behaviour of the different materials. The substitute ocean water used for polarisation was the same composition as the substitute ocean water used for slurry erosion-corrosion tests. The substitute ocean water used is based on ASTM specification D1141-90 but contains only the three main compounds listed.

The chemical composition of the substitute ocean water used is shown in table 4.1:

\begin{tabular}{|c|c|}
\hline Compound & Concentration, gil \\
\hline $\mathrm{NaCl}$ & 24.53 \\
\hline $\mathrm{MgCl}_{2}$ & 5.20 \\
\hline $\mathrm{Na}_{2} \mathrm{SO}_{4}$ & 4.09 \\
\hline
\end{tabular}

Table 4.1: Chemical composition of Substitute Ocean Water.

\subsection{REPRODUCIBILITY OF STANDARD TESTS}

The following points have been identified as primary sources of error in the standard tests:

- Erodent surface smoothing during slurry erosion testing.

- Carrier fluid temperature variation by $\pm 5^{\circ} \mathrm{C}$.

- Weighing inaccuracies $( \pm 1 \%)$ as material mass loss per test period is small.

- Variation in the amount of corrosive ions in solution due to mixing and weighing inaccuracies.

- Increase in dissolved ions as a result of evaporation of carrier fluid during testing. This factor has been minimised by the large volume (100L) and closed nature of the holding tank in the slurry jet rig. 
The erodent concentration in the slurry jet remains constant for the duration of any test as well as for any set of tests. This has been verified experimentally and remains true as long as the ejector nozzles are not adjusted, the viscosity of the fluid remains constant and sufficient erodent is present in the system. Wear of the ejector causing erodent concentration variations was closely monitored and calibrated to ensure consistency.

The reproducibility of the slurry erosion tests was quartified using two 842 grade specimens, in a tap water slurry. Table $\mathbf{4 . 2}$ gives the results and the error values of three mass loss tests per specimen.

\begin{tabular}{|c|c|}
\hline Mass Loss $(\mathbf{m g} / \mathbf{h})$ & Specimen \\
\hline 7.61 & 1 \\
6.89 & 1 \\
8.29 & 1 \\
6.05 & 2 \\
8.36 & 2 \\
7.39 & 2 \\
\hline Average = 7.43 mg & \\
Standard Deviation $=0.88 \mathrm{mg}$ or $11.8 \%$ \\
\hline
\end{tabular}

Table 4.2: Mass loss and error values for slurry erosion tests.

Since the slurry erosion rate determination method uses four mass loss measurements on which regression analysis is performed, standard error values for all slurry erosion rate tests were determined. In no test was the error from the regression analysis found to be larger than $6 \%$.

The excellent reproducibility of the electrochemical testing can be illustrated by superimposing two potentiodynamic scans on different specimens of the same cermet under the same conditions, as shown in figure 4.6. 


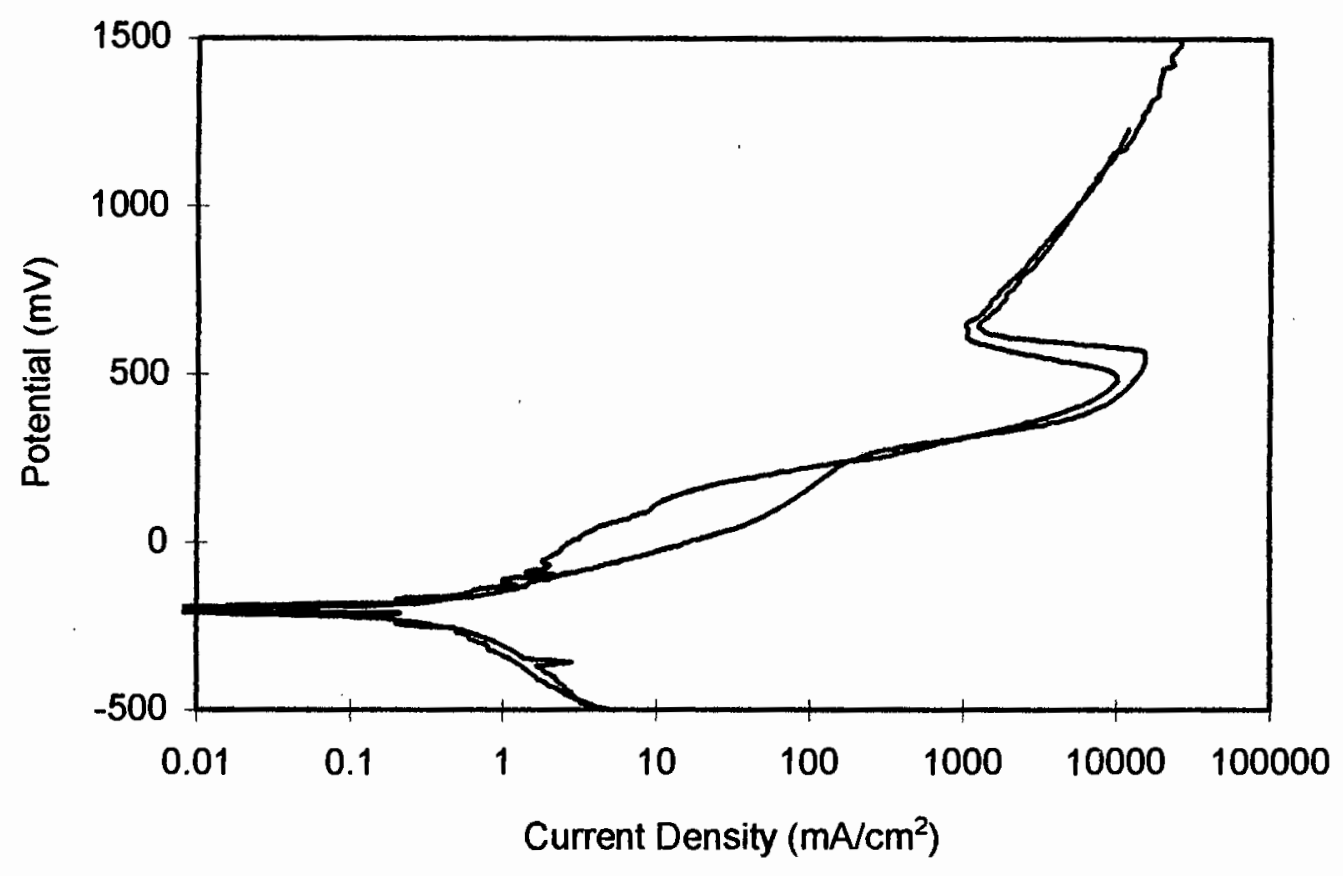

Figure 4.6: Potentiodynamic polarisation scans of the 839 grade in salt water solution.

\subsection{COMPRESSION TESTING}

Compression tests on the pure binder grades were performed using a Zwick Tensile Testing Apparatus. A tension to compression stage was used to impose a compressive load. The load was applied at a constant strain rate of $10^{-3} \mathrm{~s}^{-1}$ up to a maximum load of $40 \mathrm{kN}$ or compressive failure. The elastic strain occurring in the tension/compression cage was calibrated using a load cell and subtracted from test results. 


\section{CHAPTER FIVE}

\section{RESULTS}

\subsection{SLURRY EROSION}

Under steady state conditions, erosion follows a linear relationship and may therefore be quoted as mass loss per unit mass of impacting particles. Compositional changes within a material cause density variations and thus units of mass loss are less significant as to the amount of material lost during wear applications. The slurry erosion rates will thus be quoted as the normalised, volume loss per unit mass of erodent $\left(\mathrm{mm}^{3} / \mathrm{kg}\right)$.

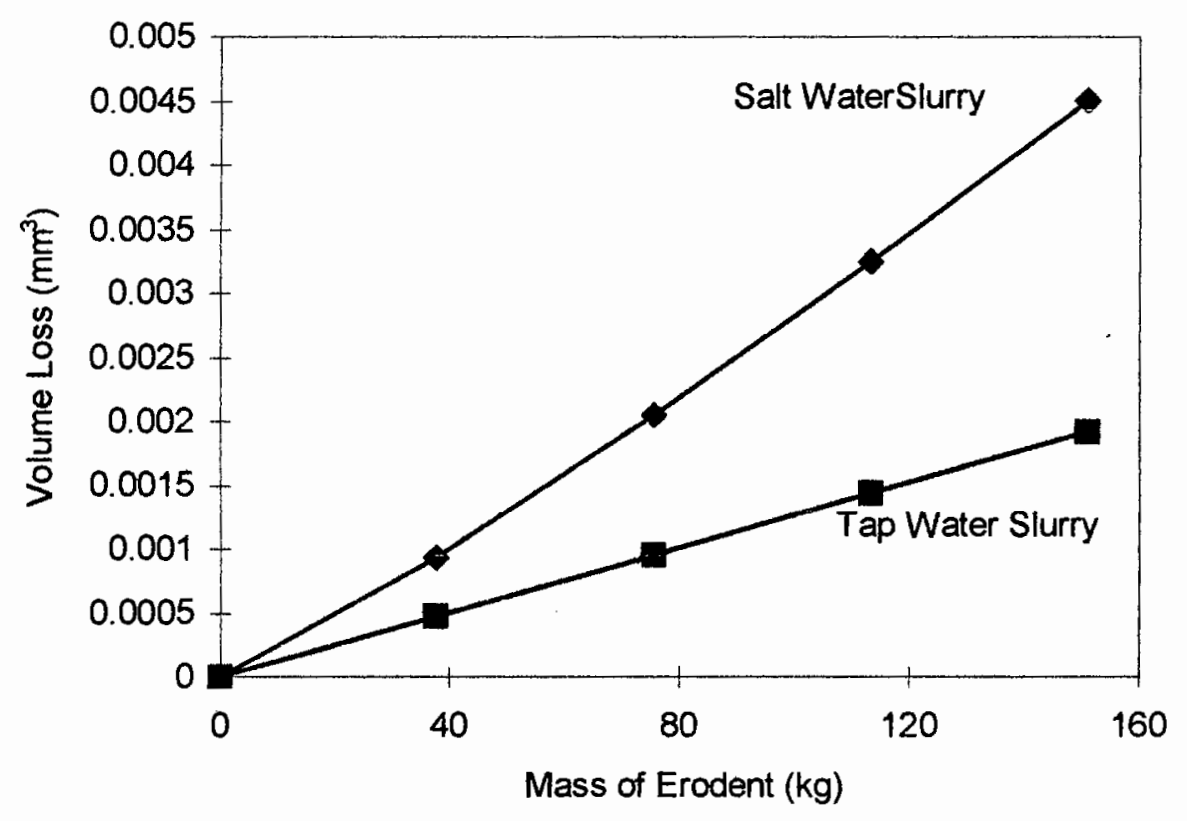

Figure 5.1: Slurry erosion rates of the 839 Grade in both carrier fluids plotted as a function of mass of erodent impacted on the target. Note the linear nature of the curves and the increased erosion rate in a salt water slurry.

The linearity of the slurry erosion rates obtained in both carrier fluids, namely tap water and salt water (substitute ocean water) is represented by the 839 grade in figure 5.1. The volume loss increases linearly with time throughout the period of measurement, with the intercept of the graph at the origin. The regression analysis 
of slurry erosion rates also passes through the origin. The erosion rates for all the grades under both conditions are shown in table 5.1 .

\begin{tabular}{|c|c|c|c|}
\hline \multirow{2}{*}{ 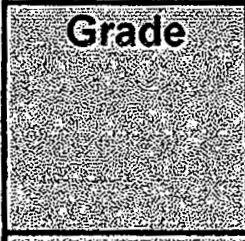 } & \multicolumn{2}{|c|}{ 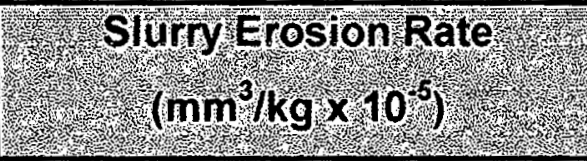 } & \multirow{2}{*}{$\begin{array}{l}\text { SRatio } \\
(\mathrm{TSX}(00) \\
\frac{(\%)}{(\%)}\end{array}$} \\
\hline & Tap Water (T) & Salt Water (S) & \\
\hline \multicolumn{4}{|c|}{$10 \mathrm{wt} \%$ Binder Cermets, } \\
\hline 439 & 2.77 & 4.90 & 56.5 \\
\hline 833 & 2.90 & 5.34 & 54.3 \\
\hline 842 & 1.19 & 2.63 & 45.2 \\
\hline 839 & 1.27 & 2.89 & 43.8 \\
\hline 840 & 2.39 & 4.62 & 51.7 \\
\hline 841 & 1.93. & 4.13 & 46.7 \\
\hline 864 & 3.26 & 5.12 & 63.7 \\
\hline 834 & 3.62 & 6.46 & 56.0 \\
\hline \multicolumn{4}{|c|}{, 6 wo Binder Germets } \\
\hline $\mathrm{C6}$ & 3.57 & 6.22 & 57.7 \\
\hline P6 & 1.67 & 4.17 & 40.0 \\
\hline v7 & 2.07 & 3.78 & 54.9 \\
\hline V6 & 10.56 & 20.35 & 51.9 \\
\hline \multicolumn{4}{|c|}{ 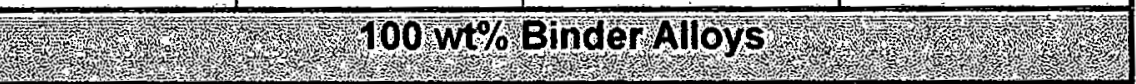 } \\
\hline Uct 1 & 18.70 & 27.60 & 67.8 \\
\hline Uct 2 & 16.45 & 23.34 & 70.5 \\
\hline Uct 3 & 20.15 & 27.91 & 72.2 \\
\hline Uct 4 & 27.42 & 35.92 & 76.3 \\
\hline Uat 5 & 26.29 & 35.55 & 73.9 \\
\hline Uct 6 & 41.29 & 50.01 & 82.6 \\
\hline Uct 7 & 18.74 & 22.12 & 84.7 \\
\hline
\end{tabular}

Table 5.1: Slurry erosion rates for all grades in tap and salt water carrier fluids. The ratio of tap water slurry erosion rate to salt water slurry erosion rate is represented as a percentage.

The slurry erosion rates were established for all the materials tested in both carrier fluids and the results are plotted in figures $5.2(a-c)$. In all these graphs the composition of the binders varies from the high cobalt grades on the left to the high 
nickel grades on the right. The intermediate grades namely 833-864 and Uct 2-Uct 5 have chromium additions to the binder phase of $5 \mathrm{wt} \%$.

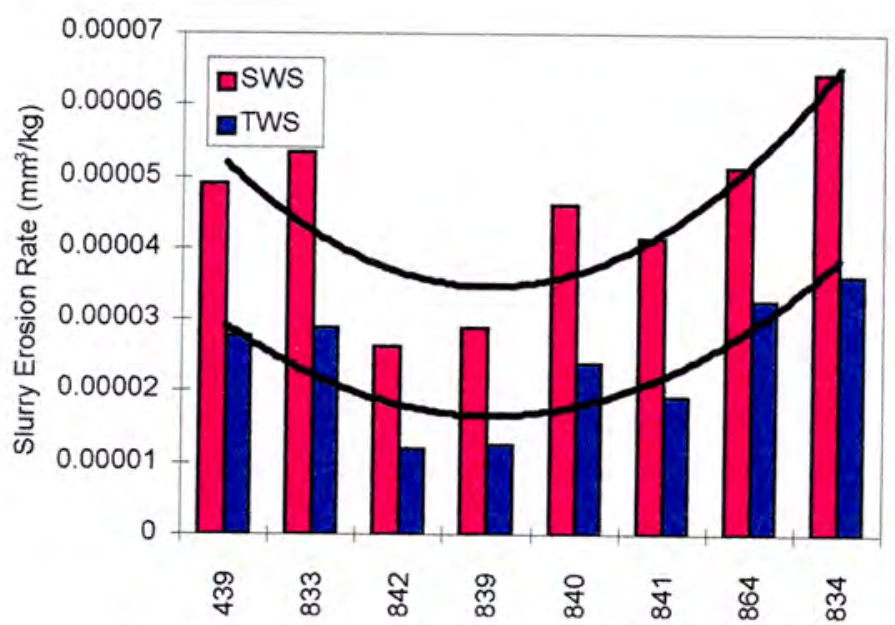

Figure 5.2(a): Slurry erosion rates and trends in erosion rate for $10 \mathrm{wt} \%$ binder grade cermets in salt water solution (SWS) and tap water solution (TWS). Black curves indicate trend in performance.

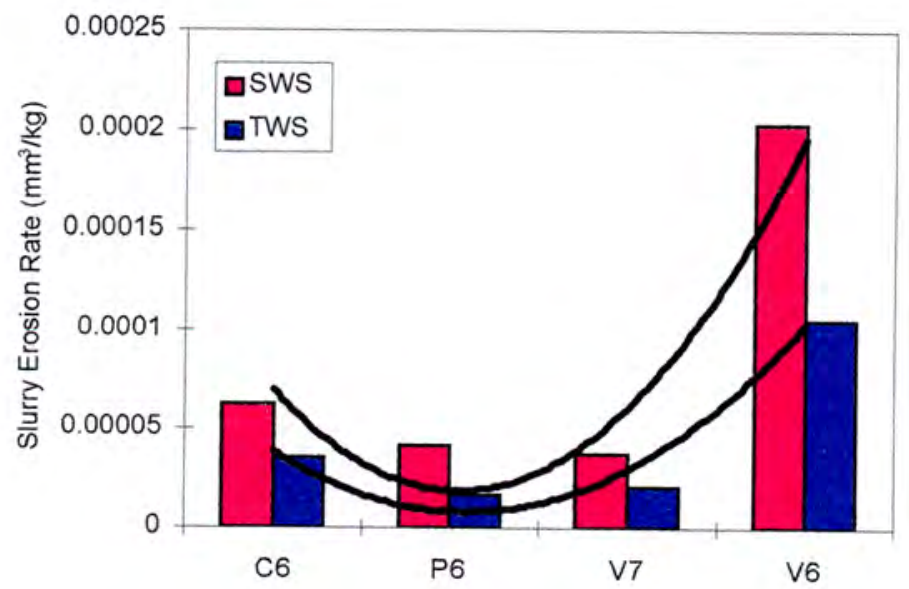

Figure 5.2(b): Slurry erosion rates and trends in erosion rate for $6 \mathrm{wt} \%$ binder grade cermets in salt water solution (SWS) and tap water solution (TWS). Note the higher slurry erosion rates for the $6 \mathrm{wt} \%$ cermet grades than the $10 \mathrm{wt} \%$ cermet grades. 


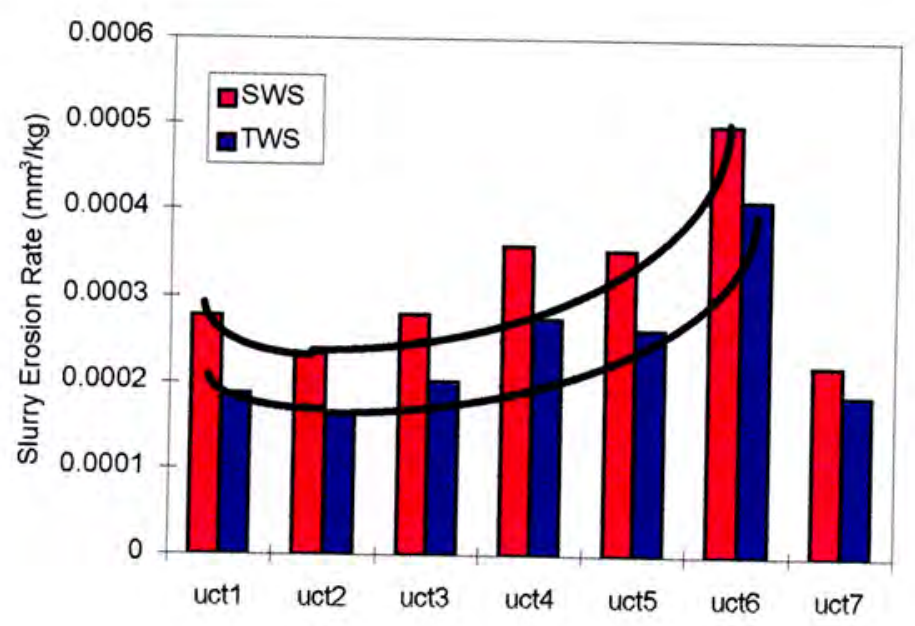

Figure 5.2(c): Slurry erosion rates and trends in erosion rate for pure metal binder grades in salt water solution (SWS) and tap water solution (TWS). Note the pure nickel (Uct 7) does not fit the trend.

With the exception of the pure nickel $100 \mathrm{wt} \%$ binder grades the slurry erosion rates shown in the above 3 figures exhibit a defined trend with the lowest slurry erosion rate occurring when the composition of the binder phase has a high wt\% cobalt and small additions of chromium or chromium and nickel.

\subsubsection{SLURRY EROSION SURFACE MICROSCOPY}

The scanning electron microscope was used to examine the surface of the specimens after slurry erosion in order to evaluate the extent of damage and determine the different modes of material loss. Although slight variations in the surfaces were observed, the SEM micrographs chosen were considered representative of the eroded surfaces. Figure 5.3(a-d) show the slurry eroded surfaces of the four $6 \mathrm{wt} \%$ grades. Note that in all four grades the binder is preferentially removed although the extent varies to some degree. Taper sections of the eroded surfaces reveal that the depth to which binder removal occurs is only that which will allow WC grain removal. Thus a dynamic balance exists between the removal of the binder phase and WC grain removal. An increase in the binder removal rate resulting from a more corrosive binder will thus not be seen in the micrographs of the surfaces. 


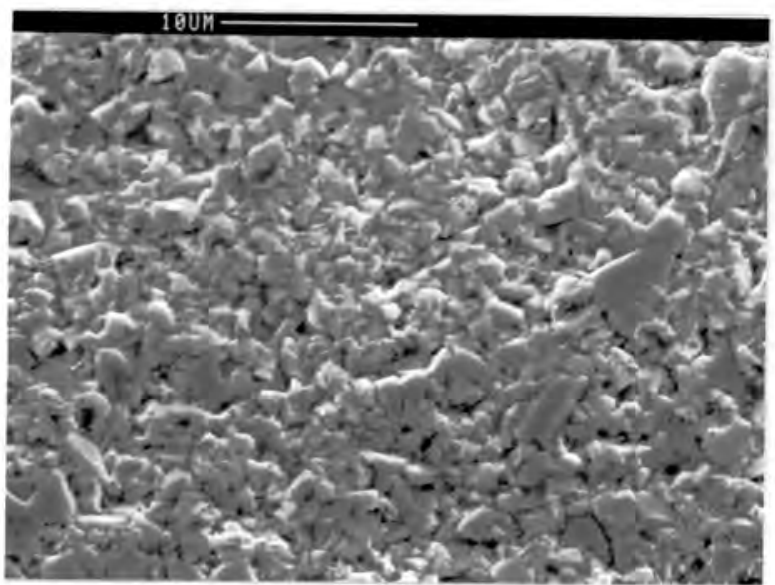

(a) $\mathrm{C} 6$

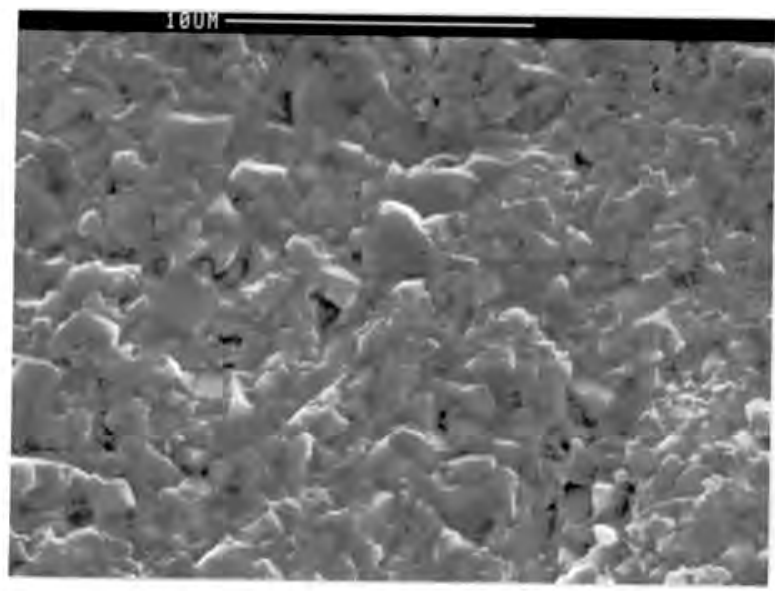

(c) V7

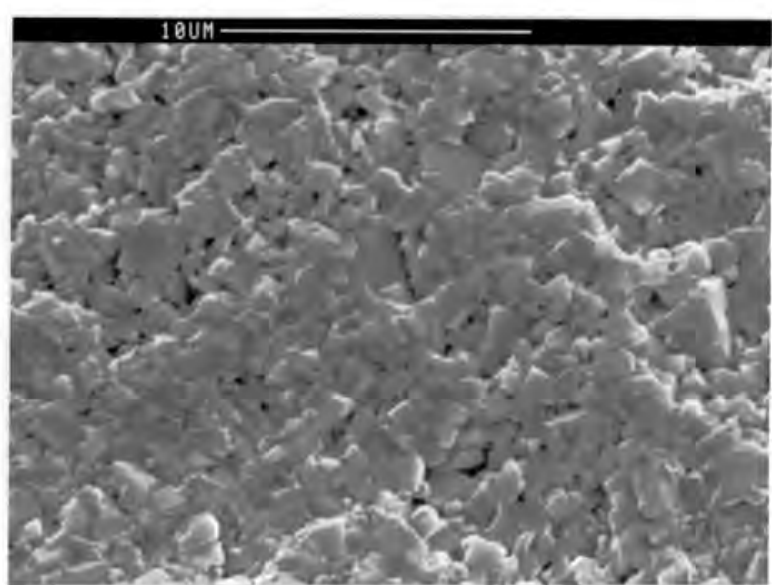

(b) V6

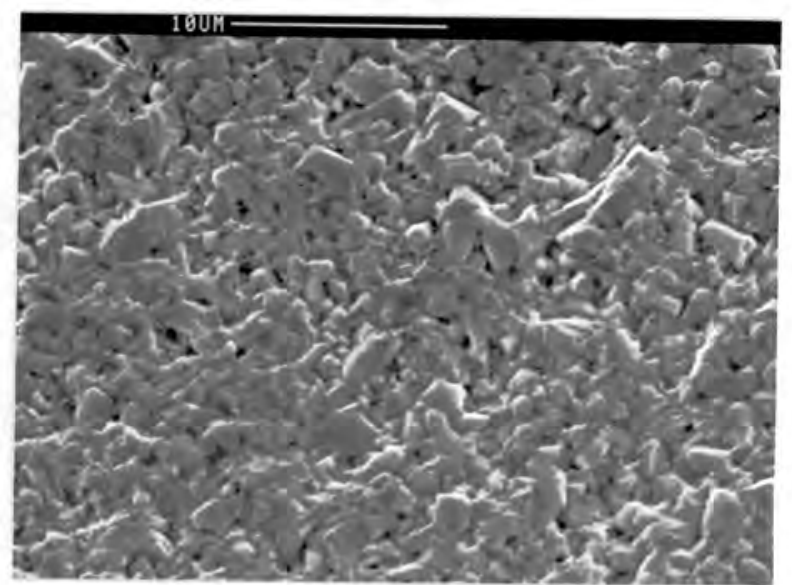

(d) P6

Figure 5.3: SEM micrographs of the slurry erosion surfaces after 4 hours of slurry erosion in a tap water carrier fluid.

Observation of the erosion process by monitoring the sequential loss of material from a polished surface highlights the mode of material removal. Figure 5.4 shows a sequence, where the initial impact sites are corrosively attacked causing the binder to be removed until a stage where WC grain removal is possible. This process leads to a dynamic balance of binder removal and WC grain removal. The initial impact and subsequent impacts cause binder extrusion and WC grain brittle fracture as can 
be seen in Figure 5.5. This binder extrusion causes irregularities on the surface of the specimen which serve to enhance the corrosion process.

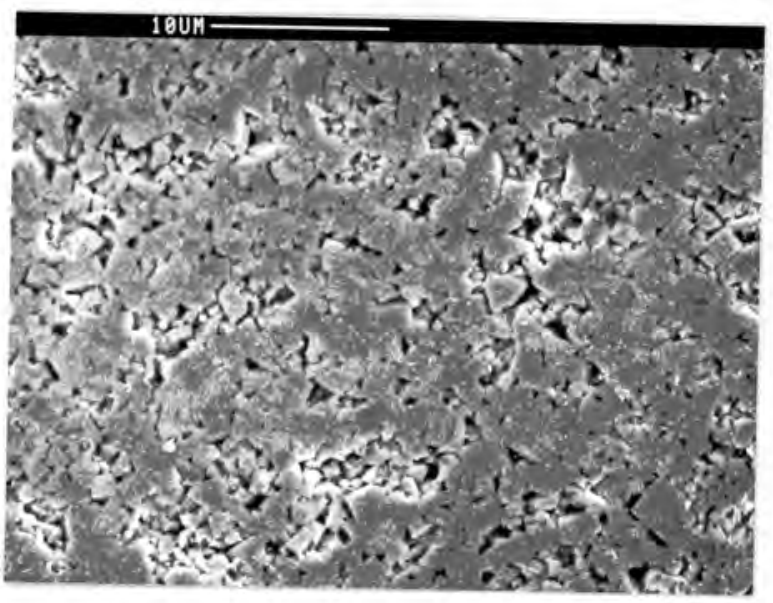

(a)

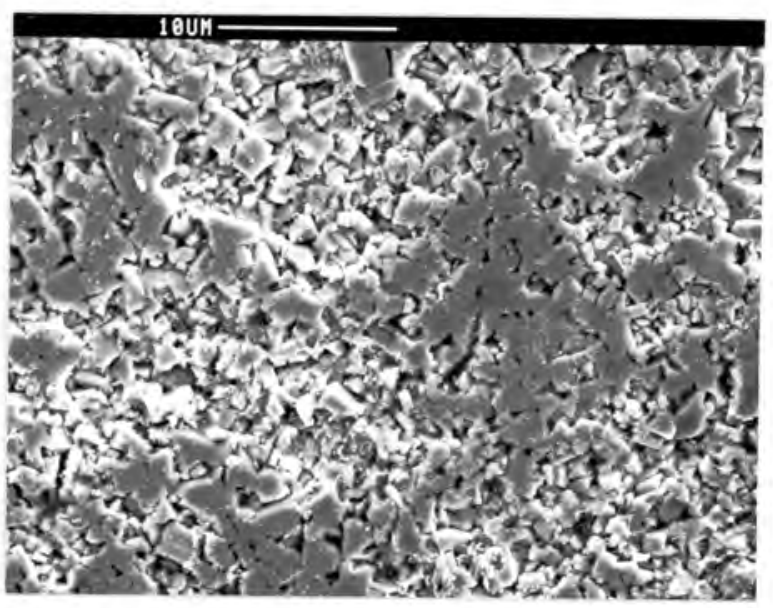

(b)

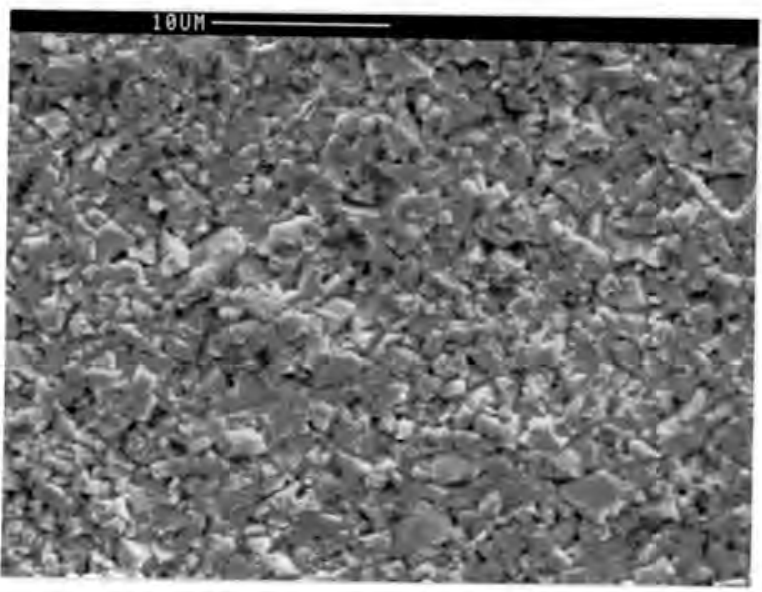

(c)

Figure $5.4(a-c)$ : Sequence of progressive loss of material from a polished surface. Note the loss of binder phase followed by WC grain removal. (a), (b) and (c) are after 3, 6 and 12 minutes of slurry erosion respectively. 


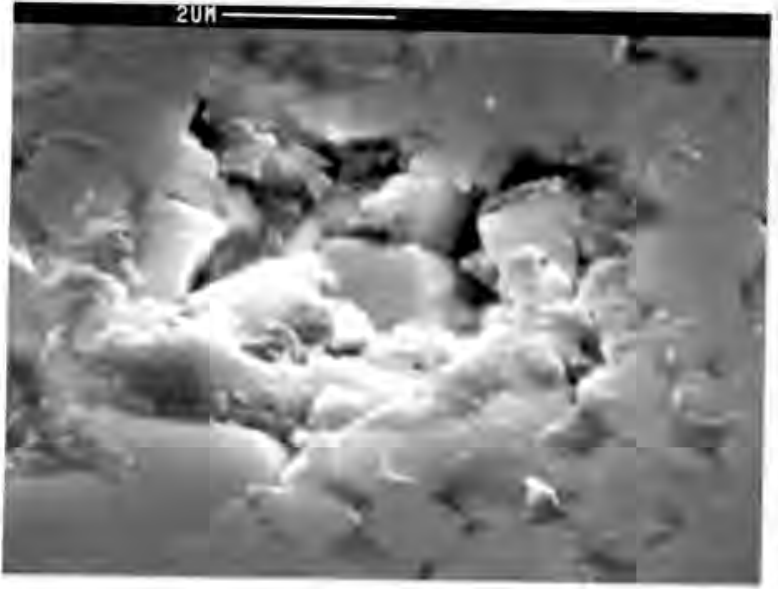

(a)

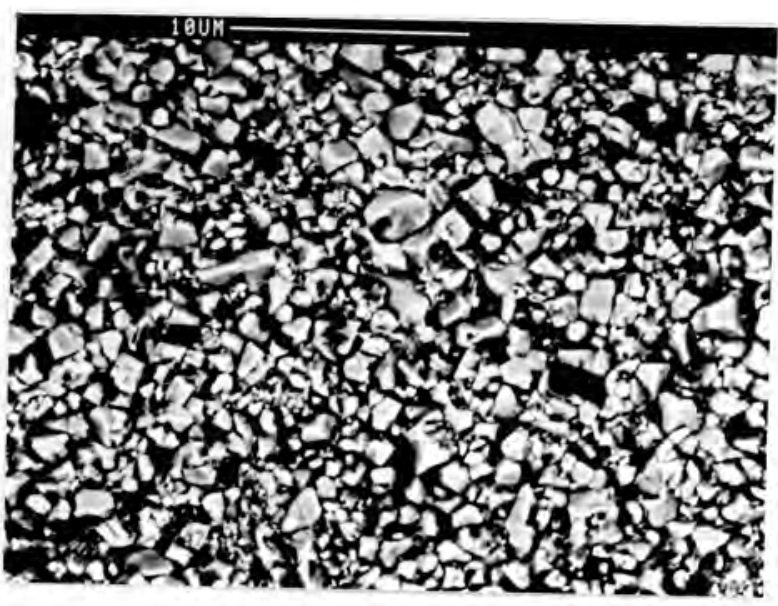

(b)

Figure 5.5: (a) Micrograph of a single impact site, where WC grain movement can be identified by the binder extrusion on the edges of the impact site. Note the binder removal in the centre of the impact site. (b) A backscattered image of an eroded surface. Note the small cracks evident in the WC grains indicative of impact erosion.

\subsubsection{INFLUENCES ON SLURRY EROSION}

\section{Effect of Hardness on Slurry Erosion Rate}

The influence of binder composition can be seen in figure 5.6 where the hardness values of the cermets and the pure metal binder grades are compared. The composition of the binder varies from high cobalt content on the left side to high nickel content on the right side of the graph. The trends for the cermets and the pure metal binder grades are superimposed. The nickel rich binders are softer than the cobalt rich binders and this influences the cermets' hardness in the same manner although, because of the lower volume fraction of binder in the cermets, to a lesser degree. 


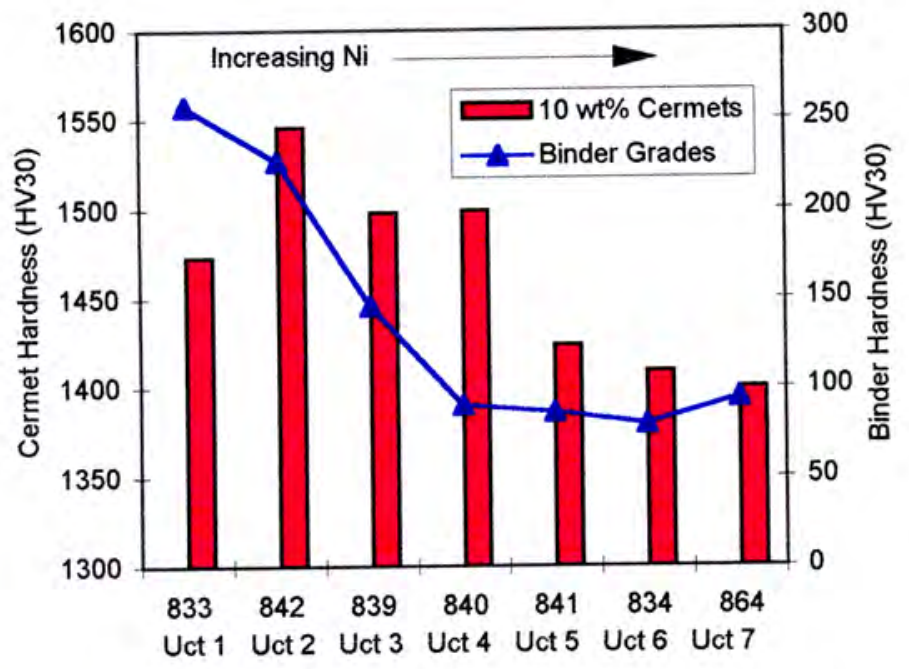

Figure 5.6: The influence of binder hardness on the hardness of the cermet grades. Note the left side of the graph is high cobalt and the right high nickel.

The influence of target material hardness on the slurry erosion resistance of the hardmetals and the binder metal grades is shown in figure $5.7(a \& b)$ respectively. The salt water slurry erosion rates are plotted against hardness in these figures. $A$ decrease in erosion rate with increase in cermet hardness is apparent for both $10 \%$ and $6 \%$ binder content. The decrease in rate is however $350 \%$ greater for the 6 $w t \%$ binder grades than the $10 w t \%$ binder grades The same trends are evident when comparing tap water slurry erosion rates to hardness.

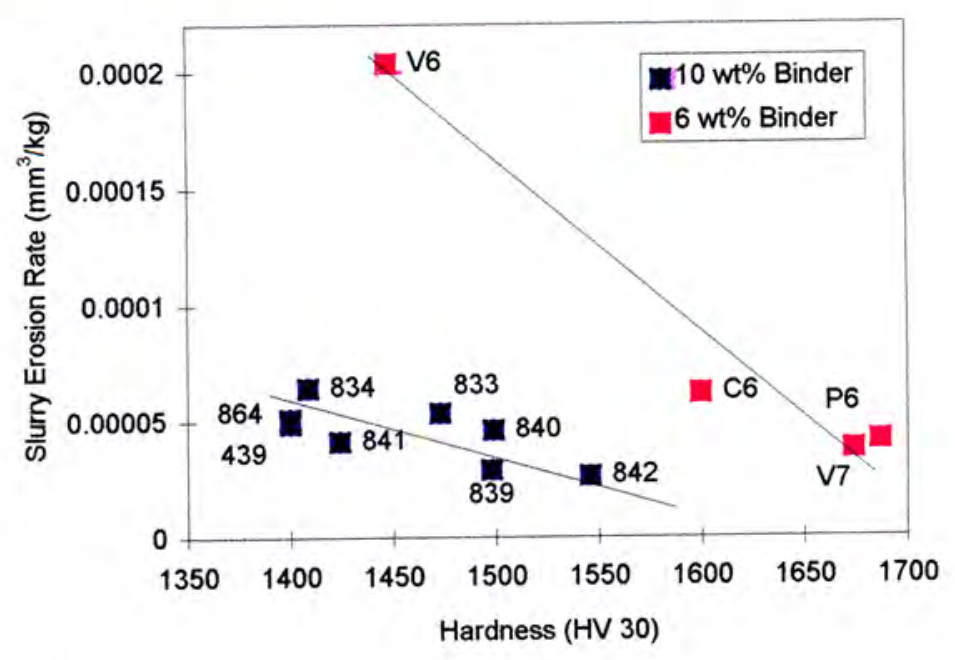

Figure 5.7 (a): Salt water slurry erosion rates vs hardness for $10 w t \%$ and 6 wt $\%$ grades. 


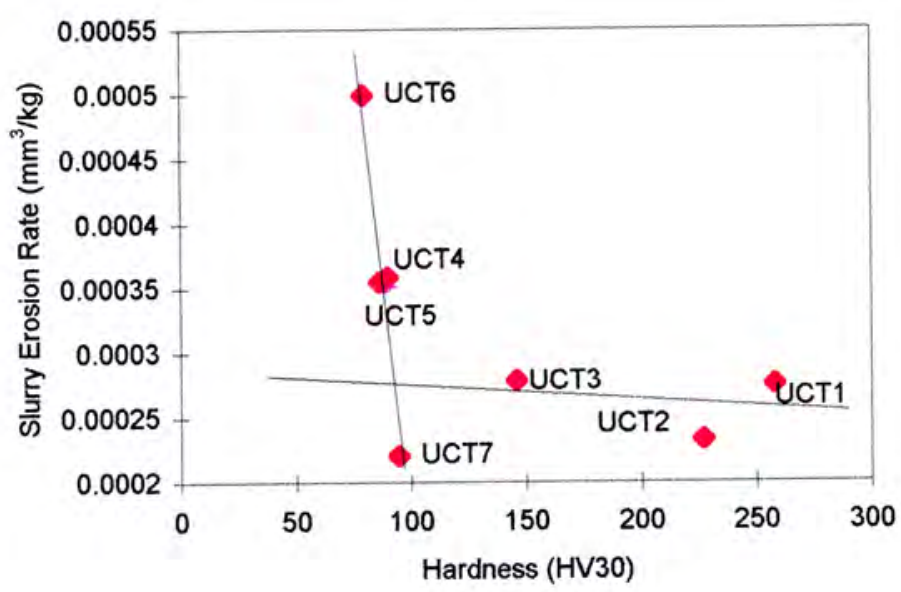

Figure 5.7 (b): Salt water slurry erosion rates vs hardness for pure metal binder grades.

The general trend of decreasing erosion rate with increasing hardness is followed in the pure binder metal grades. It would appear however that above a hardness level of approximately $100 \mathrm{HV}$ the erosion resistance is similar.

\section{Effect of Carrier Fluid on Slurry Erosion Rate}

The T:S ratio shown in table 5.1 gives an indication of the resistance of each grade to a more aggresive corrosive environment. As the ratio percentage increases, the effect of the corrosive environment can be considered to have less influence on the slurry erosion rate and the corrosion resistance can be said to be improved. An increase in binder content of the cermet grades enhances the resistance to the corrosive environment and this trend is extended to the pure binder metal grades. The T:S ratio is plotted for the three categories of materials tested in figure 5.8. The average change is $52.2 \%, 51.0 \%$ and $75.4 \%$ for the $10 \mathrm{wt} \%, 6 \mathrm{wt} \%$ and pure binder metal grades respectively, indicating the importance of synergistic erosion-corrosion wear mechanisms. 


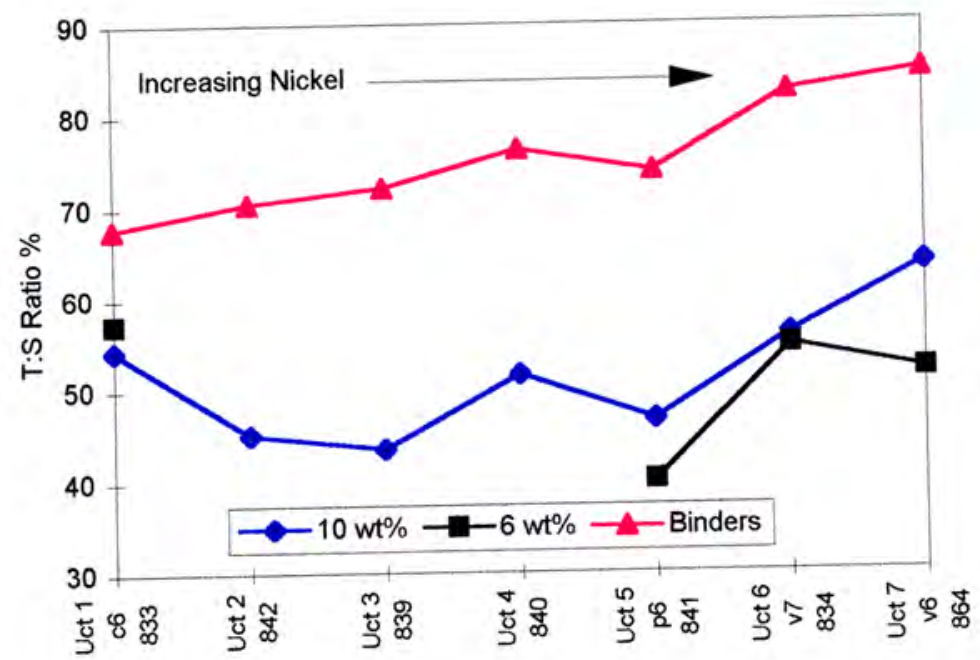

Figure 5.8: Ratio (as a percentage) of tap water slurry erosion rate over salt water slurry erosion rate for all grades.

It must also be noted that although the erosion rates were not related to the corrosion resistance of the binder directly, the influence of the corrosive environment is lessened as the binder composition tends toward the more corrosion resistant nickel binder grades.

Thus two important factors can be seen in the above graph. The corrosion resistance of the materials tested improves both as the binder volume fraction increases and as the volume fraction of the corrosion resistant nickel increases.

\section{The Importance of Binder Strain Behaviour}

Compression testing was conducted on two specimens per pure metal binder grade to determine the strain behaviour of the binder phase. The stress-strain curves for the pure binder metals are shown in figure 5.9. The maximum load to which the specimens were subjected was $40 \mathrm{kN}$ or when failure occurred. 


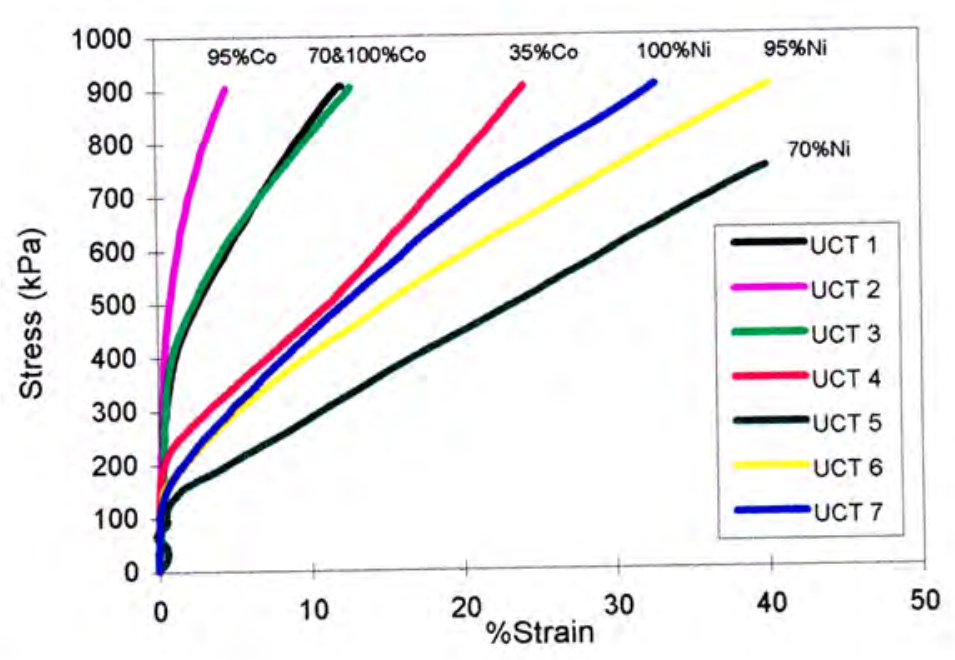

Figure 5.9: Compression stress-strain curves for the pure binder metals.

The ductility of the binder metals varies with binder composition. Uct 2 with 5 wt\% chromium and $95 \mathrm{wt} \%$ Co has a higher work hardening rate that the pure Co (Uct 1) grade. As the percentage of $\mathrm{Ni}$ is increased, the ductility increases to that of the pure Co grade and then further with increasing $\mathrm{Ni}$ content. The work hardening rate however, reaches a minimum with a composition of $70 \mathrm{wt} \% \mathrm{Ni}, 3.5 \mathrm{wt} \% \mathrm{Cr}$ and 26.8 $w t \%$ Co after which the rate increases as the composition becomes closer to pure nickel. The work hardening behaviour of the binder grades is plotted relative to the slurry erosion rates of the pure binder grades and the $10 \mathrm{wt} \%$ cermets in figure 5.10 .

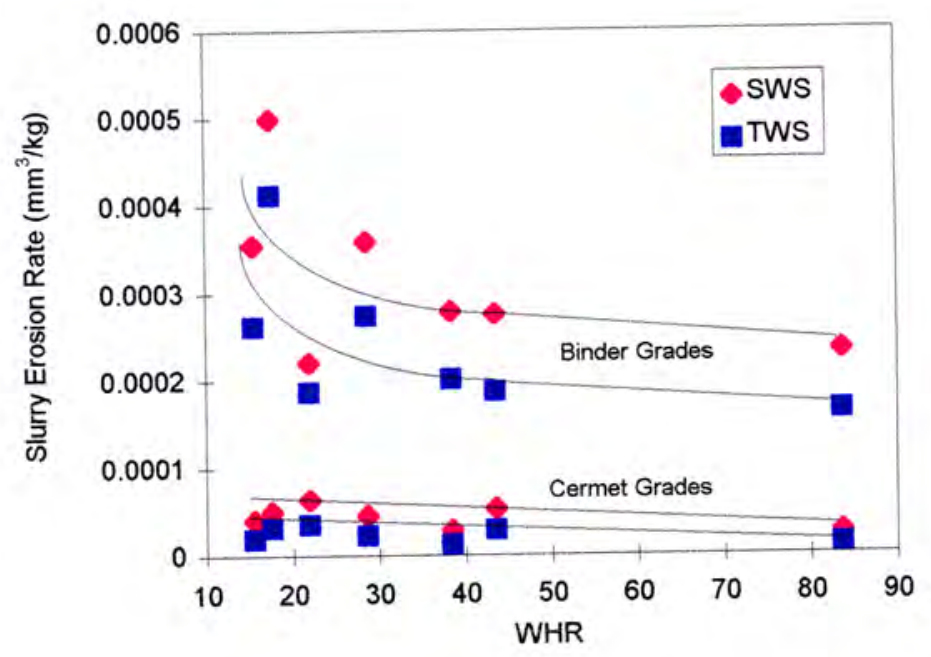

Figure 5.10: The slurry erosion rate of the pure binder grades and the $10 \mathrm{wt} \%$ cermets are plotted relative to the compressive work hardening behaviour of the binder grades. 
The work hardening behaviour of the binder grades was calculated by linear regression of the stress-strain curves. The slurry erosion rates decrease with increasing work hardening rate for the high work hardening values but no clear trend is noticed for the more ductile grades. The work hardening behaviour of the pure binder grades influences the slurry erosion resistance more than in the cermet grades. The differences in binder ductility were visible when the slurry eroded surfaces of the pure binder grades were examined in the electron microscope. Figures 5.11 (a\&b) show the eroded surfaces of the Uct 1 and Uct 7 grades. The high nickel Uct 7 grades show severe plastic deformation and lip formation of the erosion surface. The less ductile, cobalt rich Uct 1 grade shows more smearing and less cutting of the eroded area.

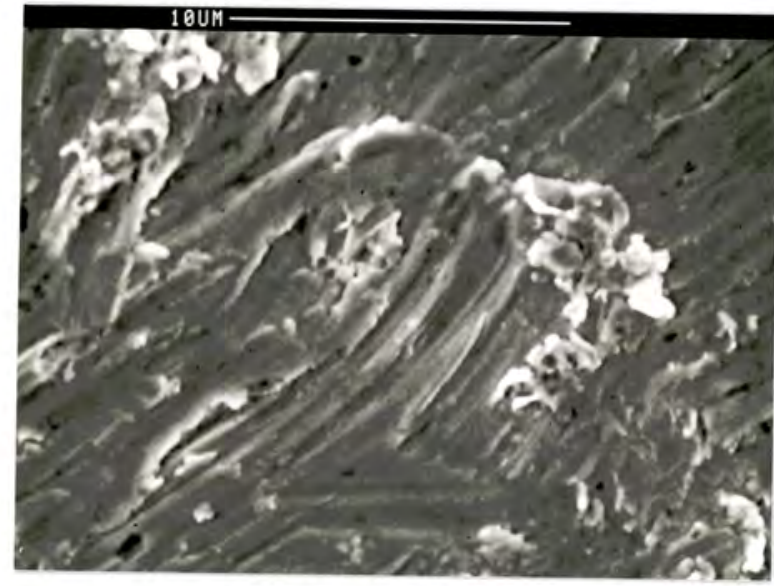

(a) Uct 1

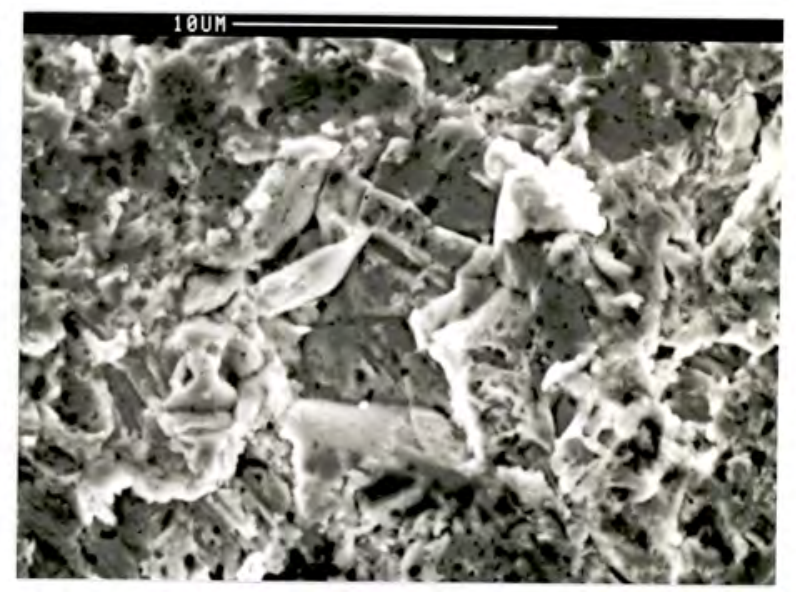

(b) Uct 7

Figure 5.11: Slurry erosion surfaces of the pure metal binder grades.

\section{Binder Phase Transformation}

X-ray diffraction on pre- and post slurry erosion samples was conducted on the pure binder grades and the 10 wt\% cermets. A slurry erosion induced phase transformation of cobalt from. f.c.c to h.c.p. was not visible in the XRD traces of the binder grades or the $10 w t \%$ cermets grades. In the $10 w t \%$ grades the post slurry erosion surface was predominantly WC grains. Thus the binder phase peaks were less evident and as a result of the rough surfaces the peaks were not as well defined. Furthermore the cobalt hexagonal phase peaks are coincident with the WC 
hexagonal peaks, which did not allow the extent of any possible phase transformation to be determined.

\subsection{CORROSION}

Anodic polarisation curves for $10 \mathrm{wt} \%, 6 \mathrm{wt} \%$ and pure binder metal grades in both the $\mathrm{H}_{2} \mathrm{SO}_{4}$ solution and the salt water solution are shown in Figure 5.12(a-f). The expected increase in passivation behaviour, decrease in corrosion potential and drop in current density occur as the nickel volume fraction within the binder phase is increased. A more distinct passivation region can be seen in the pure metal binder grades in $\mathrm{H}_{2} \mathrm{SO}_{4}$ than in the cermet grades, although the passivation current density of the cermets is lower than that of the pure binder metals. Passivation of the binder grades in salt water is not observed although passivation of the cermets in the salt water solution is evident This is not unexpected as the cermets have high volume fractions of the WC phase.

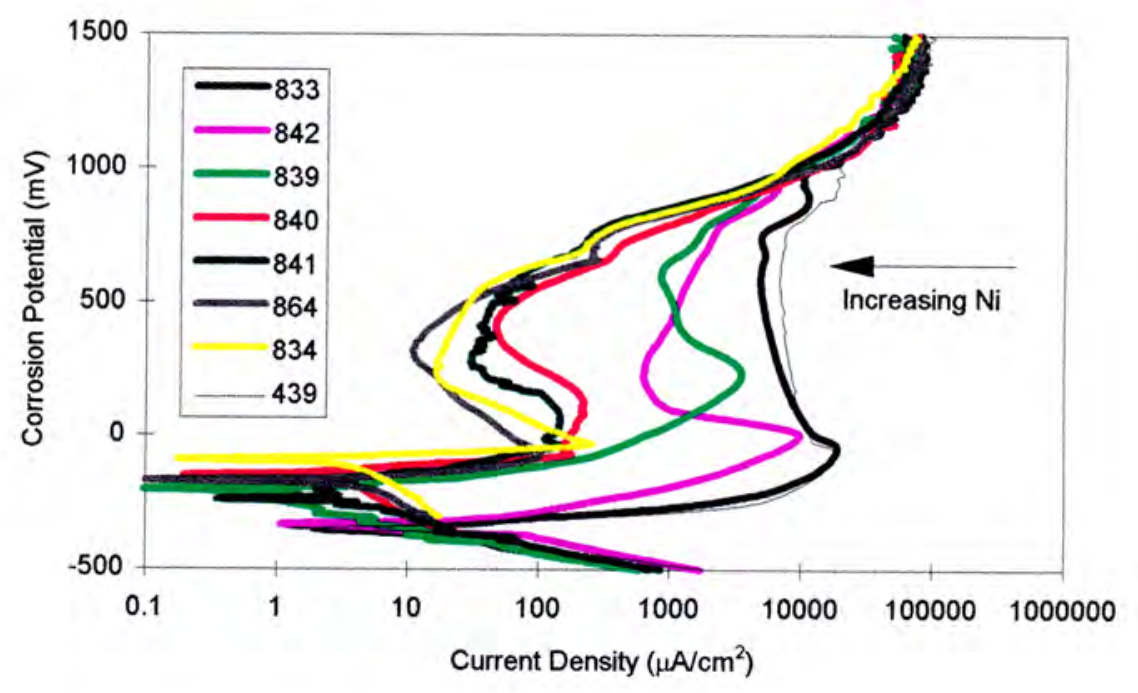

Figure 5.12 (a): Anodic polarisation curves for the 10 wt\% binder grades in $1 \mathrm{~N} \mathrm{H}_{2} \mathrm{SO}_{4}$. 


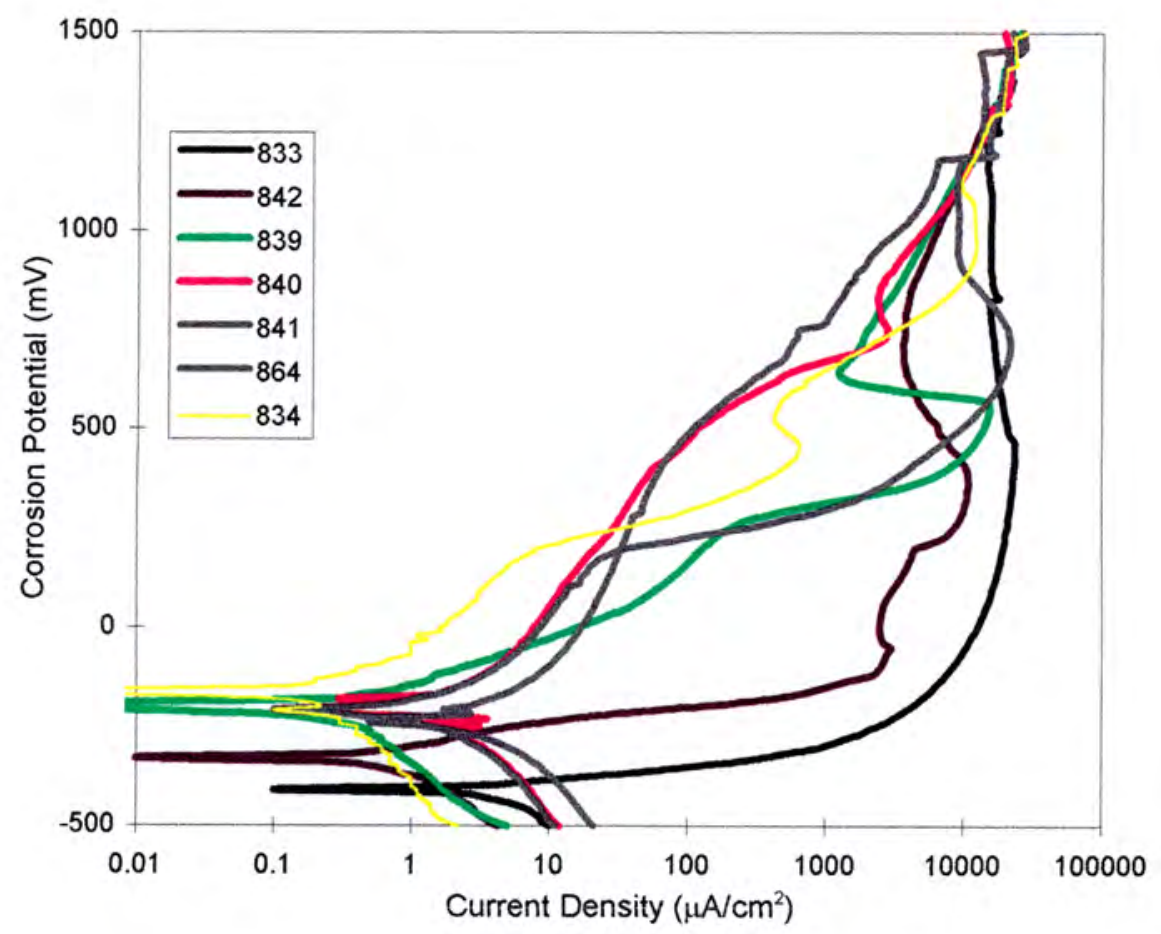

Figure 5.12 (b): Anodic polarisation curves for the $10 \mathrm{wt} \%$ binder grades in substitute ocean water.

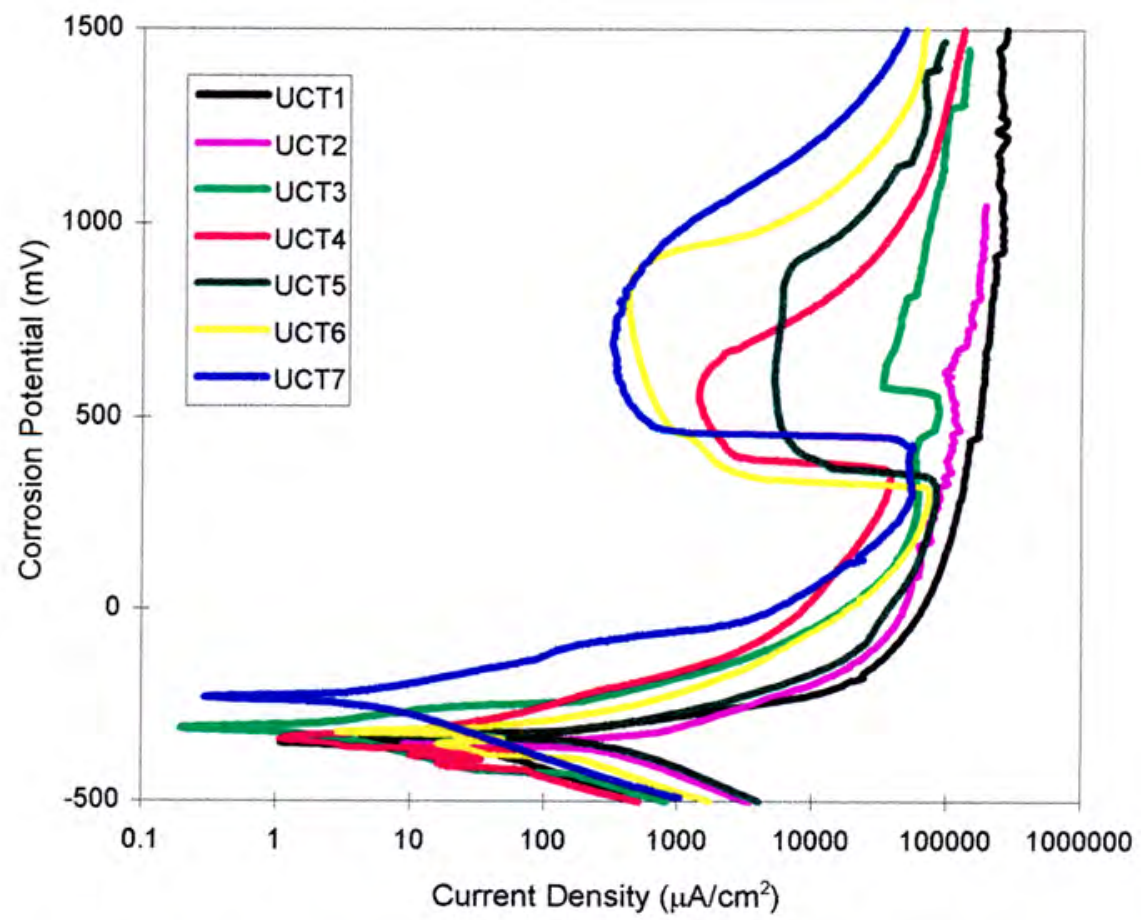

Figure 5.12 (c): Anodic polarisation curves for the pure metal binder grades in $1 \mathrm{~N} \mathrm{H}_{2} \mathrm{SO}_{4}$. 


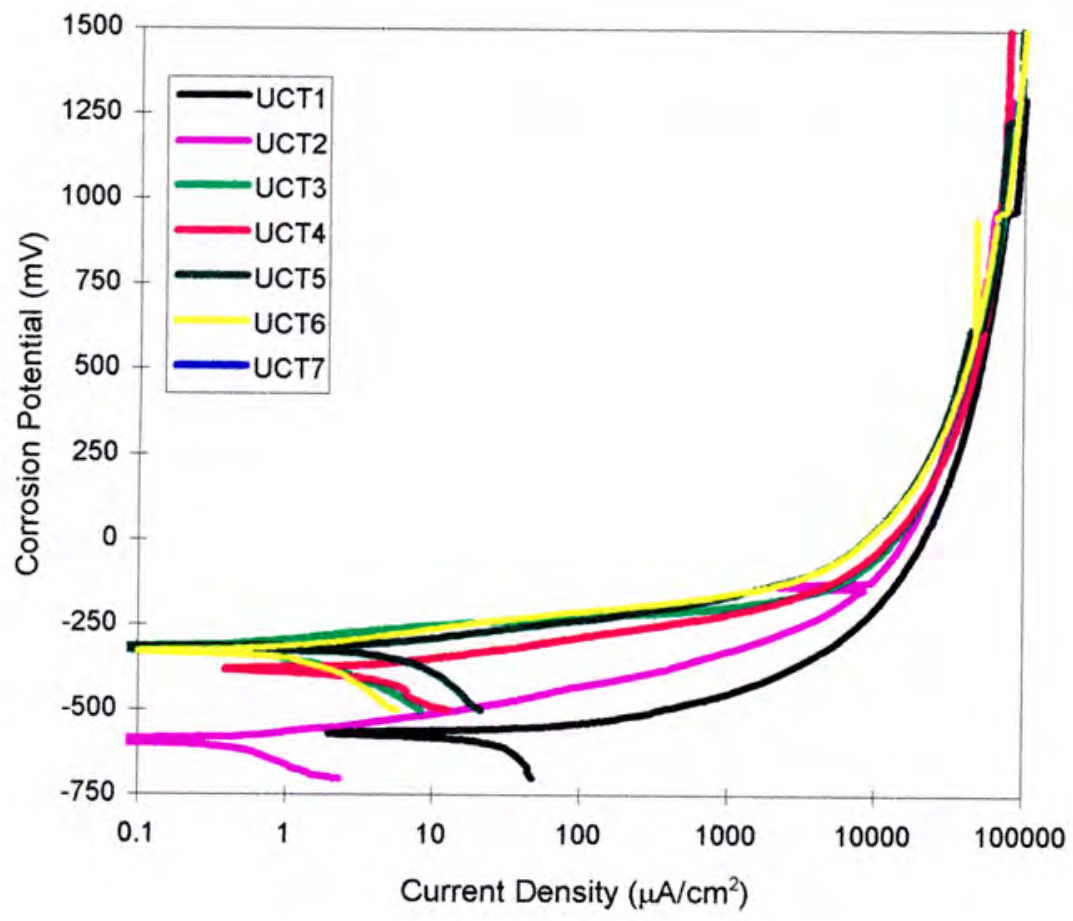

Figure 5.12 (d): Anodic polarisation curves for the pure metal binder grades in substitute ocean water.

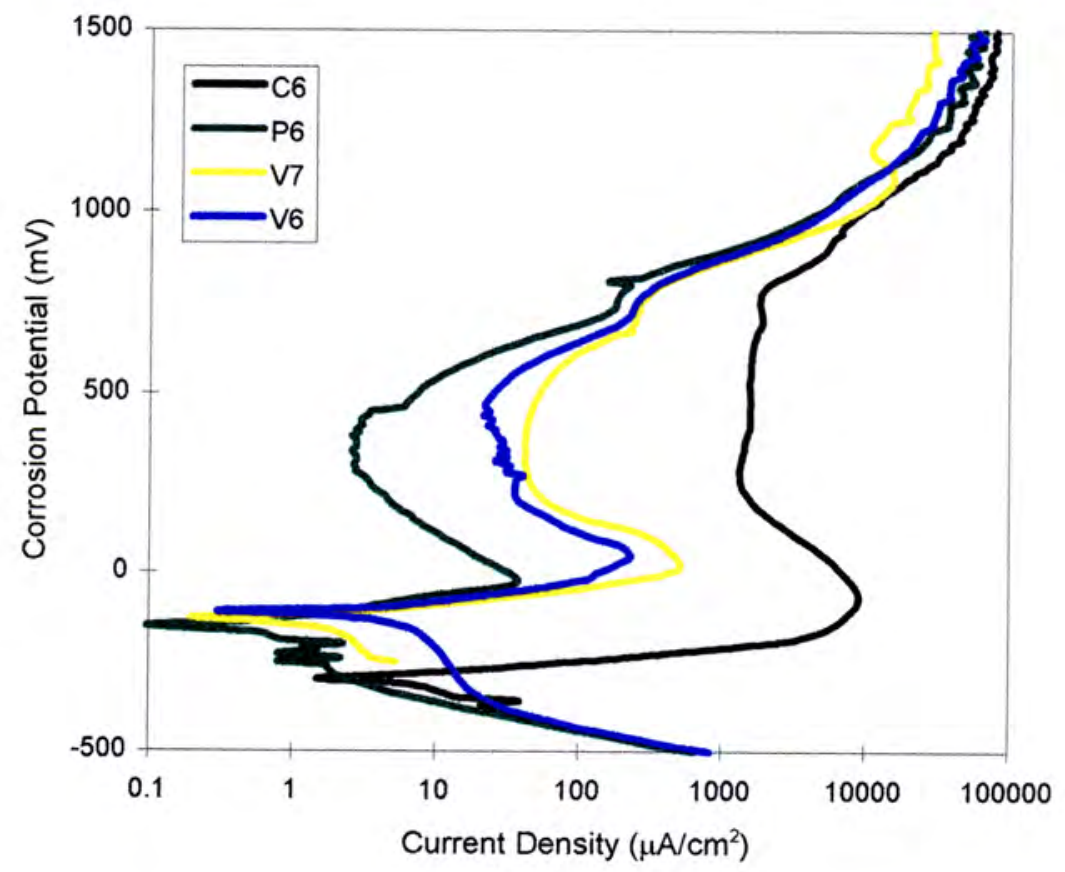

Figure 5.12 (e): Anodic polarisation curves for the 6 wt\% binder grades in $1 \mathrm{~N} \mathrm{H}_{2} \mathrm{SO}_{4}$. 


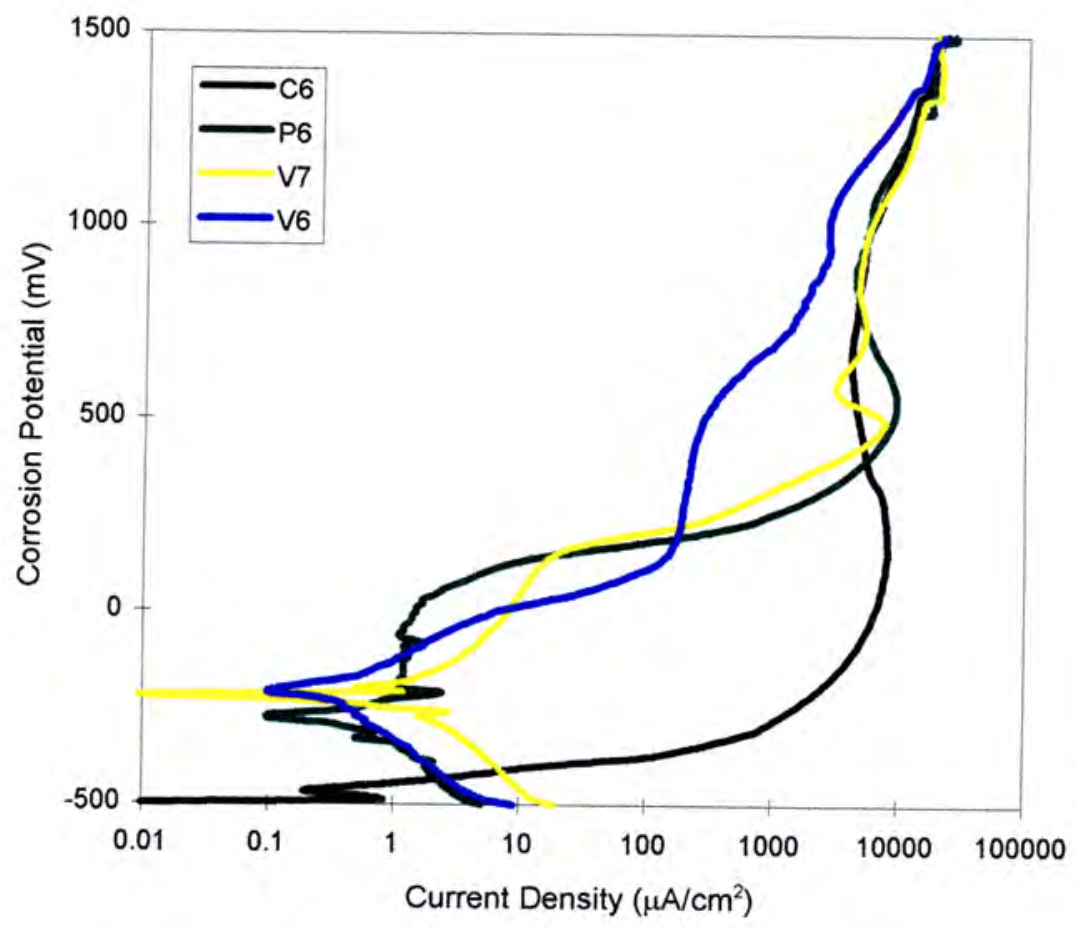

Figure 5.12 (f): Anodic polarisation curves for the $6 w t \%$ binder grades in substitute ocean water.

Surfaces corroded during anodic polarisation measurements were also examined in the SEM. The surfaces are shown in Figures 5.13 (a\&b) for the $\mathrm{C} 6$ (Co binder) and the V6 ( $\mathrm{Ni}$ binder) grade. It can be seen the $\mathrm{C} 6$ grade (a) has lost the binder, although the WC grains have maintained their skeletal structure. The WC grains in this case have not been lost and the initial polished surface can still be seen. The WC grains of the V6 grade, however, have fallen away from the corroded surface once the binder has been lost due to corrosive action and the underlying material is thus seen. This underlying material has however lost the binder phase as can be seen in (b). Figure 5.14 (a\&b) show micrographs of the boundary of the corrosion zone where some crevice corrosion has occurred. We note here the retention of the WC skeletal structure in the $\mathrm{C} 6$ grade (a), although it is severely cracked, whilst in the V6 grade (b) the skeletal structure has been removed. The severe cracking is due to a drying phenomenon of the binder free WC suspension. 


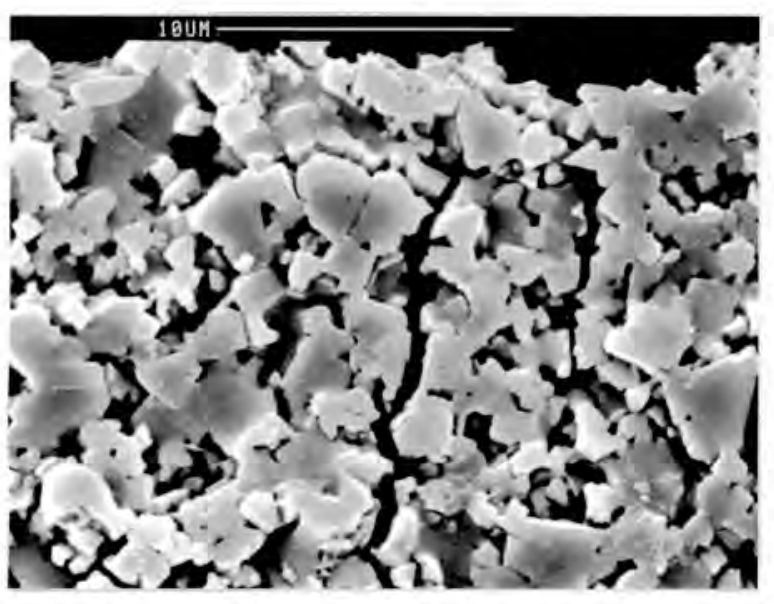

(a) $\mathrm{C6}$

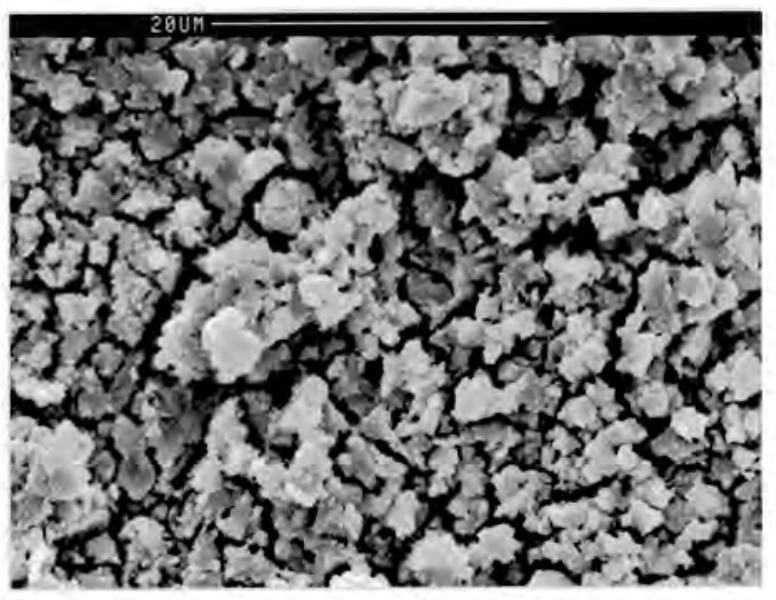

(b) V6

Figure 5.13: SEM micrographs of the corroded surfaces after anodic polarisation in $1 \mathrm{~N}$ $\mathrm{H}_{2} \mathrm{SO}_{4}$.

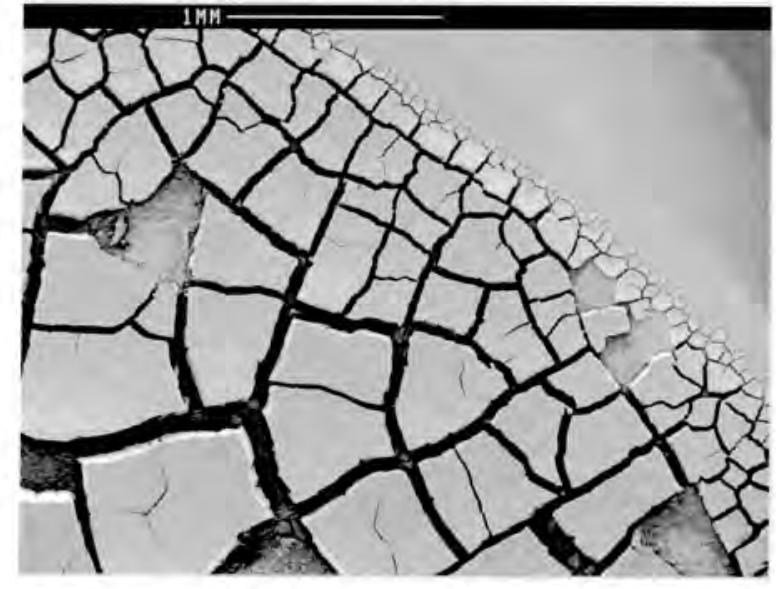

(a) $\mathrm{C6}$

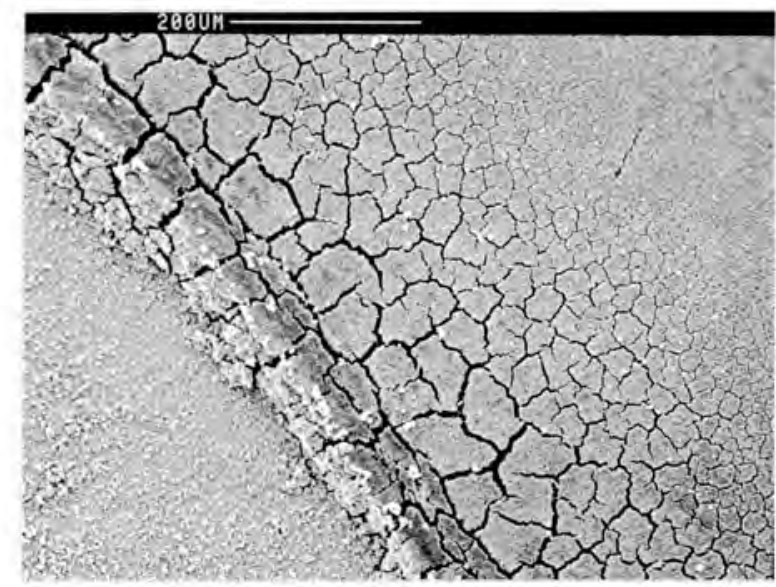

(b) V6

Figure 5.14: SEM micrographs of the polarisation region boundary. Note the retention of the skeletal structure in the cobalt binder grade (C6).

Complete binder removal has been observed in the alloyed binder grades as shown in figure 5.15. This micrograph shows the extent to which binder removal can occur during corrosion and thus adversely affect the cermets' properties. 


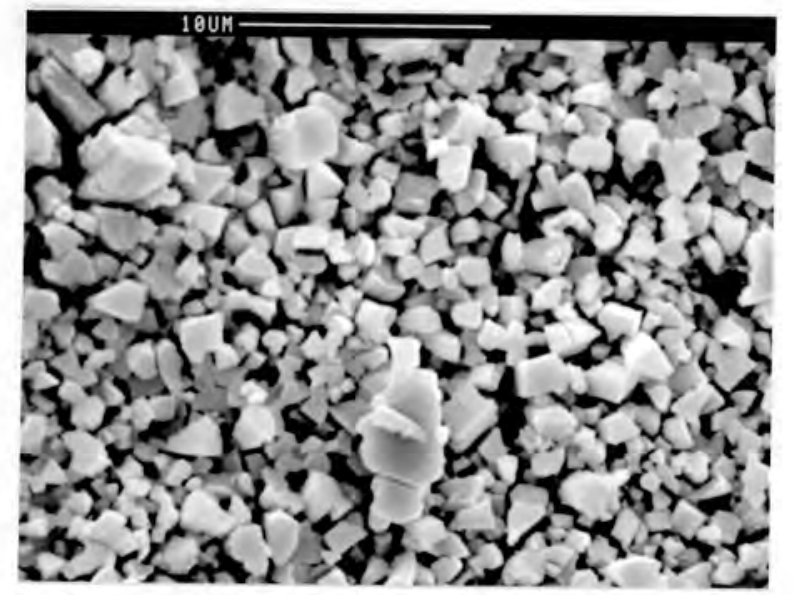

Figure 5.15: Complete binder removal after anodic polarisation of a 842 grade. 


\section{CHAPTER SIX}

\section{DISCUSSION}

\subsection{INTRODUCTION}

The loss of material during a wear process is a complex relationship between many interacting variables. Changing one variable can therefore have important consequences on the behavioural pattern of the total system. In this work, a variety of WC based hardmetals and binder metal alloys have been subjected to slurry erosion where the impact velocity, impact angle, erodent concentration and erodent characteristics remained constant. Thus many variables have been kept constant, allowing only the effect of binder compositional variations on the erosive-corrosive wear process to be investigated. However variations in the binder phase composition may influence not only the binder and composite properties and corrosion resistance but also the manufacturing processes, the wetting ability of the binder to metallic carbides and the binder-carbide interface strength, all of which will ultimately affect its behaviour. In this study however the performance of the cermet is considered in its entirety.

Slurry erosion combines the effects of impact erosion and corrosion to form a dynamic balance with the properties of the target materials. A wide variety of applications exist where wear components are subjected to slurry erosion conditions such as seal rings, linings, valves, jet nozzles, saw blades, fluid mixers and conveyer scrapers. These slurry conditions can vary in make-up from those with a highly erosive nature to those with a highly corrosive nature. This extreme variation in the nature of slurry erosion conditions requires the properties of a slurry erosion resistant material to be suited to the particular operating conditions. It must therefore be noted that the results obtained in this work are for a particular set of laboratory test conditions and can not be considered to be totally indicative of all slurry erosion conditions. Thus caution must be exercised in comparing the present results and those recorded elsewhere and obtained under different testing conditions. 


\subsection{MODE OF MATERIAL REMOVAL}

During slurry erosion, the force of the impacting solid particles is predominantly absorbed by the plastic matrix resulting in extrusion (Figure 5.5(a)) and subsequent loss of the ductile binder phase together with the displacement and removal of whole WC grains. Only limited brittle fracture of carbide grains was observed (Figure 5.5(b)). However synergistic erosion-corrosion of the binder phase, results in the preferential removal of the binder phase and therefore poorly supported WC grains. This enhances the ability of the erodent to dislodge WC grains from the specimen surface. Thus a balance arises between loss of binder and loss of WC grains, limiting the damage zone to a finite depth. These surface characteristics are illustrated in figure 5.3 in which WC grains are seen standing proud of the matrix.

The mechanism of material removal is thus the combined effect of erosion by solid particles and corrosion. The ability of a material to withstand this type of wear is thus a balance between good mechanical properties, to withstand the erosive component and good corrosive properties, to withstand the corrosive component.

The relative effects of each component of slurry erosion are difficult to separate. The influence of the more corrosive carrier fluid however can be seen in table 5.1 and figure 5.2. Significant increases in the slurry erosion rates are observed when the more corrosive salt water carrier fluid is used, indicating the contribution of the corrosive environment to be a most important influence on the synergistic wear rate. Tests conducted to establish the corrosive contribution to the slurry erosive wear rate, by subjecting the specimens to a fluid jet without erodent particles, showed no measurable mass loss of the cermet after a 2 hour test period, indicating that the erosive component is necessary in allowing the corrosive component to significantly influence the wear rates.

When a metal is subjected to erosive wear, each mechanical event will cause rupture or removal of any oxide film in a localised region of the surface thereby exposing bare metal to the environment. In a ceramic-metal composite any movement of the phases 
of the composite or mechanical event can lead to breakdown of the oxide film on the binder phase. The exposed interface between the WC grains and the binder phase in WC-based hardmetals is extremely susceptible to this type of oxide breakdown and thus to rapid localised corrosion of the newly created surfaces due to galvanic corrosion in the presence of an electrolyte. The less noble binder phase is more susceptible to this localised attack thus enhancing binder removal and in turn, the erosion rate. The more aggressive the solution the faster this corrosion will occur, thus explaining the increased rate of erosive-corrosive attack when tap water is changed to salt water.

\subsection{SLURRY EROSION}

The results of slurry erosion tests show that the cermets with a $10 \mathrm{wt} \%$ binder phase and binder compositions within the range of $70-90 w t \% \mathrm{Co}, 5 w \mathrm{t} \% \mathrm{Cr}$ and $0-25 \mathrm{wt} \% \mathrm{Ni}$ have improved slurry erosion resistance. The slurry erosion rates for the pure binder grades also show a change in erosion rate with a change in composition. The alloyed $94 \mathrm{wt} \%$ Co, $6 \mathrm{wt} \% \mathrm{Cr}$ (Uct 2) grade shows the highest slurry erosion resistance relative to the pure Co grade, although the pure nickel grade (Uct 7) also shows an erosion resistance of similar magnitude to that of the Uct 2 grade. Whilst the erosion rates of the cermets and the binder grades follow similar trends the pure nickel binder grade (Uct 7) deviates from this trend markedly. Thus the modelling of cermet slurry erosion rates based on the performance of binders alone can not be considered accurate.

A general trend of decreasing slurry erosion rate with increasing hardness in both the 6 and $10 \mathrm{wt} \%$ cermet grades was found. The hardness of the cermet grade is clearly influenced by the hardness of the binder phase and is thus related to the composition of the binder phase as can be seen in figure 5.6. Binder strengthening enhances the ability of the cermet to resist impact damage during slurry erosion and consequently the wear resistance is improved. The decrease in erosion rate with increasing hardness is however $350 \%$ greater in the $6 \mathrm{wt} \%$ grades than in the $10 \mathrm{wt} \%$ grades at similar hardness levels thus indicating that the slurry erosion resistance of the 6 wt\% grades is more hardness sensitive than that of the $10 \mathrm{wt} \%$ binder phase grades. The hardness sensitivity of the $6 \mathrm{wt} \%$ grades is believed to be due to the ease of disruption of a 
protective oxide film particularly at the WC/binder interface during particle impact which initiates localised galvanic corrosion. Any increase in binder matrix strength lowers the relative interfacial movement and disruption of the oxide film with a consequent decrease in corrosion and overall wear rate. The $6 \mathrm{wt} \%$ binder grades with a greater preponderance of interfacial area will be consequently affected to a greater degree.

In the pure binder metal grades a general trend of decreasing erosion rate with increasing hardness is followed, but above a hardness of approximately $100 \mathrm{HV} 30$ the erosion resistance of different grades is similar. The extreme sensitivity up to a hardness of $100 \mathrm{HV}$ and the lack of sensitivity above a hardness of $100 \mathrm{HV}$ indicates that the erosion rate of these binder grades is not controlled by hardness alone and that other effects are influential. The three hardest pure binder metal grades, having hardness values over $100 \mathrm{HV}$, and showing an insensitivity of erosion rate to hardness, are the grades with a full $100 \%$ h.c.p. crystal structure.

The h.c.p. crystal structure found in the erosion resistant binders provide the binder with apparently related, high hardness, low ductility and high work hardening capacity and the ability to resist the mechanical damage caused by erodent impact. A hexagonal close packed structure is found in the high cobalt volume fraction ( $<35 \mathrm{wt} \% \mathrm{Ni}$ and $5 \mathrm{wt} \% \mathrm{Cr}$ ) binder grades. Grades with high binder volume fractions of nickel (above 35\%) show worse slurry erosion resistance combined with a decrease in and a $100 \%$ f.c.c. crystal structure.

The ability of a material to withstand strain and resist microfracture is influenced by its strain hardening capacity, as described by Ball ${ }^{29}$. The hypothetical material II (figure 2.9), representing a soft ductile metal, will have a lower work to fracture value than the material III, which has a combination of strength and strain hardening-capacity. Material II will therefore have a lower erosion resistance than material III. Thus Ball's model which relates abrasive wear to the strain-hardening capacity for different classes of materials can also be broadly applied to the pure metal binder grades tested in this work and their erosive wear behaviour. Unfortunately any binder phase transformations which absorb energy and enhance the wear resistance of the cermet could not be distinguished in XRD analysis conducted for pre and post slurry erosion conditions. The 
volume fraction of the binder phase exposed in these grades and in particular on the post erosion surfaces, in combination with a low damage zone depth and a high $\mathrm{x}$-ray penetration depth are thought to account for this lack of detection. The influence of the strength of the binder materials in the WC-based composite can be of even greater importance than in pure metals as the binders must have the ability to "hold" the WC grains during erosive wear conditions.

The ductility and work hardening ability of the binder grades has been shown to vary with composition. In general the high nickel volume fraction grades have a higher ductility than the high cobalt volume fraction grades. The slurry erosion resistance is enhanced as the material gains strength when strained, thus reducing the mechanical effects of impact damage during slurry erosion. Alloying additions of $5 \mathrm{wt} \% \mathrm{Cr}$ to a Co rich binder provide the best combination of strength, work hardening-capacity and corrosion resistance. The slurry erosion resistance of the cermet grades is influenced to a lesser degree than those of the pure binder grades by these factors, although this is thought to be a volume fraction related effect.

The chemical composition of the binder phase also affects the corrosion resistance of the cermet and thus the influence of the more corrosive carrier fluid. The ability of the binder phase to retard the action of corrosion and in particular localised corrosive attack when oxide films are broken will significantly reduce the degree of binder loss and thus improve the slurry erosion resistance of the hardmetal.

The slurry erosion rate of the most resistant grade (842 - 90. wt\% Co, $5 w t \% \mathrm{Cr}, 1.3 \mathrm{wt} \%$ $\mathrm{Ni}$ ) had a value of only $41 \%$ relative to the WC-Co grade (833) in tap water conditions and $49 \%$ that of the WC-Co grade (833) grade in salt water conditions. The influence of the more corrosive carrier fluid is seen by examining the $T: S$ ratio as shown in table 5.1 or figure 5.8. Binder composition can be seen to influence the $T: S$ ratio, most noticeably in the pure binder metal grades. As the binder composition becomes more nickel rich, the $T: S$ ratio increases, indicating that the corrosive medium is having less effect on the binder metal erosion. i.e. the binder becomes more corrosion resistant as the nickel 
the alloyed Co-Cr-Ni grades, but the slurry erosion behaviour deteriorates with increasing nickel volume fraction. Thus passivation behaviour is not necessarily a good guide to superior corrosion resistance under conditions when any passive film formation is continuously being disrupted, such as in slurry erosion conditions. In such conditions the hardness, deformation characteristics and possible phase transformations of the binder phase may be dominant in determining the wear rates.

Nevertheless, the nickel-chromium-cobalt and in particular the chromium cobalt, although not always having improved pure corrosion properties, do show a distinct improvement over a cobalt binder cermet in tested slurry erosion-corrosion conditions. The influence of binder composition is an important factor in the design of a long life cermet for erosion-corrosion conditions as the importance of synergistic wear rates must not be neglected.

\section{Post Polarisation Surface Microscopy}

Electron microscopy of the post anodic polarisation specimen surfaces, as shown in figures 5.13 and 5.14 , indicates a change in the extent of the relative binder phase dissolution. Complete breakdown of the WC skeletal structure occurred in the nickel binder (V6) grade as compared to the retention of the WC skeletal structure in the cobalt binder (C6) grade. The nickel binder phase passivates to the extent that the corrosion current density is of the same order of magnitude as that of the WC phase ${ }^{51}$. This similarity of corrosion current densities in the passivated regime allows the WC phase and the nickel binder phase to corrode at similar rates, thus allowing the WC skeletal structure to be broken down. In the case of the cobalt binder phase however, the dissolution rate of the cobalt is four orders of magnitude higher than that of the WC phase, and thus only the cobalt phase is removed and the WC skeletal structure remains intact. 


\subsection{SUMMARY}

Corrosion is a property of the system and thus depends on such factors as the geometry of the material and the flow conditions of the environment. Wear is also a property of the system which depends critically on the precise wear conditions. The combined synergistic action of corrosion and erosive wear is clearly a complex situation where the usefulness or otherwise of laboratory tests to quantify the wear process depends on the extent to which they relate to industrial applications.

The results discussed are thus of value in the selection of materials for use in a given wear situation. If a component such as a pipe lining, is subjected to light erosive action in a corrosive environment then WC-based cermets with a high nickel wt\% binder could be more cost effective than a WC-Co hardmetal. In contrast, a component which is subjected to highly erosive conditions with only a mild or an aggressive corrosive element, should be manufactured from a WC-Co or WC-Co(Cr) cermet. Thus by critical evaluation of the operating conditions, optimum material selection will lead to reduced wear rates. 


\section{CHAPTER SEVEN}

\section{CONCLUSIONS}

The conclusions that can be reached from this study are as follows:

1. The synergistic action of erosion and corrosion on WC hard metals results in greatly enhanced wear rates compared to either erosion or corrosion processes alone.

2. The slurry erosion resistance of cermets with pure metal binders of either $\mathrm{Co}$ or $\mathrm{Ni}$ are improved by alloying. The $10 \mathrm{wt} \%$ binder grade with a binder composition of approximately $95 \mathrm{wt} \% \mathrm{Co}$ with $5 \mathrm{wt} \% \mathrm{Cr}$ showed the best slurry erosion resistance. The increase in binder strength, coupled to a hexagonal crystal structure and high hardness all contribute to its high slurry erosion resistance.

3. A more corrosive environment during slurry erosion causes increases in the slurry erosion wear rate as the effectiveness of the corrosive component in the synergism of material removal is enhanced.

4. Improving the corrosion resistance of the binder phase does not directly enhance the slurry erosion resistance since passivating films which form on the surface are continually broken during the erosion process. Thus improved erosion-corrosion performance of cermets is not necessarily achieved by upgrading the binder phase to a more corrosion resistant material.

5. The selection of a WC based hardmetal for slurry erosion resistance can only be made following a critical evaluation of the system parameters. 


\section{REFERENCES}

1. W. J. Tomlinson and C. R. Linzell, Anodic Polarisation and Corrosion of Cemented Carbides with Cobalt and Nickel Binders, J. of Materials Science, Vol 23, 1988, pp. 914918.

2. S. Ekemar, L. Lindholm and T. Hartzell, Nickel as a Binder in WC-Based Cemented Carbides, Proceedings of the 10th Plansee Seminar, June 1981, pp. 477-492.

3. A. Ball and A. W. Paterson, Microstructural Design of Erosion Resistant Hard Metals, Proceedings of the International Conference on Recent Developments in Special Steels and. Hard Metals, Rhodes Island, 1985, pp. 377-391.

4. S. B. Luyckx, Slip Systems of Tungsten Carbide Crystals at Room Temperature, Acta Metallurgica, 1970 , Vol. 16, pp. 535-544.

5. J. Gurland and H.E. Exner, A Review of Parameters Influencing some Mechanical Properties of Tungsten Carbide Alloys, Powder Metallurgy, 1970, Vol. 13, No. 25, pp. 12-31.

6. H. E. Exner, Physical and Chemical Nature of Cemented Carbides, International Metals Reviews, 1979, Review No. 243 , No. 4 pp. 149-173.

7. D. N. French and D.A. Thomas, Hardness Anisotropy and Slip in WC Crystals, Transactions of the AIME, 1965, Vol. 233, pp. 950-952.

8. R. M. Greenwood, M.H. Loretto and R.E. Smallman, The Defect Structure of Tungsten Carbide in Deformed Tungsten Carbide-Cobalt Composites, Acta Metallurgica, 1982, Vol. 33. pp. 1193-1196.

9. E. Roebuck, E.A. Almond and A.M. Cottendon, The influence of Composition, Phase Transformation and Varying the Relative F.C.C and H.C.P Phase Contents on the Properties of Dilute Co-W-C Alloys, Materials Science and Engineering, 1984, Vol. 66, pp. 363-375. 
10. O. Rüdiger, D. Hirschfeld, A. Hoffmann, J. Kolaska, G. Ostermann and J. Willbrand, Composition and Properties of the binder metal in cobalt bonded Tungsten-carbide, Cobalt, 1971, Vol. 7, pp 29-38.

11. K. J. Brookes, World Directory and Handbook of Hardmetals and Hard Materials, 1992, 5th Edition, Hertfordshire: Int Carbide Data.

12. B. Aronsson, Influence of Processing on Properties of Cemented Carbide, Powder Metallurgy, 1987, Vol. 30, pp.175-181.

13. H. C. Lee and J. Gurland, Hardness and Deformation of Cemented Carbides, Materials Science and Engineering, Vol. 33, 1978, pp. 125-133.

14. H. F. Fischmeister and H. E. Exner, Planseeber. Pulvermet., Vol 13, 1965, pp. 178

15. J.Gurland and N.M Parikh, Microstructure aspects of the Fracture of Two Phase Alloys, Fracture, Vol 2, 1972, pp. 841-878, Ed H. Lebowitz.

16. A. M. Human, I. T. Northrop, S. B. Luyckx and M. N. James, A Comparison between Cemented Carbides containing Cobalt- and Nickel-Based Binders, J of Hard Materials, Vol. 2, No. 3-4, 1991, pp. 245-255.

17. R. Cooper, S. A. Manktelow, F. Wong and L. E. Collins, The Sintering Characteristics and Properties of Hard Metal with Ni-Cr Binders, Materials Science and Engineering, 1988, pp.269-273.

18. M. H. Poech and H. F. Fischmeister, Acta Metall. Mater., Vol 40, 1992, pp. 487-494.

19. K. H. Zum Gahr, Microstructure and Wear Materials, Tribology Series, Vol. 10, Elsevier, 1987.

120. G. P. Tilly, Erosion Caused by Impact of Solid Particles, Treatise on Materials Science and Technology, Vol 13, 1979, pp. 287-319.

21. C. M. Preece, Erosion of Metals and Alloys, Nato Advanced Study Inst., Proc. of 1975 conference on surface effects in crystal plasticity, 1976, pp. 889-909. 
22. I. Finnie, Erosion of surfaces by Solid Particles, Wear 3, 1960, pp. 87-103.

23. J. G. Bitter, A Study of Erosion Phenomena - Part I, Wear 6, pp. 5-21.

24. J. H. Nielson and A. Gulchrist, Erosion of a Stream of Solid Particles, Wear 11, 1968, pp. $111-122$.

25. G. P. Tilly, A Two Stage Mechanism of Ductile Erosion, Wear, Vol 23, 1973, pp. 87-96.

26. R. Bellman and A. Levy, Erosion Mechanisms in Ductile Metals, Wear 70, 1981, pp. 1-27.

27. P.G.Shewdon, Particle Size Threshold in the Erosion of Metals, Wear 68, 1981,pp. 253258.

28. A. Ball, On the Mechanisms of Wear and the Performance of Engineering Metals, J. of South African Institute of Mining and Metallurgy, Vol 86, No. 1, 1986, pp. 1-13.

29. A. Ball, On the Importance of Work Hardening in the Design of Wear Resistant Materials, Wear, Vol. 91, 1983, pp. 201-207.

30. A. V. Levy, The Platelet Mechanism of Erosion of Ductile Metals, Wear 108, 1986, pp. 1-21.

31. J. E. Field and I. M. Hutchings, Impact Erosion Processes, Paper presented at 3rd Conf. of Mechanical Properties under High Rates of Strain, Oxford, 1984, Institute of Physics.

32. B. R. Lawn and D. B. Marshall, Indentation Fracture and Strength Degradation In Ceramics, Fracture Mechanics of Ceramics, P. C. Bradt and F. F. Lange (eds) Plenum Press, New York, pp. 205-229.

33. B. R. Lawn and M. V. Swain, Microfracture beneath Point Indentations in Brittle Solids, J. of Materials Science, Vol 2, No. 3, 1967, pp. 682-700.

34. K. Anand and $\mathrm{H}$. Conrad, Microstructure effects in the erosion of Cemented Carbides, Wear of Materials, Vol. 1, 1989, pp. 1136-142. 
35. S. K. Hovis, J. E. Talia and R. O. Scattergood, Erosion in Multiphase Systems, Wear 108, 1986, pp. $139-155$.

36. G. P. Tilly and W. Sage, The Interaction of Particle and Material Behaviour in Erosive Processes, Wear 16, 1970, pp. 447-465.

37. P. G. Shewmon, Particle Size Threshold in the Erosion of Metals, Wear 68, 1981, pp. 253258.

38. S. Bahadur and R. Badruddin, Erodent Particle characterisation and the effect of Particle Size and Shape on Erosion, Wear 138, 1990. pp. 189-208.

39. J. R. Zhou and, S. Bahadur, The effect of Blending of Silicon Carbide Particles on the Erosion of Ti-6Al-4V, Wear 132, 1989, pp. 235-246.

40. S. M. Wiederhorn and B. R. Lawn, Strength Degradation of Glass Impacted by Sharp Particles, J. of the American Ceramic Society, Vol. 62, 1979, pp. 66-70.

41. R. A. Vaughn and A. Ball, Erosion processes for Hard Materials subjected to Impact by Different Erodents, J. of Hard Materials, Vol 2, 1991, pp. 257-269.

42. R. A.Vaughn, The Effects of Hardness, Toughness, Microstructure and Thermomechanical Heating on the Erosion of Ceramic and Ultrahard Materials, MSc Thesis, Univerisy of Cape Town, 1991.

43. I. Finnie, J. Wolak and Y. Kabil, Erosion of metals by solid particles, J. of Materials, Vol. 2, No. 3,1967, pp.683-700

44. R.C.Pennefather, The solid Particle Erosion of WC-Co Alloys, MSc Thesis, University of Cape Town, 1986.

45. J. B. Zu, I. M. Hutchings and G. T. Burstein, Design of a Slurry Erosion Test Rig, Wear, 1990, pp. 331-344.

46. J. A. Laitone, Aerodynamic Effects in the Erosion Process, Wear 56, 1979, pp. 239-246. 
47. G. L. Sheldon, Similarities and Differences in the Erosion Behaviour of Materials, J. of Basic Engineering, Transactions of the ASME, 1970, pp. 619-626.

48. I. G. Wright, D. K. Shetty and A. H. Clauer, Slurry Erosion of WC-Co Cermets and its Relationship to Materials Properties, Proc. of the 6th Int. Conf. on Erosion By Liquid and Solid Impact, 1983, pp. 63.1-63.8.

49. H. Conrad, Y. Shin and G. A.. Sargent, Erosion of Sintered WC-Co Alloys, Proceedings of the International Conference on Recent Developments in Special Steels and Hard Metals, Pretoria, South Africa, 1982, pp. 423-429.

50. D. K. Shetty, I. G. Wright and J. T. Stropki, The Slurry Erosion of WC-Co Cermets and Ceramics, A.S.L.E. Transactions, 1984, Vol. 28, pp. 123-133.

51. A. M. Human, The Corrosion of Tungsten Carbide Based Cemented Carbides, PhD Thesis, University of Darmstadt, 1994.

52. R. E. Nöel and A. Ball, On the Synergistic Effects of Abrasion and Corrosion during Wear, Wear, Vol. 87, 1983, pp. 351-361.

53. W. J. Tomlinson and I. D. Molyneux, Corrosion, Erosion-Corrosion, and the Flexural Strength of WC-Co Hardmetals, J. of Materials Science, Vol. 26, 1991, pp. 1605-1608.

54. R. J. Wood and S.P. Hutton, The Synergistic Effect of Erosion and Corrosion: Trends in published results, WEAR, Vol. 140, 1990, pp. 387-394.

55. B. W. Madsen, Measurement of Erosion-Corrosion Synergism with a Slurry Wear test apparatus, WEAR, Vol. 123, 1988, pp. 127-142.

56. E.Heitz, Chemo-Mechanical Effects of Flow on Corrosion, Corrosion, NACE, Vol. 47, 1991, pp 135-145.

57. A. J. Sparks and I. M. Hutchings, Effects of Erodent Recycling in Solid Particle Erosion, Wear, Vol. 162-164, 1993, pp. 136-147. 
58. J. B. Zu, Bridging Slurry Erosion and Airborne Solid Particle Erosion, Department of Materials Science and Engineering, University of Cambridge, 1990.

59. J. A. Bester, Slurry Erosive Corrosive Wear, MSc Thesis, Department of Materials Engineering, University of Cape Town, 1992.

60. E. J. Wentzel and C. Allen, Erosion-Corrosion Resistance of Tungsten Carbide Hard Metals with different Binder Compositions, Wear, Vol. 181-183, 1995, pp.63-69. 
APPENDIX 1: Chemical Compositions of Materials

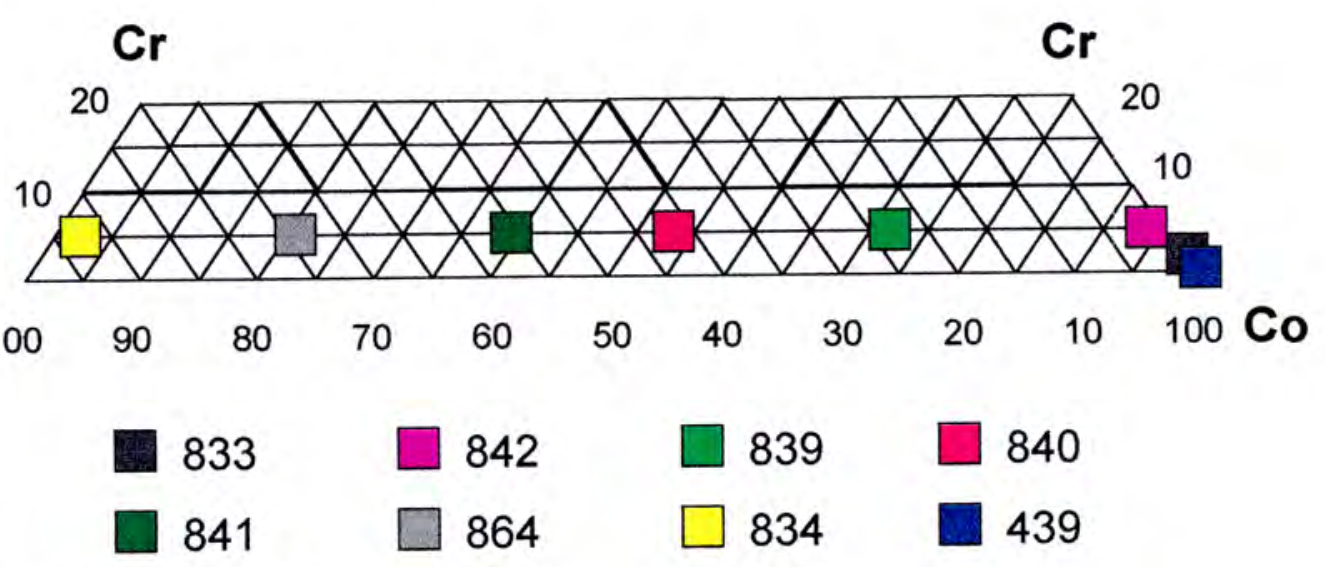

10 wt $\%$ Cermet Binder Compositions.

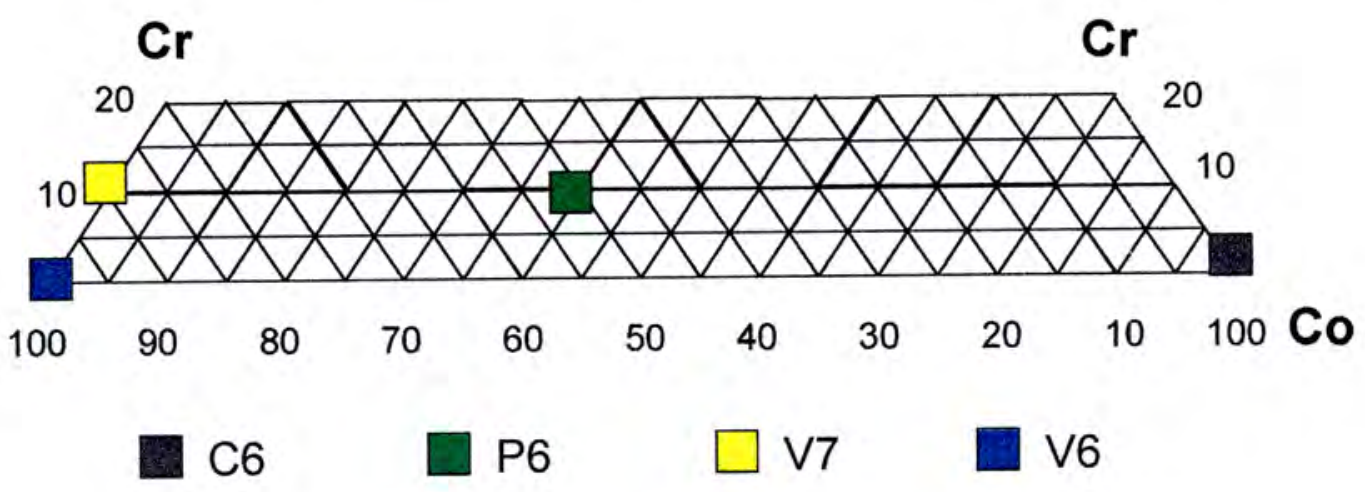

6 wt\% Cermet Binder Compositions.

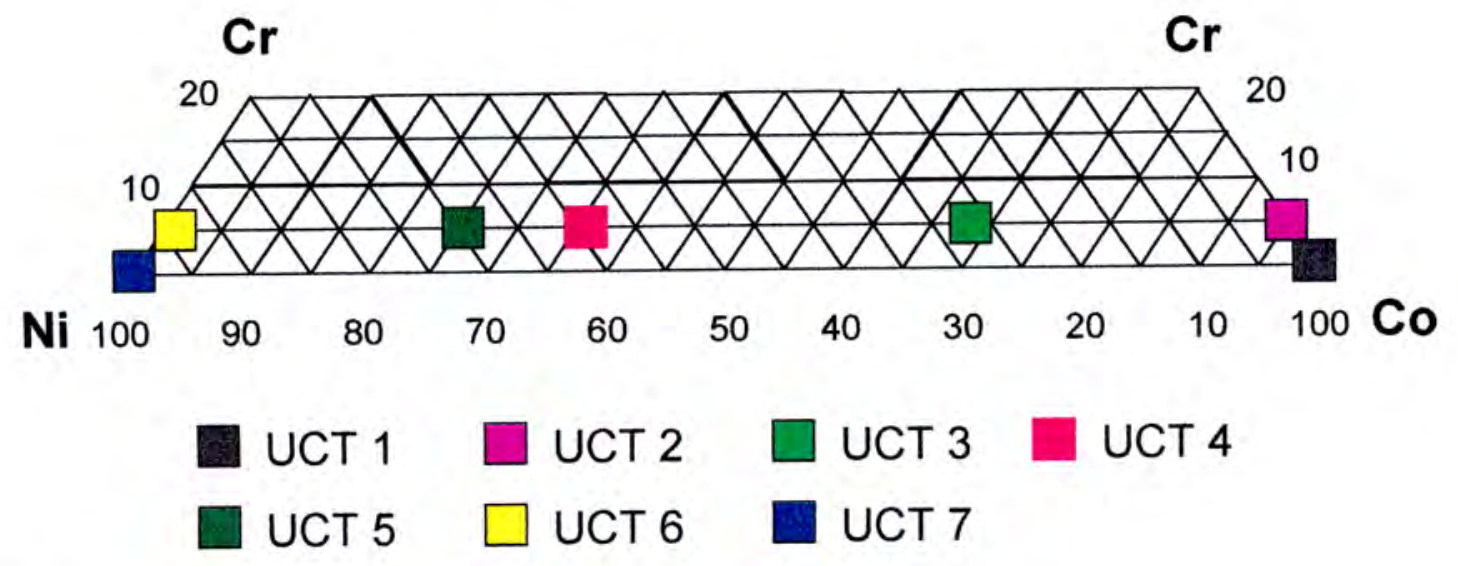

Binder Metal Alloy Compositions. 


\section{APPENDIX 2: Turbo C++ Program for Polarisation Data Thinning}

I would like to acknowledge Mr J. Fitton for his assistance with this software.

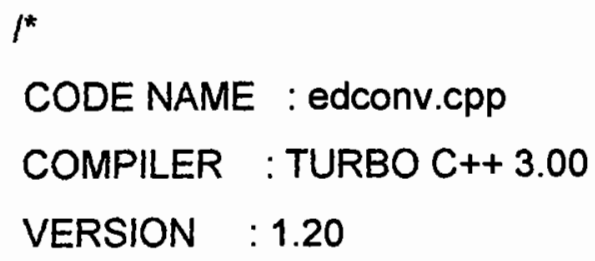

Step is the value of $\mathrm{mV}$ between each thinned data point.

Note: $-500-1500 \mathrm{mV}$ range only.

$l^{*}$ \#define_8087chip 1 */

\# define_ARGS 2

\#include <conio.h> \#include <ctype.h> \#include $<$ dos. $h>$ \#include < math.h> \#include <stdio.h> \#include <stdlib.h> \#include <string.h>

\#include "cursor.c" \#include "mouse.c"

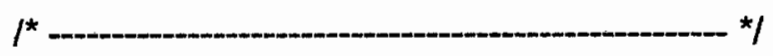

| 
void title(int argc)

${ }^{*}$ Display title screen and help screen depending on number of params *

\{

cirscr();

textattr(15);

cPuts(" CORROSION DATA CONVERSION Ver 1.20

Written by J Fitton Irln");

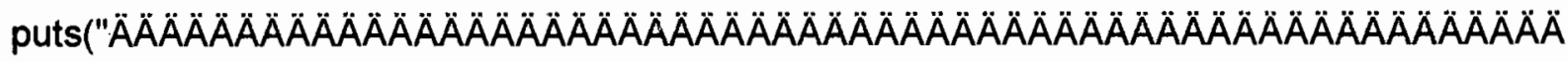

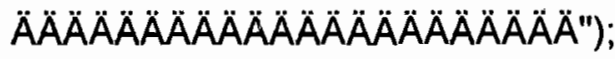

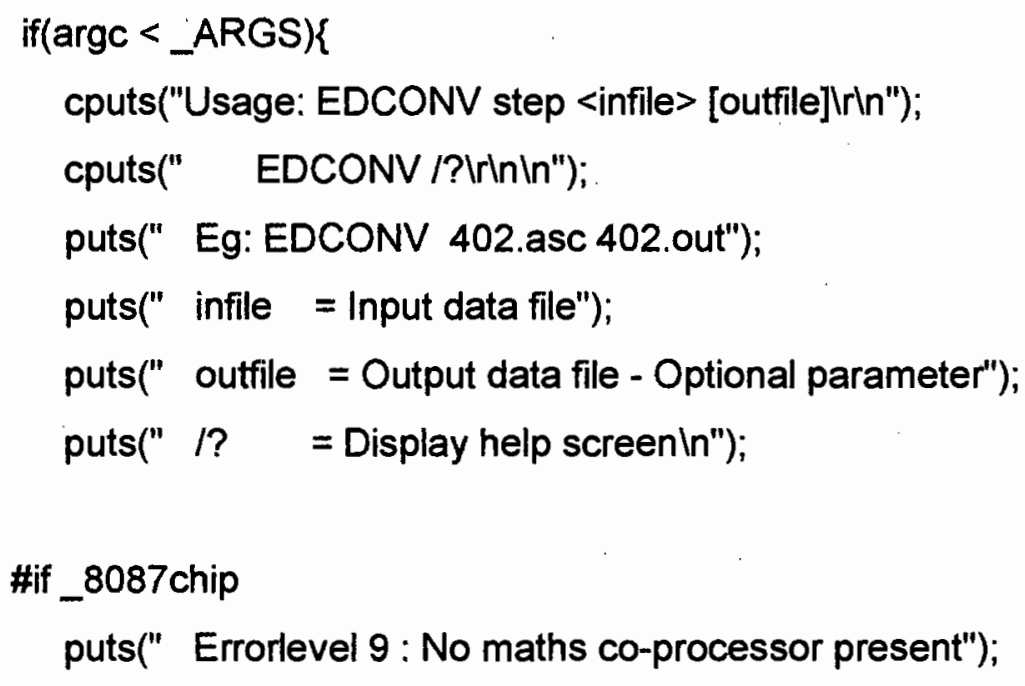

\#endif

puts(" Errorlevel 7 : Input / Output files cannot be opened");

puts(" Errorlevel 6 : Input file too long");

puts(" Errorlevel 5 : Input data could not be converted");

puts(" Errorlevel 2 : User interupted processing");

puts(" Errorlevel 1 : Input arguments invalid");

puts(" Errorlevel 0 : Processing successfullrln!n");

\}

textattr(7);

\} 

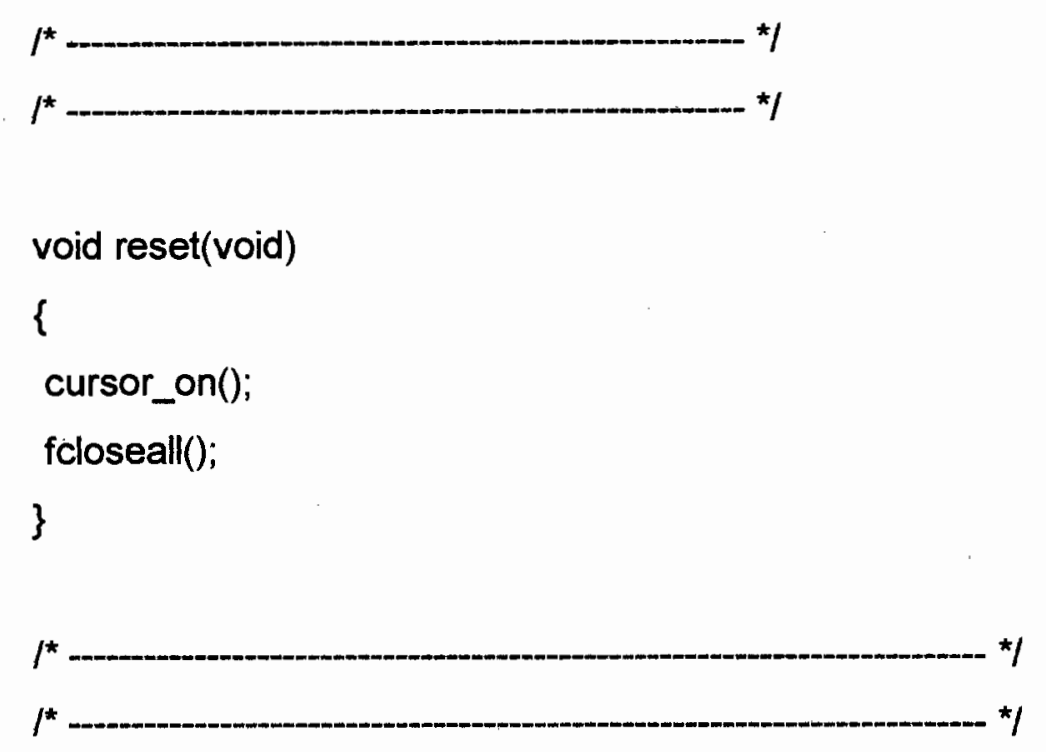

int read_data(FILE *strm, char *data, unsigned int maxlen)

$I^{\star}$ Read chars from input file, until EOL or maxlen exceeded *

\{

int cnt;

I* Read data record to EOL */

for(cnt=0; !feof(strm) \&\& cnt < maxlen; cnt++)\{

data[cnt] = fgetc(strm);

if(data[cnt] == 'Ir' || data[cnt] == 'In') break;

if $(\mathrm{cnt}==0 \& \&$ data[0] $==0 \times 1 \mathrm{~A})\{$

cnt $=-1$;

break;

\}

\}

if(cnt == maxlen $\& \&$ (data[cnt] != 'Ir' \&\& data[cnt] != 'In'))\{

cnt--;

data $[\mathrm{cnt}]=0 \times 00$;

printf("Warning: Record exceeds buffer length IrlnRec: \%04u \%sIrln",maxlen,data);

\} 


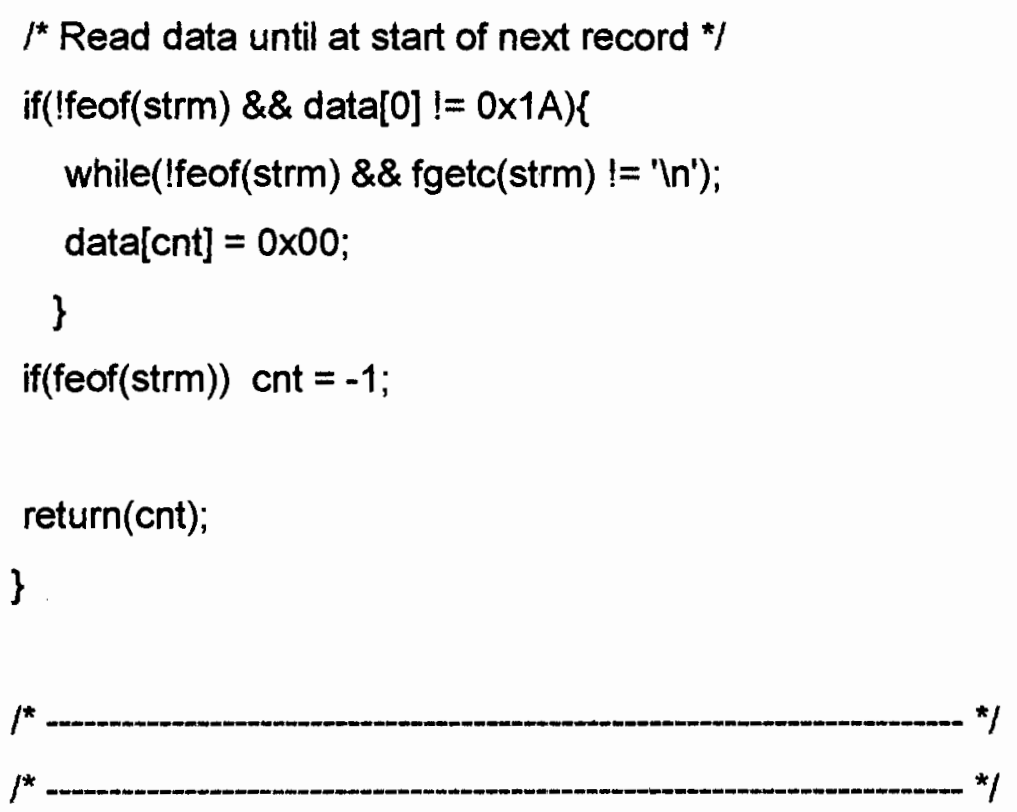

int main(int argc, char *argv[)

\{

FILE *infile,

*outfile,

*errfile;

char outfilename[80],

errfilename[80],

infilename[80];

struct date dd;

struct time $\mathrm{tt}$;

double current, inbuf2;

float inbuf, potential, prev, prev1, init, step;

char tmp_string[128];

unsigned long cnt, cnt2;

title(argc);

if(argc <_ARGS) 
if(argv[1][1] != '?') return(1); else return(255);

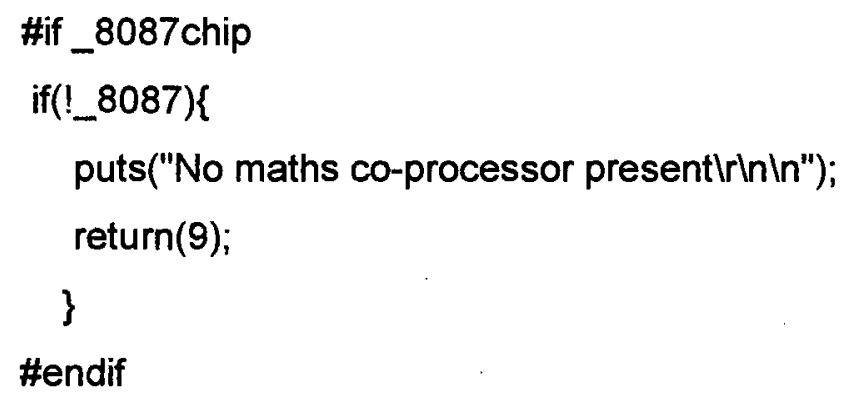

$/$ Set init file extension and generate filename */

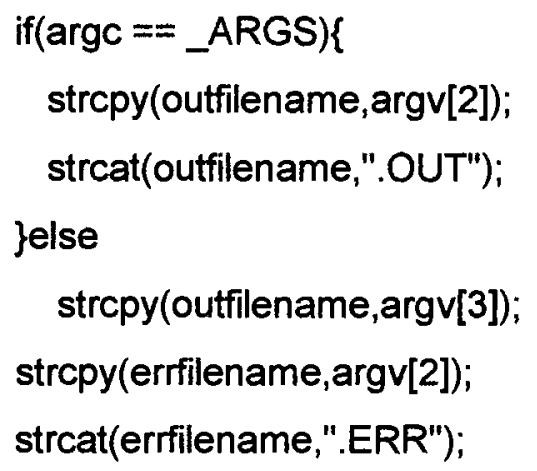

\section{$1 *$ Open files */}

infile = fopen(infilename,"rb");

outfile = fopen(outfilename,"w");

errfile = fopen(erfilename,"w");

if(infile $==$ NULL $)\{$

printf("Unable to open INFILE : \%sirInIn",infilename);

return(7); 


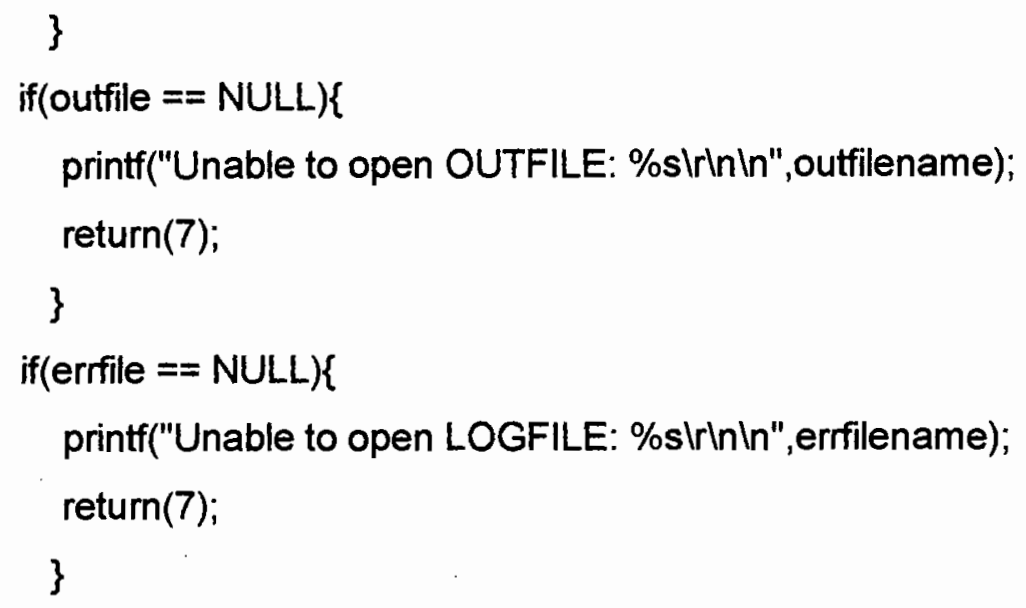


$I^{*}$ Set all parameters to zero $*$

inbuf2 $=$ init $=$ current $=$ potential $=+0.0$;

$\mathrm{cnt}=\mathrm{cnt} 2=0$;

prev $=$ prev $1=-500$;

$I^{*}$ Read initial data set $*$

fscanf(infile, "\%f \%lf",\&inbuf, \&inbuf2);

init = inbuf;

I* Write inititial progress "report" */

$I^{\star}$ cprintf("\%8lu pts processed $\mid r ",++$ cnt); ${ }^{\star} /$

while(!kbhit() \&\& !mousehit() \&\& !feof(infile))\{

if(inbuf $>$ prev $)\{$

fprintf(outfile,"\%fln",prev);

prev $=$ prev + step;

cnt2 = cnt2 + step;

\}else\{

$I^{*}$ Read input file and process data until EOF or user interupts processing *

prev1 = prev;

prev = 100000;

while(!kbhit() \&\&!mousehit() \&\& !feof(infile))\{

$I^{*}$ Write progressive progress "report" */

if(cnt $\% 100=0$ ) cprintf("\%8lulr",cnt);

$I^{*}$ Main processing *I

if(fscanf(infile, "\%f \%lf",\&inbuf, \&inbuf2))\{ 


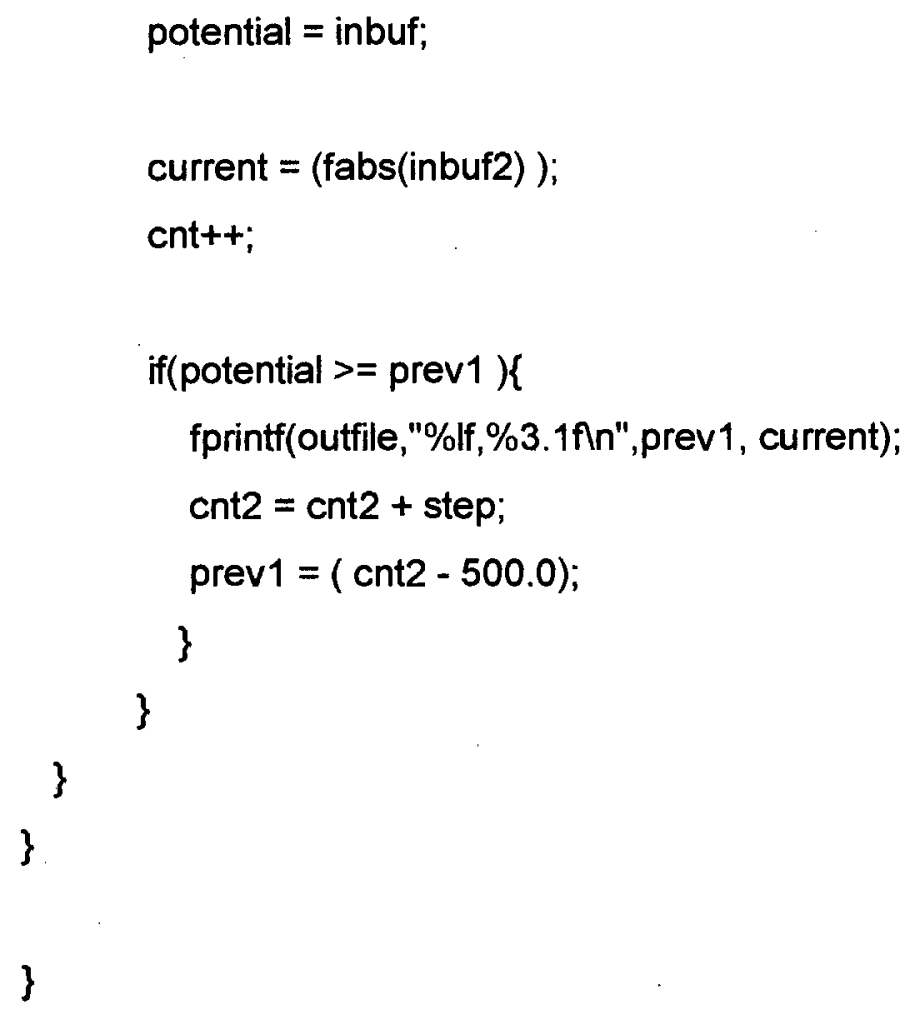


fcloseall();

return $(0)$;

\}

\}

$I^{*}$

$I^{*}$ End of code: Edconv.cpp Ver 1.20

$l^{*}$ $-*$ 


\section{APPENDIX 3: Publications and Presentations}

\section{PUBLICATIONS}

E. J. Wentzel and C. Allen, Erosion-Corrosion Resistance of Tungsten Carbide Hard Metals with different Binder Compositions, Wear 181-183, 1995, pp. 63-69.

E. J. Wentzel and C. Allen, Proc. of the 33rd Annual Electron Microscopy Society of South Africa Conference, Vol 24, University of Port Elizabeth, 1994, pp. 45.

E. J. Wentzel and C. Allen, The Erosion-Corrosion Resistance of Tungsten Carbide Hard Metals, Awaiting Publication in The Journal of Refractory and Hard Materials, 1995.

\section{PRESENTATIONS}

Wear of Materials (WOM) Conference 1995 Boston, USA, Erosion-Corrosion Resistance of Tungsten Carbide Hard Metals with Different Binder Compositions, Presented by Prof. C Allen.

Powder Metallurgy Association of South Africa, Powder Technology '94, September 1994, Johannesburg, Erosion-Corrosion Resistance of Tungsten Carbide Hard Metals with Different Binder Compositions, Presented by E. Wentzel.

Electron Microscopy Society of South Africa, EMSSA 1994, December 1994, University of Port Elizabeth, Erosion-Corrosion of WC Hard Metals, Presented by E. Wentzel.

International Powder Metallurgy Association of South Africa Conference, September 1995, Johannesburg, Erosion-Corrosion Resistance of Tungsten Carbide Hard Metals with Different Binder Compositions, Presented by E. Wentzel. 